An Increment of Analysis

\title{
Estimated Airborne Release of Plutonium From Westinghouse Cheswick Site as a Result of Postulated Damage From Severe Wind and Seismic Hazard
}
J. Mishima
L. C. Schwendiman
J. E. Ayer

June 1979

Prepared for

Division of Environmental Impact Studies

Argonne National Laboratory

under Contract EY-76-C-06-1830

Pacific Northwest Laboratory

Operated for the U.S. Department of Energy

by Battelle Memorial Institute 


\title{
NOTICE
}

This report was prepared as an account of work sponsored by the United States Government. Neither the United States nor the Department of Energy, nor any of their employees, nor any of their contractors, subcontractors, or their employees, makes any warranty, express or implied, or assumes any legal liability or responsibility for the accuracy, completeness or usefulness of any information, apparatus, product or process disclosed, or represents that its use would not infringe privately owned rights.

The views, opinions and conclusions contained in this report are those of the contractor and do not necessarily represent those of the United States Government or the United States Department of Energy.

\author{
PACIFIC NORTHWEST LABORATORY \\ operated by \\ BATTELLE \\ for the \\ UNITED STATES DEPARTMENT OF ENERGY \\ Under Contract EY-76-C-06-1830
}
Printed in the United States of America Available from
National Technical Information Service
United States Department of Commerce
5285 Port Royal Road
Springfield, Virginia 22151

Price: Printed Copy $\$$ $\because$ Microfiche $\$ 3.00$

NTIS

- Pages Selling Price

$\begin{array}{ll}001-025 & \$ 4.00 \\ 026-050 & \$ 4.50 \\ 051-075 & \$ 5.25 \\ 076-100 & \$ 6.00 \\ 101-125 & \$ 6.50 \\ 126-150 & \$ 7.25 \\ 151-175 & \$ 8.00 \\ 176-200 & \$ 9.00 \\ 201-225 & \$ 9.25 \\ 226-250 & \$ 9.50 \\ 251-225 & \$ 10.75 \\ 276-300 & \$ 11.00\end{array}$


PNL -2965

UC-20e

\section{2}

An Increment of Analys is

ESTIMATED AIRBORNE RELEASE OF PLUTONIUM FROM WESTINGHOUSE CHESWICK SITE AS A RESULT OF POSTULATED DAMAGE FROM SEVERE WIND AND SEISMIC HAZARD

J. Mishima

L. C. Schwendiman

J. E. Ayer (a)

(a)Fuel Reprocessing and Recycle Branch Division of Fuel Cycle and Material Safety U.S. Nuclear Regulatory Commission

June 1979

Prepared for

Division of Environmental Impact Studies Argonne National Laboratory under Contract EY-76-C-06-1830

Pacific Northwest Laboratory

Richland, Washington 99352 
The potential airborne releases of plutonium (source terms) from postulated damage sustained by the Westinghouse Plutonium Fuel Development Laboratories at the Cheswick site in Pennsylvania as a result of various levels of wind and seismic hazard are estimated. The source terms are based on damage scenarios originated by other specialists and range up to $260 \mathrm{mph}$ for wind hazard and in excess of $0.39 \mathrm{~g}$ ground acceleration for seismic hazard. The approaches and factors used to estimate the source terms (inventories of dispersible materials at risk, damage levels and ratios, fractional airborne releases of dispersible materials under stress, atmosphere exchange rates, and source term ranges) are discussed. Source term estimates range from less than $10^{-7} \mathrm{~g}$ plutonium to greater than $130 \mathrm{~g}$ plutonium over a four-day period. 


\section{CONTENTS}

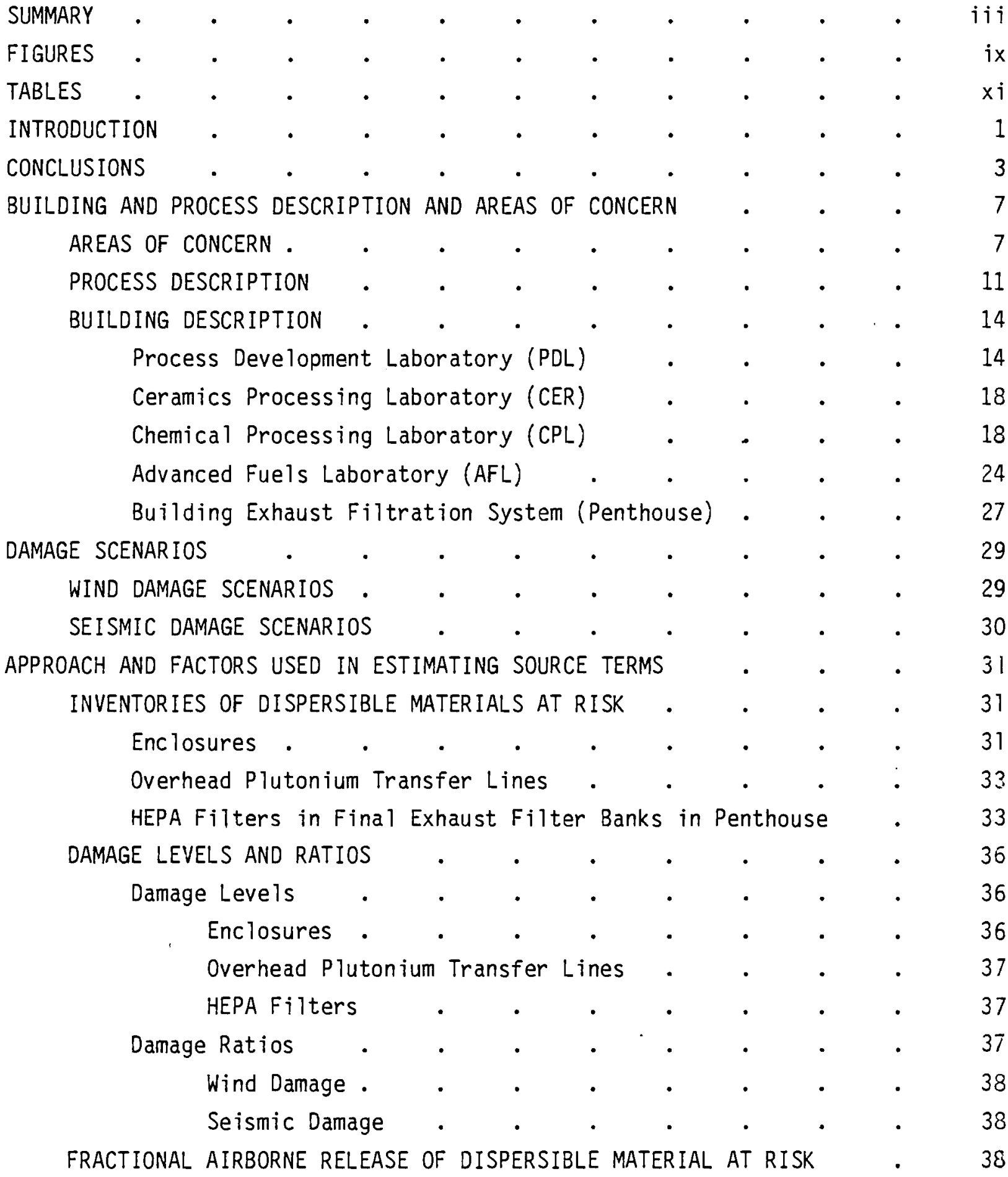




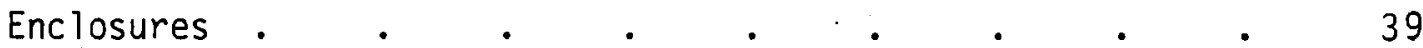

Powders in Perforated Enclosures . . . . . 39

Powders in Crushed Enclosures . . . . . . 41

Liquids in Perforated Enclosures . . . . . 41

Liquids in Crushed Enclosures . . . . . . 42

Surface Contamination in Perforated Enclosures . . 44

Surface Contamination in Crushed Enclosures . . 44

Overhead Plutonium Transfer Lines . $\quad$ • . . . 45

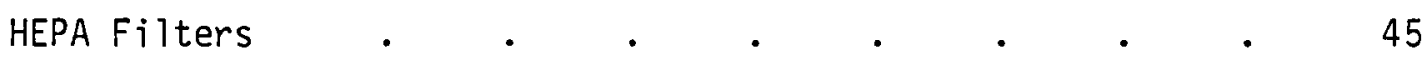

Broken Plywood-cased Filters . . . . . . 45

Perforated Metal-cased Filters . . . . . 46

Crushed HEPA Filters (Plywood- or Metal-cased) . . 46

Resuspension of Deposited Materials ..$\quad$ • . . $\quad$. 46

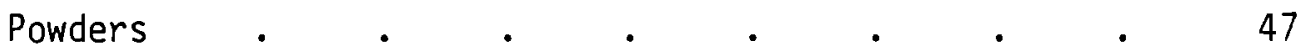

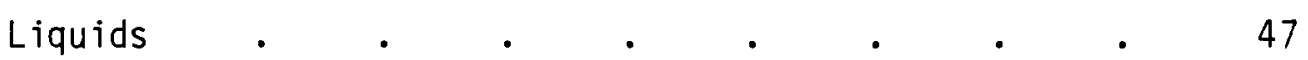

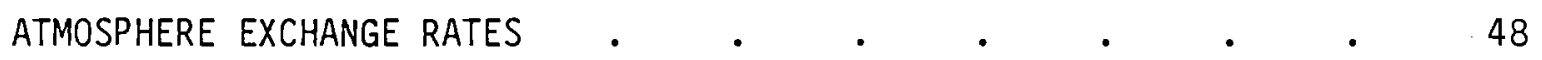

Atmosphere Exchange Rate--Wind Hazard . . . . . 48

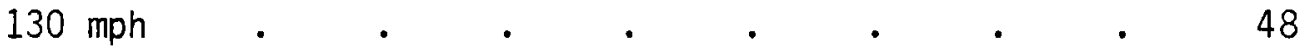

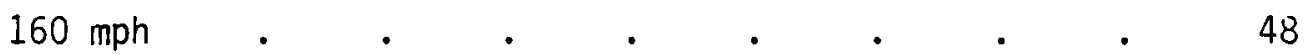

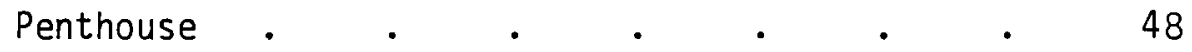

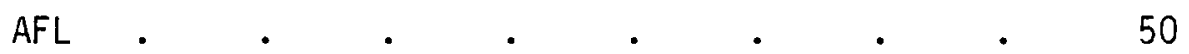

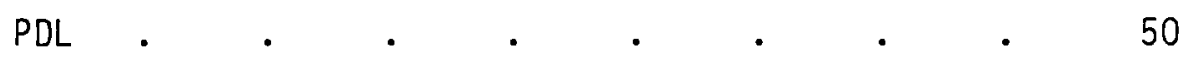

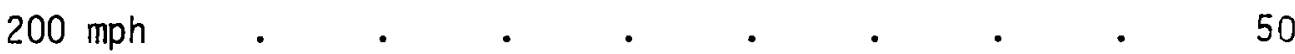

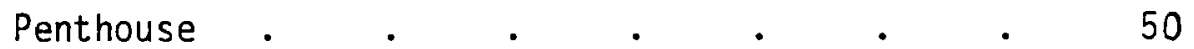

Production Areas (AFL, PDL, CER, and CPL). . 51

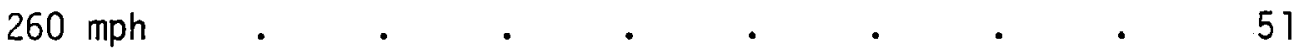

Atmosphere Exchange Rate--Seismic Hazard . . . . 51

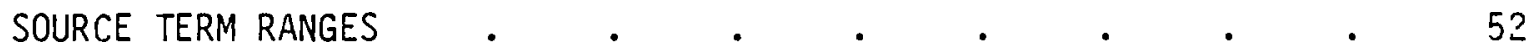

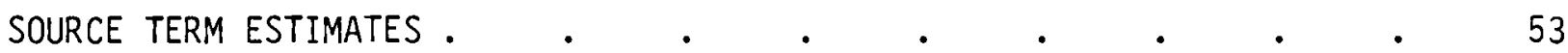

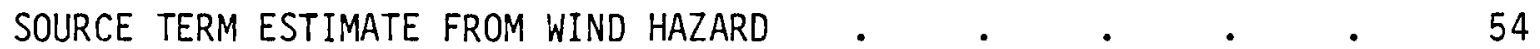

$130 \mathrm{mph}, 2 \times 10^{-5} / \mathrm{yr}$ Probability of Occurrence $\quad$. 54

$160 \mathrm{mph}, 7 \times 10^{-6} / \mathrm{yr}$ Probability of Occurrence $\quad$. $\quad 54$

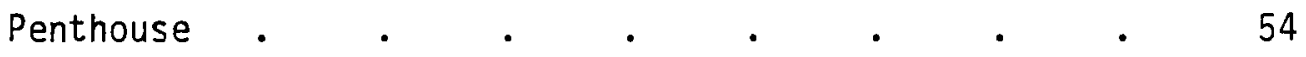

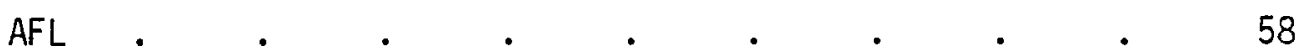




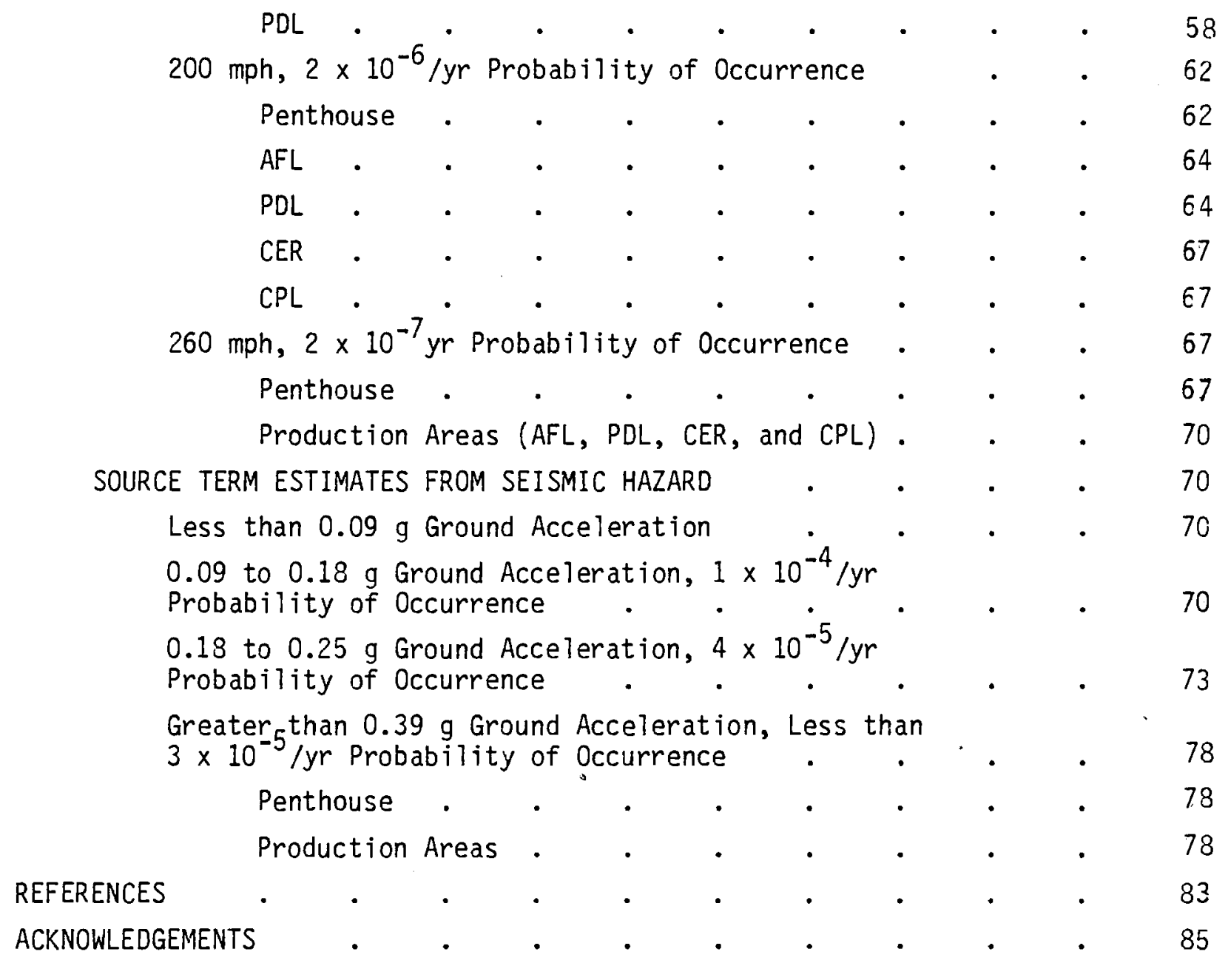




\section{FIGURES}

1 General Process Flow Diagram, Mixed Oxide Fuel • $\quad$ • . 12

2 General Process Flow Diagram, Mixed Carbide Fuel $\quad . \quad$. $\quad$. 13

3 Westinghouse PFDL Facility - General Plan . . . . . 15

4 Process Development Laboratory . . . . . . . . . . 16

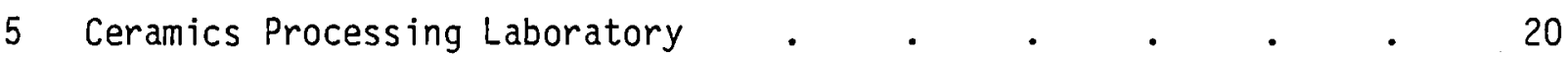

6 Chemical Processing Laboratory . . . . . . . . . 21

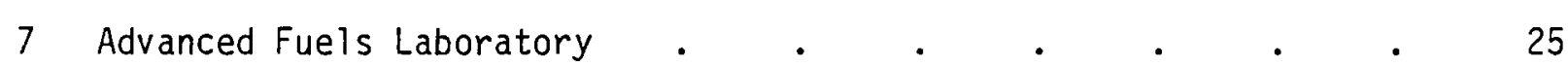

8 Particle Size Distribution of Plutonium Dioxide Powders . . 40

9 Mass Fraction versus Droplet Diameters for Sprays as a Function of Orifice Diameter and Upstream Pressure $\quad . \quad . \quad . \quad$. 43

10 Terminal Velocities of Unit Density Spheres (1 Atm, 200 C) . $\quad 49$

11 Range and Type of Damage Anticipated in the Penthouse at Wind Hazard Level of $130 \mathrm{mph} \quad . \quad . \quad . \quad . \quad . \quad . \quad . \quad 55$

12 Range and Type of Damage Anticipated in the Penthouse at a Wind Hazard Level of $160 \mathrm{mph} \quad . \quad$. $\quad . \quad . \quad . \quad$.

13 Range and Type of Damage Anticipated in the AFL at a Wind Hazard Level of $160 \mathrm{mph}$

14 Range and Type of Damage Anticipated in the PDL at a Wind Hazard Level of $200 \mathrm{mph}$

I5 Range and Type of Damage Anticipated in the Penthouse at a Wind Hazard Level of $200 \mathrm{mph}$, Damage to the Metal-cased Filters Serving the Remaining Production Areas . . . .

16 Range and Type of Damage Anticipated in the Production Areas, Using the AFL as the Representative, at a Wind Hazard Level of $200 \mathrm{mph}$. $\quad . \quad$. $\quad . \quad . \quad . \quad . \quad . \quad . \quad$.

17a Range and Type of Damage Anticipated in the Plywood-cased Filters (Penthouse) at a Wind Hazard Level of $260 \mathrm{mph} . .$.

17b Range and Type of Damage Anticipated in the Meta1-Cased Filters (Penthouse) at a Wind Hazard Level of $260 \mathrm{mph}$. . 
18 Range and Type of Damage Anticipated in Production Areas at a Wind Hazard Level of $260 \mathrm{mph}$, AFL Representative of All Areas

19 Range and Type of Damage Anticipated in AFL at a Seismic Hazard Level of 0.09 to $0.18 \mathrm{~g}$ Ground Acceleration . . .

20 Range and Type of Damage Anticipated in CPL at a Seismic Hazard Level of 0.18 to $0.25 \mathrm{~g}$ Ground Acceleration . . . .

21a Range and Type of Damage Anticipated in Production Areas at a Seismic Level in Excess of $0.39 \mathrm{~g}$ Ground Acceleration, Damage in AFL

21b Range and Type of Damage Anticipated in Production Areas at a Seismic Level in Excess of $0.39 \mathrm{~g}$ Ground Acceleration, Damage in $C P L$ 


\section{TABLES}

1 Source Term Estimates from the Westinghouse Plutonium Fue 1

Development Laboratory as a Result of Wind and Seismic Hazard .

2 Maximum and Normal Operational Quantities of SNM Located in Enclosures at Westinghouse Plutonium Fuel Development Laboratory .

3 Inventories of Dispersible Materials at Risk and Duty Cycles for Enclosures in the Process Development Laboratory, Fabrication Mode .

4 Inventories of Dispersible Materials at Risk and Duty Cycles for Enclosures in the Ceramics Processing Laboratory, Fabrication Mode.

5 Inventories of Dispersible Materials at Risk and Duty Cycles for Enclosures in the Chemical Process Development Laboratory, Fabrication Mode.

6 Inventories of Dispersible Materials at Risk and Duty Cycles for Enclosures in the Advanced Fuels Laboratory, Fabrication Mode .

7 Plutonium Content of Surface Contamination in Typical Enclosures as a Function of Plutonium Compounds

8 Contributions of Various Areas in the Westinghouse PFDL to Wind and Seismic Hazard Source Term Estimates, Wind Hazard, $130 \mathrm{mph}$, $2 \times 10^{-5}$ Per Year Probability of Occurrence

9 Contributions of Various Areas in the Westinghouse PFDL to Wind and Seismic Hazard Source Term Estimates, Wind Hazard, $160 \mathrm{mph}$, $7 \times 10^{-6}$ Per Year Probability of Occurrence . . .

10 Contributions of Various Areas in the Westinghouse PFDL to Wind and Seismic Hazard Source Term Estimates, Wind Hazard, $200 \mathrm{mph}$, $2 \times 10^{-6}$ Per Year Probability of Occurrence

11 Contributions of Various Areas in the Westinghouse PFDL to Wind and Seismic Hazard Source Term Estimates, Wind Hazard, $260 \mathrm{mph}$, $2 \times 10^{-7}$ Per Year Probability of Occurrence

12 Contributions of Various Areas in the Westinghouse PFDL to Wind and Seismic Hazard Source Term Estimates, Seismic Hazard, 0.09 to $0.18 \mathrm{~g}$ Ground Acceleration, $1 \times 10^{-4}$ Per Year Probability of 0ccurrence 
13 Contribution of Various Areas in the Westinghouse PFDL to Wind and Seismic Hazard Source Term Estimates, Seismic Hazard, 0.18 to $0.25 \mathrm{~g}, 4 \times 10^{-5}$ Per Year Probability of Occurrence .

14 Contribution of Various Areas in the Westinghouse PFDL to Wind and Seismic Hazard Source Term Estimates, Seismic Hazard, Greater than $0.39 \mathrm{~g}$ Ground Acceleration, less than $3 \times 10^{-5}$ Per Year Probability of Occurrence. 


\section{INTRODUCTION}

This increment of analysis is a portion of an interdisciplinary study sponsored by the United States Nuclear Regulatory Commission (NRC) to estimate the potential radiological hazard to the general population as a result of the impact of natural phenomena upon existing commercial mixed oxide fabrication plants. This report covers the potential release of radionuclides from the Westinghouse Plutonium Fuel Development Laboratories (PFDL) at Cheswick, Pennsylvania as a result of wind and earthquake hazards.

Engineering Decision Analysis Company (EDAC) provided the description and condition of the facility (EDAC 1977a). Features whose failure might have a significant effect on the release of radioactive material were identified (Mishima, Schwendiman and Ayer 1977). The probability of various levels of wind hazard at the site was assessed by Fujita (1977), while Teknekron Energy Analysts Corporation (TERA) provided the same service for the seismic potential (1977). Texas Tech (1978) provided the potential responses of the structure and contained equipment to the various degrees of wind hazard, and EDAC (1977b) provided analysis for the response to seismic events. These last two analyses provided the "damage scenarios" upon which the estimates of the potential airborne releases of the contained radioactive material from the facility (scurce term) were based.

The study is coordinated by the Division of Environmental Impact Studies of the Argonne National Laboratory (ANL), who assigned the task of providing "realistic" estimates of the potential source terms generated by the damage scenario to Pacific Northwest Laboratory (PNL). (a)

The estimated airborne releases of contained radioactive material form the basis for the calculated dose which is one component of the overall risk analysis, the objective of the entire study. The primary concern in the

(a) Pacific Northwest Laboratory is operated for the Department of Energy by Battelle Memorial Institute. 
calculation of downwind dose for this study is inhalation (McPherson and Watson 1978, p. 3), and in this increment the primary emphasis will be the release of plutonium particulate material of a size range that can be carried downwind and inhaled. Particles $10 \mu \mathrm{m}$ Aerodynamic Equivalent Diameter (a) (AED) or less are conservatively assumed to be the respirable fraction. Such an assumption overstates the potential effect by a factor of 1.5 to greater than an order of magnitude, depending upon the lung deposition model chosen (Mercer 1977, Figure 1). Finally, although a "realistic" estimate is desired, much of the behavior of the structure and equipment in accident situations is not precise, and, with such uncertainties, the estimates of airborne releases tend to be conservative, that is, estimates are probably greater than would actually be experienced.

(a) Aerodynamic Equivalent Diameter: particles exhibiting the aerodynamic behavior of a unit density sphere of the stated size. 


\section{CONCLUSIONS}

The potential mass airborne releases of plutonium (source terms) as a result of wind and seismic hazard are estimated for the Westinghouse Plutonium Fuel Development Laboratories (PFDL), Cheswick, Pennsylvania site. The postulated source terms become the basis for the estimation of potential dose to the "maximum" individual by inhalation and to the total population living within a prescribed radius of the site. The "respirable fraction" of airborne particles is thus of principal concern.

The estimated source terms are based upon the damage ratio, i.e., the fraction of enclosures crushed or punctured by increasing levels of severe hazard and the airborne releases if all enclosures suffer particular levels of damage. In an attempt to provide a realistic range of potential source terms that would include the vast majority of normal processing conditions, a "best estimate" bounded by "upper" and "lower" limits is provided. The range of source terms is calculated by combining a "high", "best estimate", and "low" damage ratio based upon a decreasing fraction of enclosures suffering crush or puncture, with the airborne release from enclosures based upon an "upper limit", "on-the-average," and "lower limit" inventory of dispersible materials at risk. Factors used to evaluate the fractional airborne release of material and the exchange rates between enclosure and exterior atmospheres are discussed.

The discussion of postulated damage and source terms is divided into wind and earthquake hazard scenarios in order of increasing severity.

The largest postulated airborne releases from the building are for the maximum wind hazard (maximum velocity of $260 \mathrm{mph}$ ) and for seismic hazard greater than $0.39 \mathrm{~g}$ ground acceleration. Both hazard scenarios postulate virtually complete destruction of the facility. Wind hazard at higher air velocities and earthquakes with higher ground accelerations should not result in significantly greater source terms. The source terms are expressed as mass 
of plutonium airborne as particles $10 \mu \mathrm{m}$ Aerodynamic Equivalent Diameter (a) (AED) or less released with time up to 3 days. From $66 \%$ to $95 \%$ of the source term is generated from $2 \mathrm{hr}$ to 4 days after the event. The overall source terms from the damage scenarios evaluated are shown in Table 1 in order of increasing severity of wind hazard and earthquake.

(a) See footnote on page 2 for definition. 
TABLE 1. Source Term Estimates from the Westinghouse PFDL as a Result of Wind and Seismic Hazard

\begin{tabular}{c|c|c|c|} 
& \multicolumn{3}{|c|}{ MASS AIRBORNE RELEASE OF PLUTONIUM IN } \\
RESPIRABIE SIZE RANGE 0 GRAMS \\
EVENT & UPPER LIMIT & BESTESTIMATE & LOWER LIMIT \\
\hline
\end{tabular}

MAXIMUM WIND SPEED $130 \mathrm{MPH}, 2 \times 10^{-5}$ PER YEAR PROBABILITY OF OCCURRENCE

INSTANTANEOUS

ADDITIONAL MASS RELEASED IN NEXT 2 HOURS

ADDITIONAL MASS REISASED IN NEXT 6 HOURS

ADDITIONAL MASS RELEASED IN NEXT 16 HOURS

ADDITIONAL MASS RELEASED IN NEXT 3 DAYS

MUXIMUM WIND SPEED $160 \mathrm{MPH}, 7 \times 10^{-6}$ PER YEAR PROBABILITY OF OCCURRENCE

INSTANTANEOUS

ADDITIONAL MASS RELEASED IN NEXT 2 HOURS

ADDITIONAL MASS RELEASED IN NEXT 6 HOURS

ADDITI ONAL MASS RELEASED IN NEXT 16 HOURS

ADDITIONAL MASS RELEASED IN NEXT 3 DAYS

$$
\begin{array}{|l|l|l|}
3 \times 10^{-4} & 5 \times 10^{-5} & \cdots \\
\cdots-- & \cdots & \cdots \\
\cdots \cdots & \cdots & \cdots \\
\cdots-- & \cdots & \cdots
\end{array}
$$

MAXIMUM WIND SPEED $200 \mathrm{MPH}, 2 \times 10^{-6}$ PER YEAR PROBABILITY OF OCCURRENCE INSTANTANEOUS

ADDITIOMLL MASS RELEASED IN NEXT 2 HOURS ADDITIONAL MASS RELEASED IN NEXT 6 HOURS ADDITIONAL MASS RELEASED IN NEXT 16 HOURS ADOITIONAL MASS RELEASED IN NEXT 3 DAYS

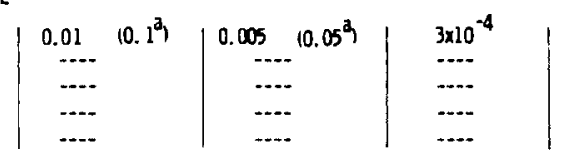

MAXIMUM WIND SPEED $260 \mathrm{MPH}, 2 \times 10^{-7}$ PER YEAR PROBABILITY OF OCC URRENCE INSTANTANEOUS

ADDITIONAL MASS RELEASED IN NEXT 2 HOURS ADDITIONAL MASS RELEASED IN NEXT 6 HOURS ADDITIONAL MASS RELEASED IN NEXT 16 HOURS ADDITIONAL MASS RELEASED IN NEXT 3 DAYS

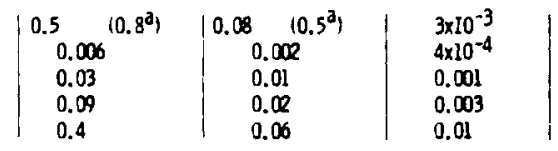

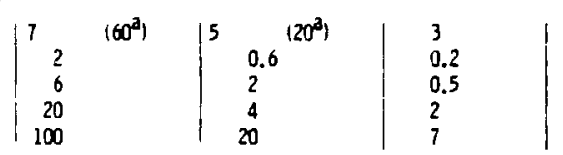

SEISMIC HAZARD

LESS THAN $0.09 \mathrm{~g}$ GROUND ACCELERATION

0.099 TO 0.189 GROUND ACCELERATION, $1 \times 10^{-4}$ PER VEAR PROBABILITY OF OCCURRENCE

INSTANTANEOUS

ADDITIONAL MASS RELEASED IN NEXT 2 HOURS

ADDITIONAL MASS RELEASED IN NEXT 6 HOURS

ADOITIONAL MASS RELEASED IN NEXT 16 HOURS

ADDITIONAL MASS RELEASED IN NEXT 3 DAYS

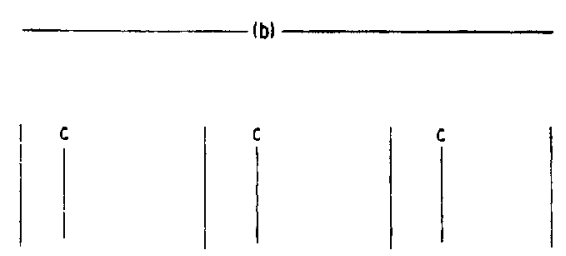

0.18 TO $0.5 \mathrm{~g}$ GROUND ACCELERATION, $4 \times 10^{-5}$ PER YEAR PROBABILITY OF OCCURRENCE

INSTANTANEOUS

ADDITIONAL MASS RELEASED IN NEXT 2 HOURS

ADDITIONAL MASS RELEASED IN NEXT 6 HOURS

ADDITI ONAL MASS RELEASED IN NEXT 16 HOURS

ADDITIONLL MASS RELEASED IN NEXXT 3 DAYS

GREATER THAN 0.39g GROUND ACCELERATION, $3 \times 10^{-5}$ PER YEAR PROBABILITY OF OCCURRENCE

INSTANTANEOUS

ADDITIONAL MASS RELEASED IN NEXT 2 HOURS

ADDITIONAL MASS RELEASED IN NEXT 6 HOURS

ADDITIONAL MASS RELEASED IN NEXT 16 HOURS

ADDITIONAL MASS RELEASED IN NEXT 3 DAYS

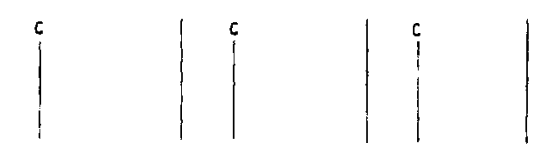

a TOTAL MASS PUESTIMATED TO BE RELEASED FROM FACILITY

DO SIGNIFICANT DAMAGE LEADING TO THE AIRBORNE RELEASE OF Pu POSTULATED

6 ESTIMATED LESS THAN $10^{-7} g$ PU ADDITIONAL AIRBORNE RELEASE OF Pu FROM STACK OF FUNCTI ONAL FACILITY

d PARTICLES 10,IM AND LESS AEROD YNAMIC EQUIVALENT DIAMETER 
$+$

$\cdots$ 
BUILDING AND PROCESS DESCRIPTION

AND AREAS OF CONCERN

\section{AREAS OF CONCERN}

Various locations in the Westinghouse Plutonium Fuel Development Laboratories (PFDL) containing significant quantities of radioactive material in dispersible form or items that could initiate a sequence of events resulting in loss of containment are designated areas of concern. The two radionuclides in the process are plutonium (Pu) and normal uranium. Of the two, plutonium is by far the more radiologically significant (Mishima, Schwendiman and Ayer 1977b). Various plutonium compounds and physical forms are present in the facility. Undiluted plutonium compounds present are plutonium dioxide powders, plutonium oxalate slurry and powder, and plutonium nitrate aqueous solution. Two combinations of plutonium and normal uranium are also found in the process--mixed oxide (MOX) and mixed carbide (MC)--in a variety of forms, i.e., powder, granules, "green" and "fired" pellets, encapsulated pellets, and aqueous solutions. The operational Pu content of MOX is $4 \%$ and of MC $15 \%$.

The maximum and normal operational quantities of plutonium and the unencapsulated forms found in all enclosures in the facility are shown in Table 2. Quantities and residence time in each enclosure are listed for both a typical fabrication and development mode. The relative quantities of plutonium in each enclosure is not an index of the relative hazard. Since the objective of this study is to assess the potential radiological risk to the downwind population, both the "dispersibility" of (ability to be entrained and transported downwind) and the probability that the material would be in jeopardy are of importance. Under most circumstances, preformed powders are more easily injected into the air than other physical forms when subjected to equal force. Liquids are also readily subdivided although considerable viscous energy is required to subdivide liquids into the "respirable" size range (Monk 1959, p. 288). Thus, for the purposes of this study, unencapsulated plutonium compounds in the form of finely divided powders and liquid solutions are considered dispersible. Other forms present, such as 
TABLE 2. Maximum and Normal Operational Quantities of SNM Located in Enclosures at West inghouse Plutonium Fuel Development Laboratory (Source: 10 CFR 2.790(d) Information)

\begin{tabular}{|c|c|c|c|c|c|c|c|}
\hline & & & & & :ory Mode & Deve 1 & \\
\hline $\begin{array}{l}\text { Glove Box } \\
\text { Unit Nos. }\end{array}$ & Function & $\begin{array}{c}\text { Material(b) } \\
\text { Type }\end{array}$ & $\begin{array}{c}\text { Max. } \\
\text { Batch }\end{array}$ & $\begin{array}{l}\text { Batch }(c) \\
\text { Size }\end{array}$ & $\begin{array}{l}\text { Residence (d) } \\
\text { Iime/week }\end{array}$ & $\begin{array}{l}\text { Batch }(c) \\
\text { Size }\end{array}$ & $\begin{array}{l}\text { Residence } \\
\text { Time/2 }\end{array}$ \\
\hline 301 & Misce 11 aneous & $\mathrm{PuO}_{2}$, MOX & $2 \mathrm{~kg}$ & & & & \\
\hline 302 & $\mathrm{PuO}_{2}$ Receiving Inspection & $\mathrm{PuO}_{2}$ & $4 \mathrm{~kg}$ & $2 \mathrm{~kg}$ & $8 \mathrm{hrs} / 10 \mathrm{wks}$ & $2 \mathrm{~kg}$ & $-0-$ \\
\hline 303 & Sieving & $\mathrm{PuO}_{2}$ & $4 \mathrm{~kg}$ & $2 \mathrm{~kg}$ & $3 \mathrm{hrs}$ & $2 \mathrm{~kg}$ & $-0-$ \\
\hline 304 & Sieving & MOX & $90 \mathrm{~kg}$ & $10 \mathrm{~kg}$ & $12 \mathrm{hrs}$ & $45 \mathrm{~kg}$ & $60 \mathrm{hrs}$ \\
\hline 305 & $\mathrm{PuO}_{2}$ Weighing and Storage & $\mathrm{PuO}_{2}$ & $4 \mathrm{~kg}$ & $2 \mathrm{~kg}$ & 1 wk & $-0-$ & $-0-$ \\
\hline 400 & Blending & MOX & $105 \mathrm{~kg}$ & $95 \mathrm{~kg}$ & $24 \mathrm{hrs}$ & $-0-$ & -0 \\
\hline 401 & Slugging Press & MOX & $105 \mathrm{~kg}$ & $95 \mathrm{~kg}$ & $16 \mathrm{hrs}$ & $45 \mathrm{~kg}$ & $8 \mathrm{hrs}$ \\
\hline 402 & Die Lube Addition & MOX & $105 \mathrm{~kg}$ & $95 \mathrm{~kg}$ & $16 \mathrm{hrs}$ & $45 \mathrm{~kg}$ & $8 \mathrm{hrs}$ \\
\hline 403 & Storage & MOX & $105 \mathrm{~kg}$ & $95 \mathrm{~kg}$ & $100 \mathrm{hrs}$ & $45 \mathrm{~kg}$ & $48 \mathrm{hrs}$ \\
\hline 404 & Development Blending & MOX & $100 \mathrm{~kg}$ & -0 & $-0-$ & $100 \mathrm{~kg}$ & (e) \\
\hline 411 & Pellet Pressing & $\operatorname{MOx}$ & $105 \mathrm{~kg}$ & $20 \mathrm{~kg}$ & - $32 \mathrm{hrs}$ & $45 \mathrm{~kg}$ & $16 \mathrm{hrs}$ \\
\hline 412 & Green Pellet Storage & MOX & $105 \mathrm{~kg}$ & $95 \mathrm{~kg}$ & $80 \mathrm{hrs}$ & $45 \mathrm{~kg}$ & $24 \mathrm{hrs}$ \\
\hline $414,415,416$ & Pellet Sintering & MOX & $190 \mathrm{~kg}$ & $95 \mathrm{~kg}$ & $100 \mathrm{hrs}$ & $45 \mathrm{~kg}$ & $60 \mathrm{hrs}$ \\
\hline 417 & Sintered Pellet Storage & MOX & $105 \mathrm{~kg}$ & $50 \mathrm{~kg}$ & $24 \mathrm{hrs}$ & $25 \mathrm{~kg}$ & $24 \mathrm{hrs}$ \\
\hline 418 & Pellet Pressing & Same as Box & would no & be used co & rently with 411 . & & \\
\hline 420 & Finished Pellet Storage & MOX & $150 \mathrm{~kg}$ & $95 \mathrm{~kg}$ & $150 \mathrm{hrs}$ & $-0-$ & $-0-$ \\
\hline 420 & Fuel Rod Loading & MOX & 4 rods & $4 \operatorname{rods}(f)$ & $24 \mathrm{hrs}$ & $-0-$ & $-0-$ \\
\hline 421 & Sintered Pellet Inspection & MOX & $105 \mathrm{~kg}$ & $95 \mathrm{~kg}$ & $48 \mathrm{hrs}$ & $-0-$ & $-0-$ \\
\hline 422 & Sintered Pellet Drying & $\operatorname{mox}$ & $105 \mathrm{~kg}$ & $95 \mathrm{~kg}$ & $24 \mathrm{hrs}$ & $45 \mathrm{~kg}$ & $24 \mathrm{hrs}$ \\
\hline 423 & Sintered Pellet Grinding & $\operatorname{MOX}$ & $7 \mathrm{~kg}$ & $3 \mathrm{~kg}$ & $24 \mathrm{hrs}$ & $3 \mathrm{~kg}$ & $12 \mathrm{hrs}$ \\
\hline
\end{tabular}


TABLE 2. (Contd)

\begin{tabular}{|c|c|c|c|c|c|c|c|c|}
\hline & & & & & Labora & ry Mode & Deve lop & Mode \\
\hline & $\begin{array}{l}\text { Glove Box } \\
\text { Unit Nos. }\end{array}$ & Function & $\begin{array}{l}\text { Material(b) } \\
\text { Type }\end{array}$ & $\begin{array}{l}\text { Max. } \\
\text { Batch }\end{array}$ & $\begin{array}{l}\text { Batch }(\bar{c}) \\
\text { Size }\end{array}$ & $\begin{array}{l}\text { Residence (d) } \\
\text { Time/week }\end{array}$ & $\begin{array}{l}\text { Batch(c) } \\
\text { Size }\end{array}$ & $\begin{array}{l}\text { Residence } \\
\text { Time /2 wk }\end{array}$ \\
\hline & 424 & Sintered Pellet Storage & MOX & $105 \mathrm{~kg}$ & $50 \mathrm{~kg}$ & $24 \mathrm{hrs}$ & $25 \mathrm{~kg}$ & $24 \mathrm{hrs}$ \\
\hline & 425 & Sintered Pellet Transfer & MOX & $110 \mathrm{~kg}$ & $15 \mathrm{~kg}$ & $8 \mathrm{hrs}$ & $-0-$ & -0 \\
\hline & 501,502 & Fuel Rod Decon and Plug & MOX & $25 \operatorname{rods}(f)$ & $12 \operatorname{rods}(f))$ & & & \\
\hline & 503 & Fuel Rod Welding & MOX & $25 \operatorname{rods}(f)$ & $25 \operatorname{rods}(f))$ & 24 IITs & $-0-$ & $-0-$ \\
\hline & 601,602 & Metallography & $\operatorname{MOX}$ & $220 \mathrm{~g} \mathrm{Pu}$ & $150 \mathrm{~g} \mathrm{Pu}$ & Cont inuous & $-0-$ & $-0-$ \\
\hline & 211 & Misc. Waste Solidification & Nitrate & $2 \mathrm{~kg} \mathrm{Pu}$ & $2 \mathrm{~g} \mathrm{Pu}$ & (e) & $-0-$ & $-0-$ \\
\hline & 212,213 & Oxidation & $\operatorname{Mox}$ & $5 \mathrm{~kg}$ & $1.5 \mathrm{~kg}$ & $16 \mathrm{hrs}$ & $1.5 \mathrm{~kg}$ & $80 \mathrm{hrs}$ \\
\hline & 221 & Oxalate Precipitation & Liquid & $1 \mathrm{~kg} \mathrm{Pu}$ & $0.5 \mathrm{~kg} \mathrm{Pu}$ & (e) & $-0-$ & $-0-$ \\
\hline & 222 & Conversion of Oxalate to Oxide & $\mathrm{PuO}_{2}$ & $2 \mathrm{~kg} \mathrm{Pu}$ & $0.5 \mathrm{~kg} \mathrm{Pu}$ & (e) & $-0-$ & $-0-$ \\
\hline & 223 & 0xide Inspection & $\mathrm{Pu}_{2}$ & $2 \mathrm{~kg} \mathrm{Pu}$ & $0.5 \mathrm{~kg} \mathrm{Pu}$ & (e) & $-0-$ & $-0-$ \\
\hline & 231 & Pu Recovery - IX Columns & Nitrate & $1 \mathrm{~kg} \mathrm{Pu}$ & $0.5 \mathrm{~kg} \mathrm{Pu}$ & (e) & & \\
\hline & 232 & Operations Equipment & None & $-0-$ & $-0-$ & $-0-$ & $-0-$ & $-0-$ \\
\hline & 233 & Scrap Dissolution & M0x, Nitrate & $2 \mathrm{~kg} \mathrm{Pu}$ & $1 \mathrm{~kg} \mathrm{Pu}$ & (e) & $-0-$ & -0 \\
\hline & 234 & Scrap Storage & MOX & $2 \mathrm{~kg} \mathrm{Pu}$ & $1 \mathrm{~kg} \mathrm{Pu}$ & 1 week & $-0-$ & $-0-$ \\
\hline & 241,242 & Process Liquid Storage & Nitrate & $10 \mathrm{~kg} \mathrm{Pu}$ & $1.5 \mathrm{~kg} \mathrm{Pu}$ & (e) & -0 & $-0-$ \\
\hline & 101,102 & Analytical & All & 220 g SNM & 175 g SNM & 1 week & و SNM & 2 weeks \\
\hline & $121,122,134$ & Analytical & All & $220 \mathrm{~g}$ SNM & $175 \mathrm{~g}$ SNM & 1 week & $175 \mathrm{~g}$ SNM & 2 weeks \\
\hline & Hoods & Analytical & All & $110 \mathrm{~g} \operatorname{SNM}(a)$ & 55 g SNM & 1 week & 55 g SNM & 2 weeks \\
\hline & NDA Room & Analytical & All & $220 \mathrm{~g}$ SNM & 75 9 SNM & 1 week & $75 \mathrm{~g} \mathrm{SNM}$ & 2 weeks \\
\hline & $151,152,153$ & Analytical & All & $220 \mathrm{~g}$ SNM & 100 g SNM & 1 week & $100 \mathrm{~g} \mathrm{SNM}$ & 2 weeks \\
\hline & Safe & Analytical & All & 2209 SNM & $50 \mathrm{~g}$ SNM & 1 week & $50 \mathrm{~g}$ SNM & 2 weeks \\
\hline
\end{tabular}


TABLE 2. (Contd)

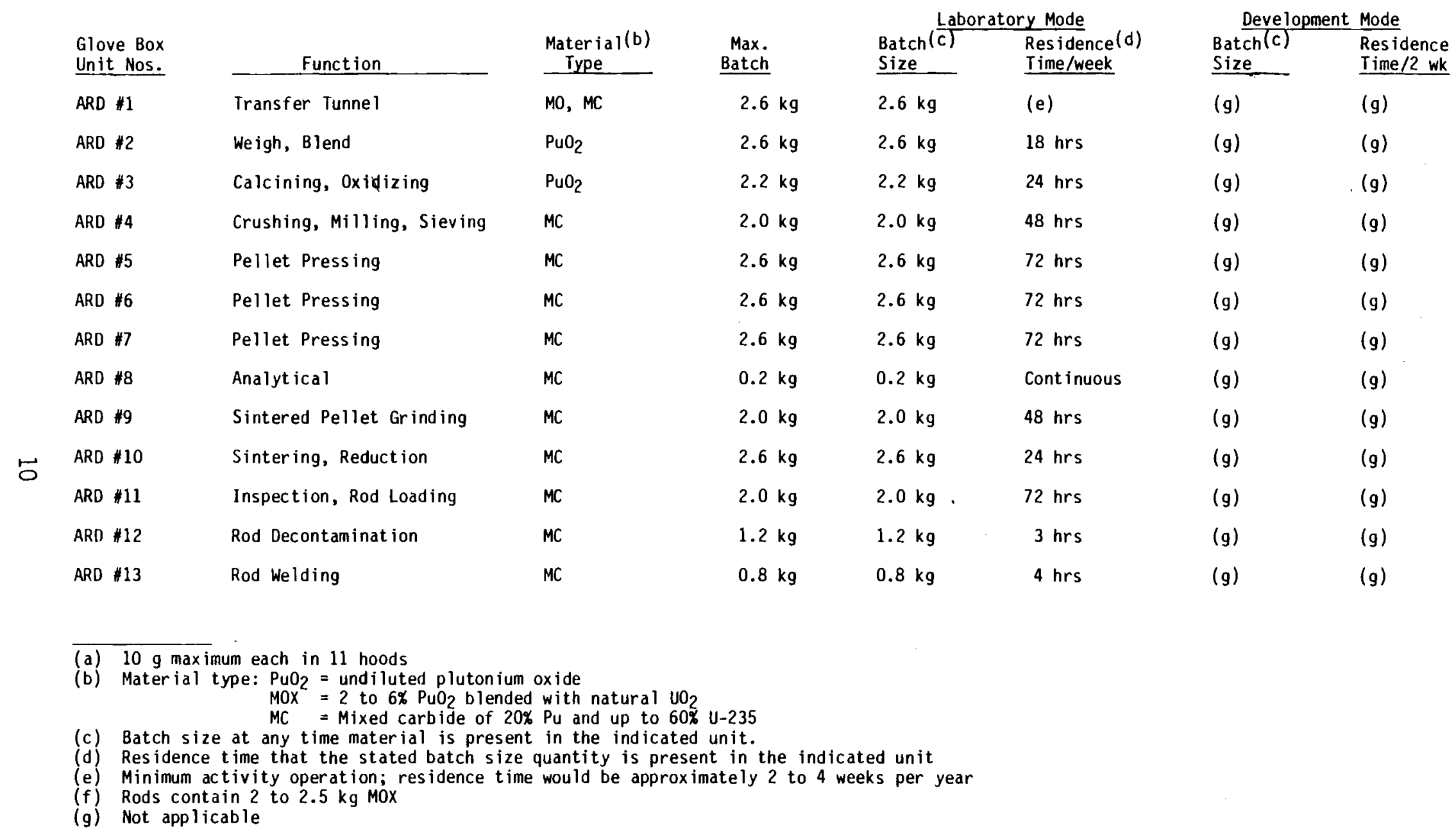


granulated powders, pellets, etc., are not considered dispersible, and the material in jeopardy in enclosures holding these forms is considered to be surface contamination in the form of a finely divided, attached powder. The residence time listed in Table 2 can be used to calculate an index of availability.

Finally, enclosures holding undiluted plutonium compounds are of greater significance than those holding MOX or MC since the radiological impact is 25 to 6 times greater for the same mass of undiluted plutonium injected into the air than for the other two materials.

Enclosures holding significant quantities of plutonium in dispersible form (powders or liquids), undiluted or combined with uranium, are found in the four areas designated in Mishima, Schwendiman and Ayer (1977a) as areas of concern: Process Development Laboratory, Ceramics Processing Laboratory, Chemical Processing Laboratory, and Advanced Fuels Laboratory. Other features of concern ( $1 \mathrm{~A}$ gas cylinders as potential missiles and oxygen gas as enhanced fire potential) are also found in these areas (Mishima, Schwendiman and Ayer 1977 , p. 16).

\section{PROCESS DESCRIPTION}

The PFDL is a fuel-manufacturing-technique development laboratory for MOX and MC fuels. The techniques involved cover the fabrication cycle from plutonium nitrate solutions (scrap recovery) and plutonium dioxide powder to complete MOX fuel rods or plutonium dioxide powder to complete MC fuel rods. Figures 1 and 2 (Westinghouse 1974, pp. 3.2-3 and 3.2-4) are process-flow diagrams of the two processes.

The PFDL is designed to process a maximum of 10 metric tons (MT) of mixed oxide per year (design basis throughput). At that rate, the facility would operate $2.4 \mathrm{hr} /$ day, 5 days/week for 48 to 58 weeks/year in the fabrication mode. Currently it is estimated that only one fourth of the time is spent in the fabrication mode with three fourths of the year spent in the development mode. The source term estimates are based upon a ful1-time fabrication mode, 


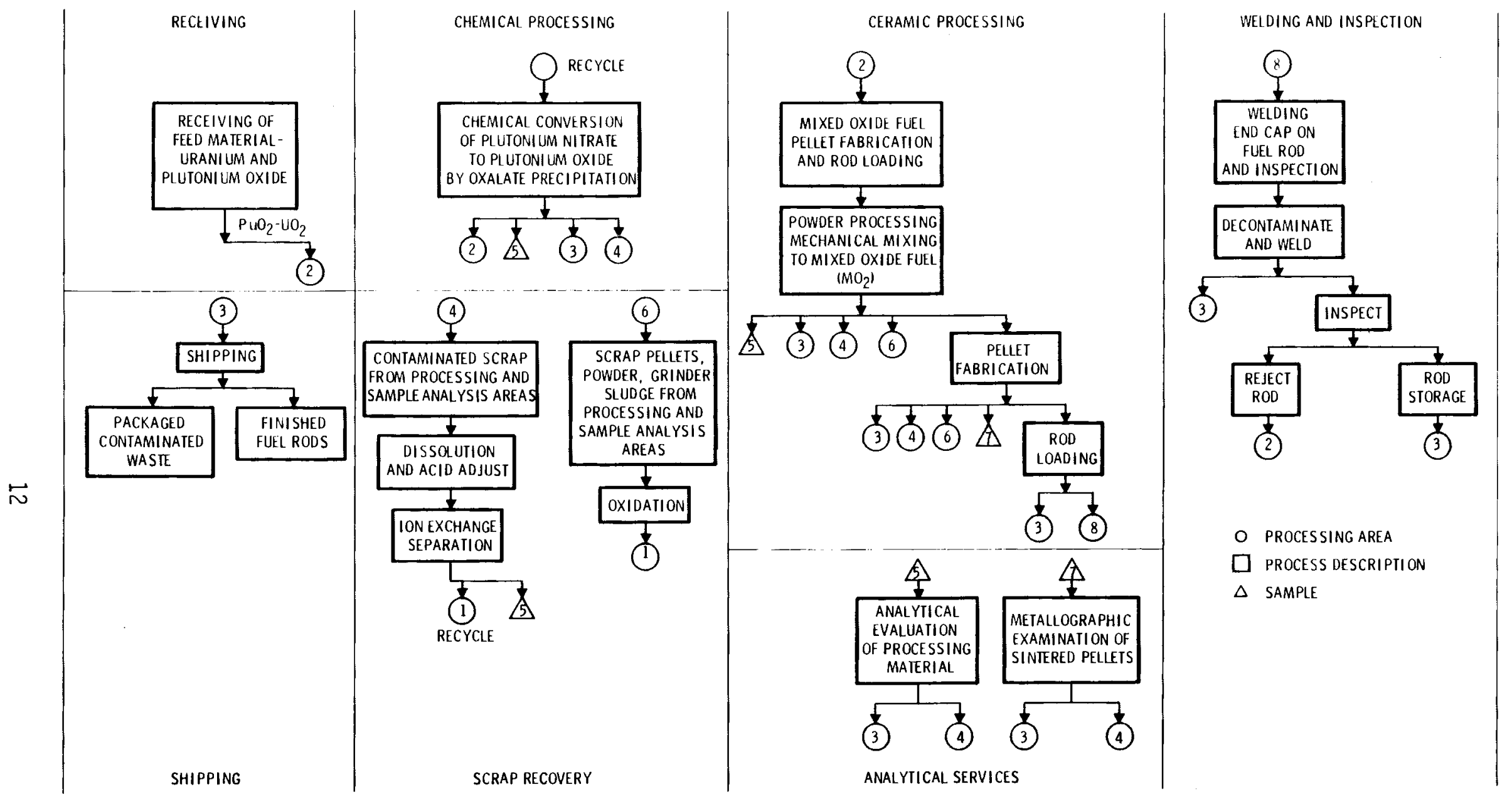

FIGURE 1. Process Flow Diagram, Mixed Oxide Fuel 


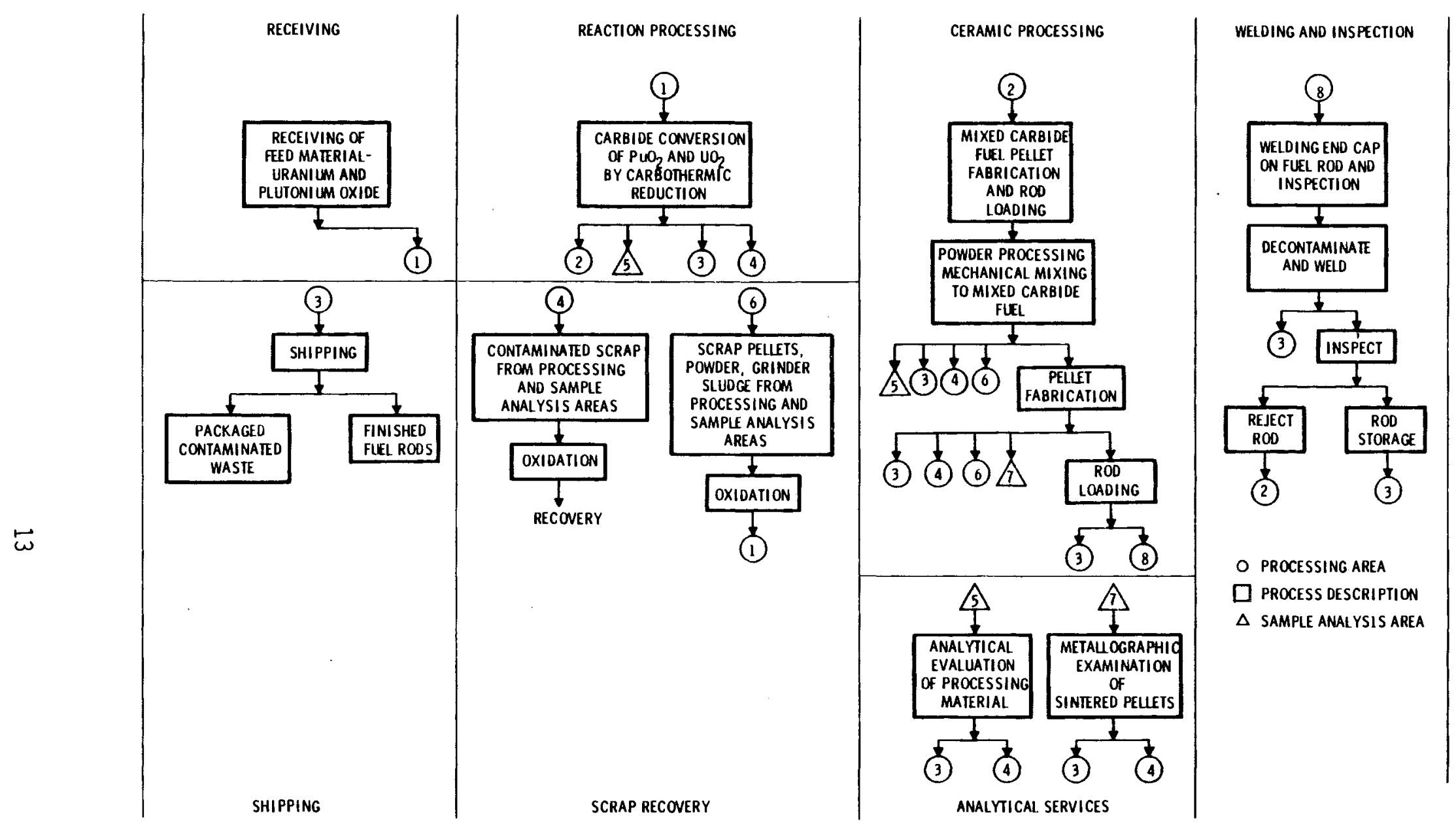

FIGURE 2. General Process Flow Diagram, Mixed Carbide Fuel 
and, since the quantities of plutonium present in the enclosures (a) and the time periods the plutonium is in jeopardy are larger for the fabrication than development mode (see Table 2), the assumption introduces a factor of 2 to 3 conservatism.

\section{BUILDING DESCRIPTION}

The main building of the PFDL is a single-story, steel-frame, open-bay structure 60-ft wide $\times 240-\mathrm{ft}$ long. A penthouse $40-\mathrm{ft}$ wide $\times 160 \mathrm{ft}$ long, centered over the ground floor, houses air handling and other equipment. The floor of the building is an on-grade concrete slab, and the exterior walls are corrugated steel siding on steel girts. The ground-floor interior walls have steel studs with cement plaster interior faces. Ceilings are made of cement plaster. The main building roof is steel decking with a 2- to 4- in. thick cast-in-place concrete slab. Because of their lightweight construction and means of attachment, additions (offices, mechanical equipment room, and shipping and receiving area) do not contribute to the support of the main building nor affect responses to wind and seismic forces (EDAC, 1977, p. 3-2). Figure 3 (EDAC 1977a) is a plan view of the ground floor and indicates the various production and working areas in the facility.

Process Development Laboratory (PDL)

The PDL is located in the eastern half of the central portion of the PFDL (see Figure 3) and houses four glove boxes numbered 301 through 304 . Figure 4 is a view of the area looking west. Plutonium dioxide powder is received in glove box 302 and is prepared for weighing and blending in glove boxes 303 and 304. Glove box 301 is used for miscellaneous operations and is not used in the routine fabrication operations. All enclosures can have dispersible materials at risk and three of the four boxes can hold undiluted plutonium dioxide. The quantities of dispersible materials at risk in the four enclosures for the fabrication mode are shown in Table 3.

(a) Glove boxes are a specific type of enclosure and are the predominant type of enclosure of concern in this study. "Glove boxes" and "enclosures" are used interchangeably in this document. 


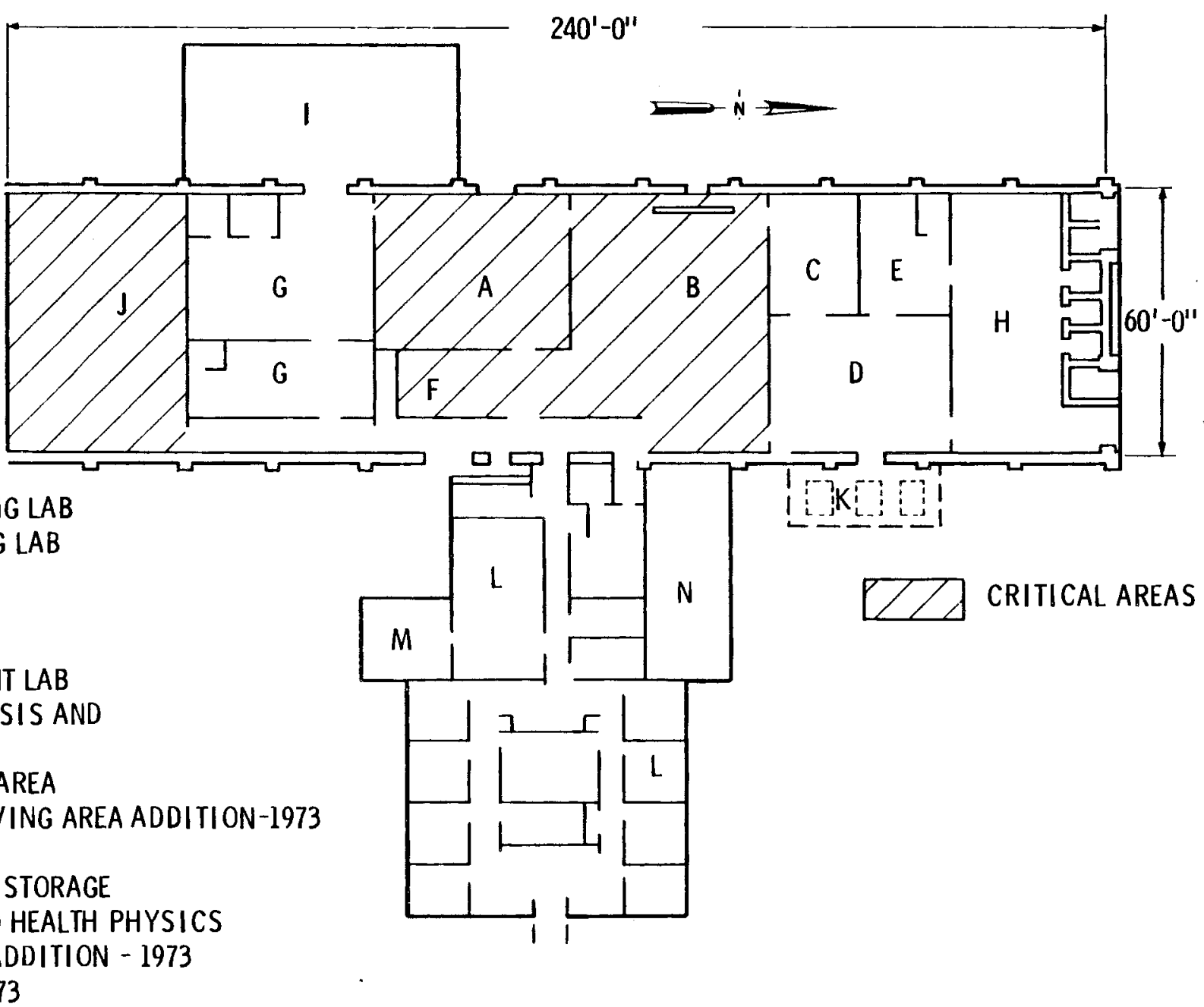

FIGURE 3. Westinghouse PFDL Facility - General Plan 


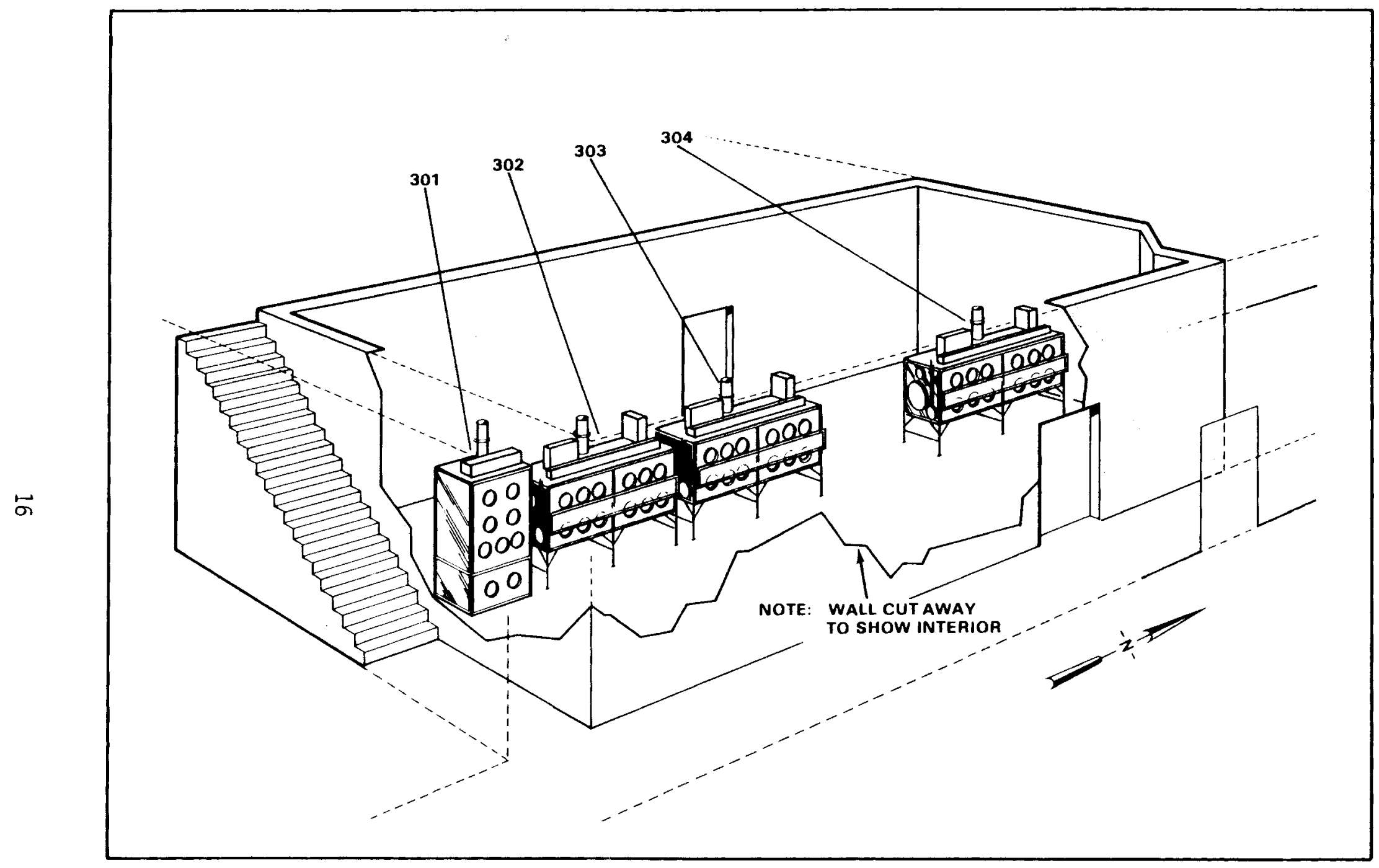

FIGURE 4. Process Development Laboratory 
TABLE 3. Inventories of Dispersible Materials at Risk and Duty Cycles for Enclosures in the Process Development Laboratory, Fabrication Mode

\begin{tabular}{|c|c|c|c|c|c|}
\hline $\begin{array}{l}\text { Glove Box } \\
\text { Number } \\
\end{array}$ & Function & $\begin{array}{l}\text { Dispersible } \\
\text { Mat'l at Risk }\end{array}$ & $\begin{array}{c}\text { Maximum Batch }(\mathrm{a}) \\
\mathrm{kg} \mathrm{Pu} \\
\end{array}$ & $\begin{array}{l}\text { Batch (b) } \\
\underline{\mathrm{kg} \mathrm{Pu}}\end{array}$ & $\begin{array}{l}\text { Duty Cycle(c) } \\
\text { kg Pu wk/wk }\end{array}$ \\
\hline 301 & Miscellaneous & $\mathrm{PuO}_{2}$ powder & 2 & 2 & $1.000(d)$ \\
\hline 302 & $\begin{array}{l}\mathrm{PuO}_{2} \text { Receiving } \\
\text { Inspection }\end{array}$ & $\mathrm{PuO}_{2}$ powder & 3.5 & 1.8 & 0.009 \\
\hline 303 & Sieving & $\mathrm{PuO}_{2}$ powder & 3.5 & 1.8 & 0.032 \\
\hline 304 & Sieving & MOX powder & 3.6 & 0.4 & $\frac{0.029}{1 .}$ \\
\hline \multicolumn{6}{|c|}{$\begin{array}{l}\text { Maximum quantity of material allowed in enclosure } \\
\text { Quantity of material routinely used in process } \\
\text { Fraction of work week in which } 1 \mathrm{~kg} \text { of uncontained plutonium in } \\
\text { dispersible form is present in enclosure } \\
\text { Assuming } 50 \% \text { residence time }\end{array}$} \\
\hline
\end{tabular}




\section{Ceramics Processing Laboratory (CER)}

The CER occupies the central portion of the ground floor of the PFDL (see Figure 3) and houses 20 glove boxes (see Table 4 for numbers). Figure 5 is a drawing of the area looking southeast. Plutonium dioxide (in screw-cap, aluminum $\mathrm{jars}$ ) is transferred into glove box 305 (weighing and storage) from glove box 304. The plutonium dioxide is blended with natural uranium dioxide and the MOX is slugged, granulated, pressed into pellets in glove boxes 400 through 411 and 418. Pellets are then sintered (heated to a high temperature in a reducing atmosphere), ground, dried, inspected, and loaded into fuel rods in the remaining enclosures in the area. The cover gas during sintering is $6.2 \%$ hydrogen in nitrogen and is not combustible in air. Several hydraulic fluid reservoirs that contain a combustible liquid are located in the area. Four of the 20 glove boxes (305, 400, 401 and 402) contain powders (plutonium dioxide $\left[\mathrm{PuO}_{2}\right]$ powder is found in glove boxes 305 and 400). (Since $\mathrm{PuO}_{2}$ powder is only "at-risk" for a short period of time during the blending operation, assuming its presence during the incident is a conservative assumption). The remaining 16 glove boxes in the CER are assumed to contain MOX surface contamination on all exposed interior surfaces to an average level of $7.5 \mathrm{~g}$ of powder per square meter (Mishima, Schwendiman and Ayer 1978). The estimated quantities of dispersible materials at risk in the CER enclosures for the fabrication mode of operation are shown in Table 4.

Chemical Processing Laboratory (CPL)

The CPL is located west of the PDL (see Figure 3 ) and houses 15 glove boxes beginning with number 200 and ending with 242. Glove boxes 200 and 201 have not been placed into service. The 13 enclosures considered in this study are shown in Table 5. A drawing of the area looking toward the southwest is presented in Figure 6 . The CPL is involved in the scrap recovery operation shown in Figure 1 and involves both a dry and wet process. (Scrap is defined as materials containing recoverable quantities of plutonium with cost a principal criterion.) Much of the scrap is out-of-tolerance MoX pellets or powder but can include floor sweepings from process enclosures, undiluted plutonium compounds, etc. "Dirty" and "clean unsintered scrap" is sintered in 
TABLE 4. Inventories of Dispersible Materials at Risk and Duty Cycles for Enclosures in the Ceramics Processing Laboratory, Fabrication Mode

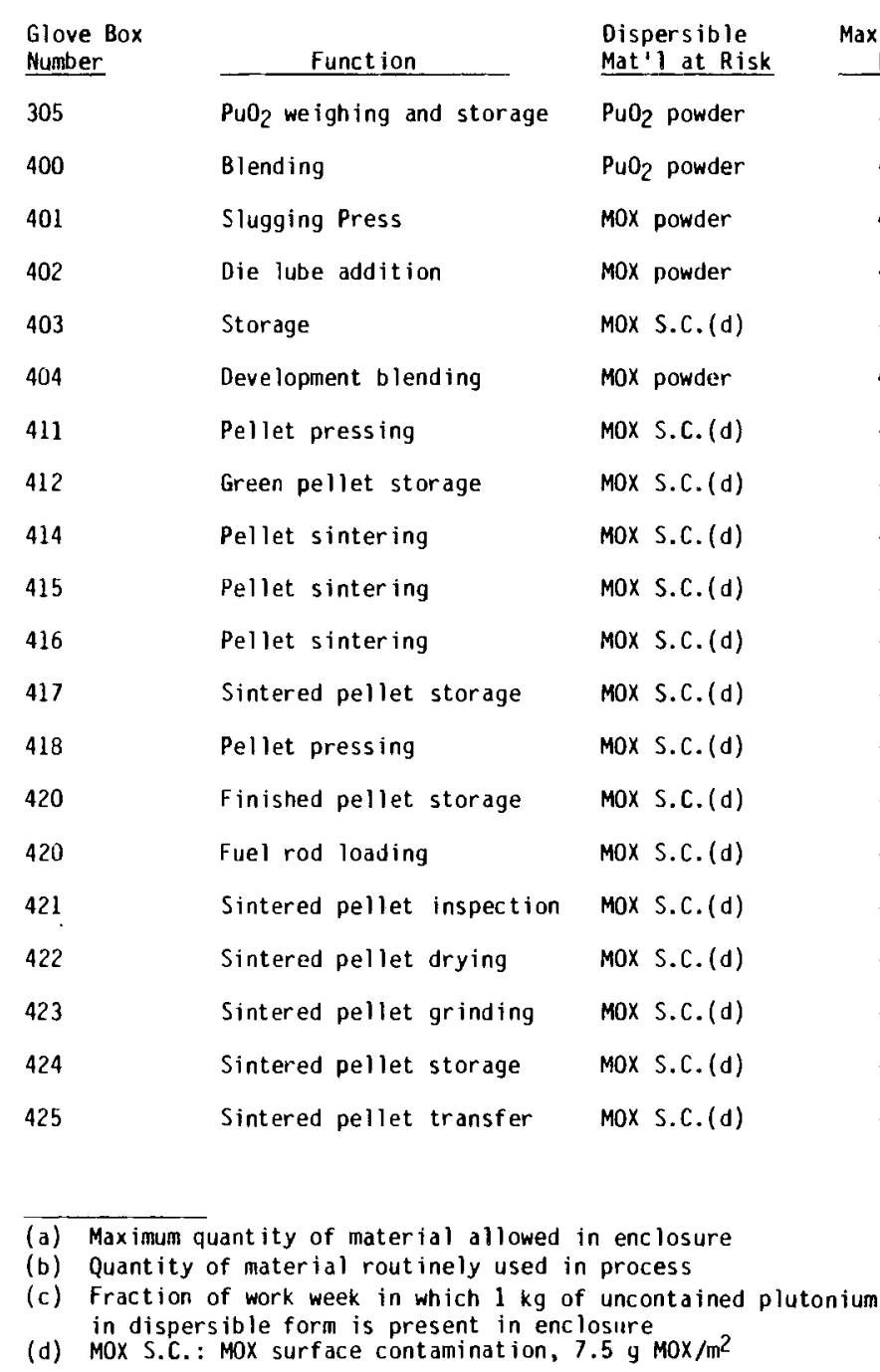




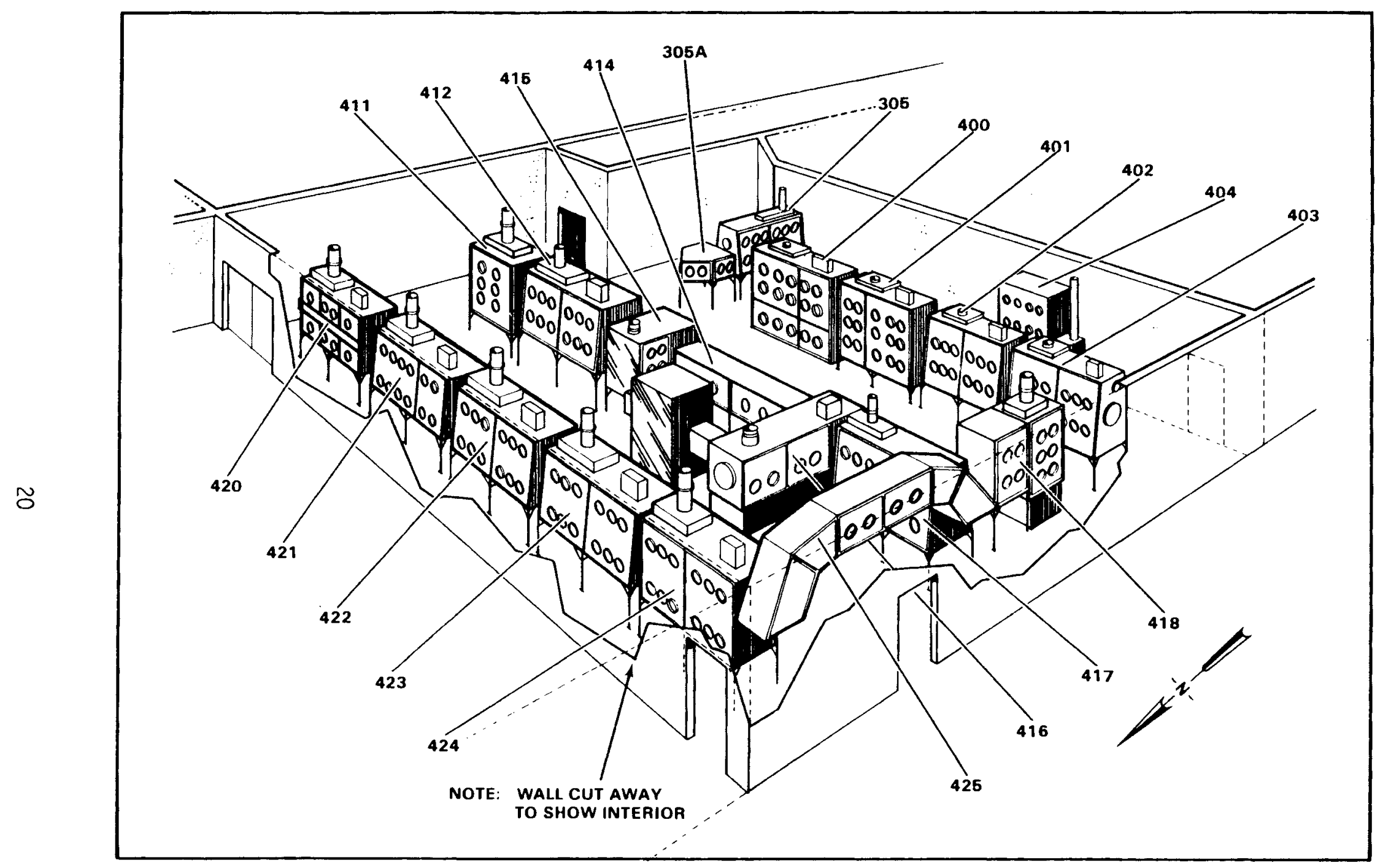

FIGURE 5. Ceramics Processing Laboratory 


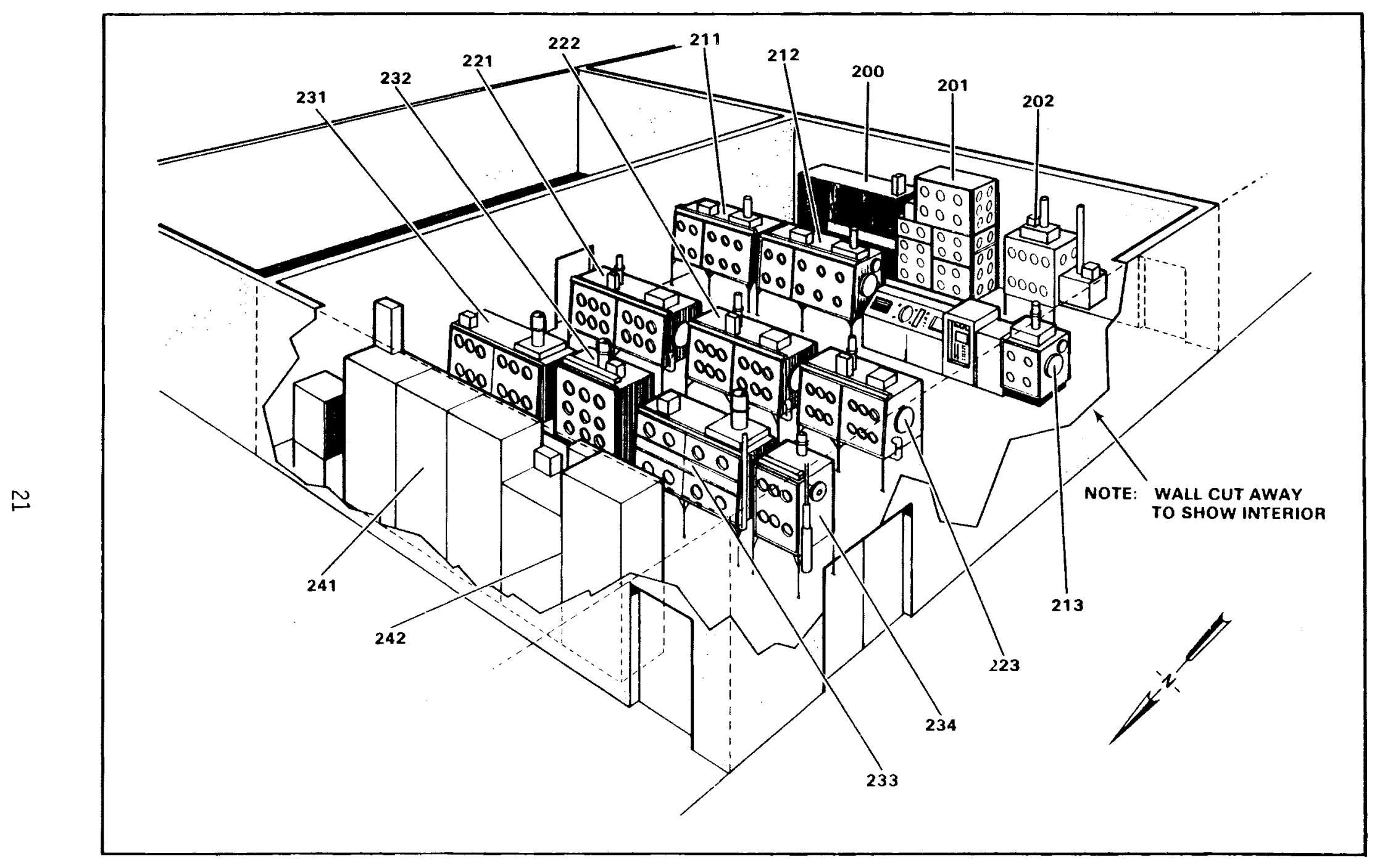

FIGURE 6. Chemical Processing Laboratory 
TABLE 5. Inventories of Dispersible Materials at Risk and Duty Cycles for Enclosures in the Chemical Processing Laboratory, Fabrication Mode

\begin{tabular}{|c|c|c|c|c|c|}
\hline $\begin{array}{l}\text { Glove Box } \\
\text { Number } \\
\end{array}$ & Function & $\begin{array}{l}\text { Dispersible } \\
\text { Mat Tat Risk }\end{array}$ & $\operatorname{Max}_{\underline{\mathrm{kg}} \mathrm{Pat}_{\mathrm{u}}} \operatorname{Batch}(\mathrm{a})$ & $\begin{array}{l}\text { Batch }(b) \\
\mathrm{kg} \mathrm{Pu}_{\underline{u}}\end{array}$ & $\begin{array}{l}\text { Duty } c y c l e(c) \\
\mathrm{kg} \mathrm{Pu}_{\mathrm{u}} / \mathrm{wk}\end{array}$ \\
\hline 211 & Misc. Waste Solidification & Pu nitrate solu. & 2 & 0.002 & 0.0002 \\
\hline 212 & Oxidation & MOX powder & & & \\
\hline 213 & Oxidation & MOX powder & 0.2 & 0.06 & 0.006 \\
\hline 221 & Oxalate precipitation & Pu oxalate slurry & 1 & 0.5 & 0.038 \\
\hline 222 & Conv. oxalate to oxide & $\mathrm{PuO}_{2}$ powder & 2 & 0.5 & 0.038 \\
\hline 223 & Oxide inspection & $\mathrm{PuO}_{2}$ powder & 2 & 0.5 & 0.038 \\
\hline 231 & $\mathrm{Pu}$ recovery-IX column & Pu nitrate solu. & 1 & 0.5 & 0.038 \\
\hline 232 & Operations equipment & -- & -- & -- & -- \\
\hline 233 & Scrap dissolution & MOX powder & 2 & 1 & 0.077 \\
\hline 234 & Scrap storage & M0X powder & 2 & 1 & 1 \\
\hline 241 & Process liquid storage & Pu nitrate solu. & 10 & 1 & 0.077 \\
\hline 242 & Process liquid storage & Pu nitrate solu. & 10 & 1.5 & $\frac{0.12}{1.43}$ \\
\hline 201 & Pu nitrate receiving & $\mathrm{PuO}_{2}$ S.C. (d) & - & -- & $\frac{0.27}{1.60}$ \\
\hline
\end{tabular}

\footnotetext{
(a) Maximum quantity of material allowed in enclosure.

(b) Quantity of material routinely used in process.

(c) Fraction of work week in which $1 \mathrm{~kg}$ of uncontained plutonium in dispersible form is present in enclosure.

(d) $\mathrm{PuO}_{2}$ S.C.: $\mathrm{PuO}_{2}$ surface contamination, $7.5 \mathrm{~g}$ powder $/ \mathrm{m}^{2}$
} 
a furnace for $40 \mathrm{hr}$. The material is then stored and combined with "cleansintered" scrap prior to oxidation in a furnace for $9 \mathrm{hr}$. The sintered material is sieved, and the fines, with small amounts of material with higher plutonium contents added, are dissolved in 1-kg batches. The total plutonium content of a dissolver batch is normalized in a 20 - to $40 \mathrm{gg}$ range with a limit of $100 \mathrm{~g} \mathrm{Pu}$ per dissolver.

The two dissolvers in glove box 233 are operated simultaneoulsy and each holds $5 \mathrm{l}$ of solution. After 3 to $4 \mathrm{hr}$ of boiling and cooling, the solution is stored until it is purified using the three ion exchange (IX) columns in glove box 231. The columns hold a strongly-basic anion exchange resin and have a capacity of $500 \mathrm{~g} \mathrm{Pu}$ each. The $\mathrm{Pu}$ is eluted from the resin using 0.35 N nitric acid. Normally, the concentration of the product solution is $40 \mathrm{~g}$ $\mathrm{Pu} / \mathrm{l}$ with a maximum value of $70 \mathrm{~g} \mathrm{Pu} / \ell$. The concentration of the waste is 25 $\mathrm{mg} \mathrm{Pu} / \mathrm{l}$.

The product solutions are stored until transfer to glove box 221 where the solutions are converted to oxalate, dried, and converted to $\mathrm{PuO}_{2}$ in the electric pot furnace in glove box 222 . The waste from the conversion of nitrate to oxalate has a concentration of $25 \mathrm{mg} \mathrm{Pu/ \ell .}$

After communition and inspection, the $\mathrm{PuO}_{2}$ is shipped to the POL. All transfers of solutions within the CPL are made via the overhead lines using vacuum, except for the IX operations ( 3 to 5 psig pressure). All lines are pumped "dry" after transfer. For the design basis throughput, 10 MT, the lines would contain solution 9 days during the 6 -week period required for scrap recovery of a contract (material from different sources) for three contracts per year. The average concentration of solutions in transit is assumed to be $\sim 21 \mathrm{~g} \mathrm{Pu/ \ell}$ (a conservative assumption) with a range of $25 \mathrm{mg}$ to $70 \mathrm{~g} \mathrm{Pu} / \ell$. Al1 enclosures except glove box 201, which is out of service, are assumed to contain dispersible material at risk. 
Advanced Fuels Laboratory (AFL)

The AFL occupies the south end of the PFDL (see Figure 3) and contains the 14 enclosures and transfer tunnels listed in Table 6 . Figure 7 is a drawing of the area looking toward the northwest. All the operations shown in the process-flow diagram in Figure 2 are performed in the AFL. Plutonium dioxide, uranium dioxide, and carbon are blended in $3.6-\mathrm{kg}$ lots $(0.54 \mathrm{~kg} \mathrm{Pu})$, pressed into pellets, and converted to low-density MC in a furnace in an inert atmosphere enclosure. All subsequent operations are performed under inert atmospheres. The MC is ball-milled, sieved, and separated into 12 separate charges in weighing containers. A manual, hydraulic press is used to make pellets of the MC, and the pellets are sintered, ground, inspected and loaded into fuel rods.

Four enclosures (ARD-1, -2, -3, and -4) are assumed to contain dispersible material at risk--two are assumed to contain $\mathrm{PuO}_{2}$ powder and two $\mathrm{MC}$ powder.

Mixed carbide is chemically reactive with the oxygen in air. The product of the reaction may have different size distributions than the starting material. A few of the pertinent chemical and physical characteristics of $M C$ are:

- chemical composition: $80 \%$ uranium, $15 \%$ plutonium, $5 \%$ carbon

- density: $10.8 \mathrm{~g} / \mathrm{cm}^{3}$ ( $80 \%$ of theoretic density)

- particle size: $-144 \mu \mathrm{m}$ to $+44 \mu \mathrm{m}$ (by sieve); average size: $9.4 \mu \mathrm{m} \sigma=0.7$

- oxidation behavior: 1) powder--newly formed material oxidizes rapidly in air at $25^{\circ} \mathrm{C}$; passivates with exposure to air; mixed oxides with a size of less than $44 \mathrm{\mu m}$ are generated; 2) pellets--do not oxidize with standing at room temperature; a slow oxidation is initiated at $250^{\circ} \mathrm{C} ; 3 \mathrm{hr}$ at $1000^{\circ} \mathrm{C}$ is required for complete oxidation in air; mixed oxides generated are not adherent. 


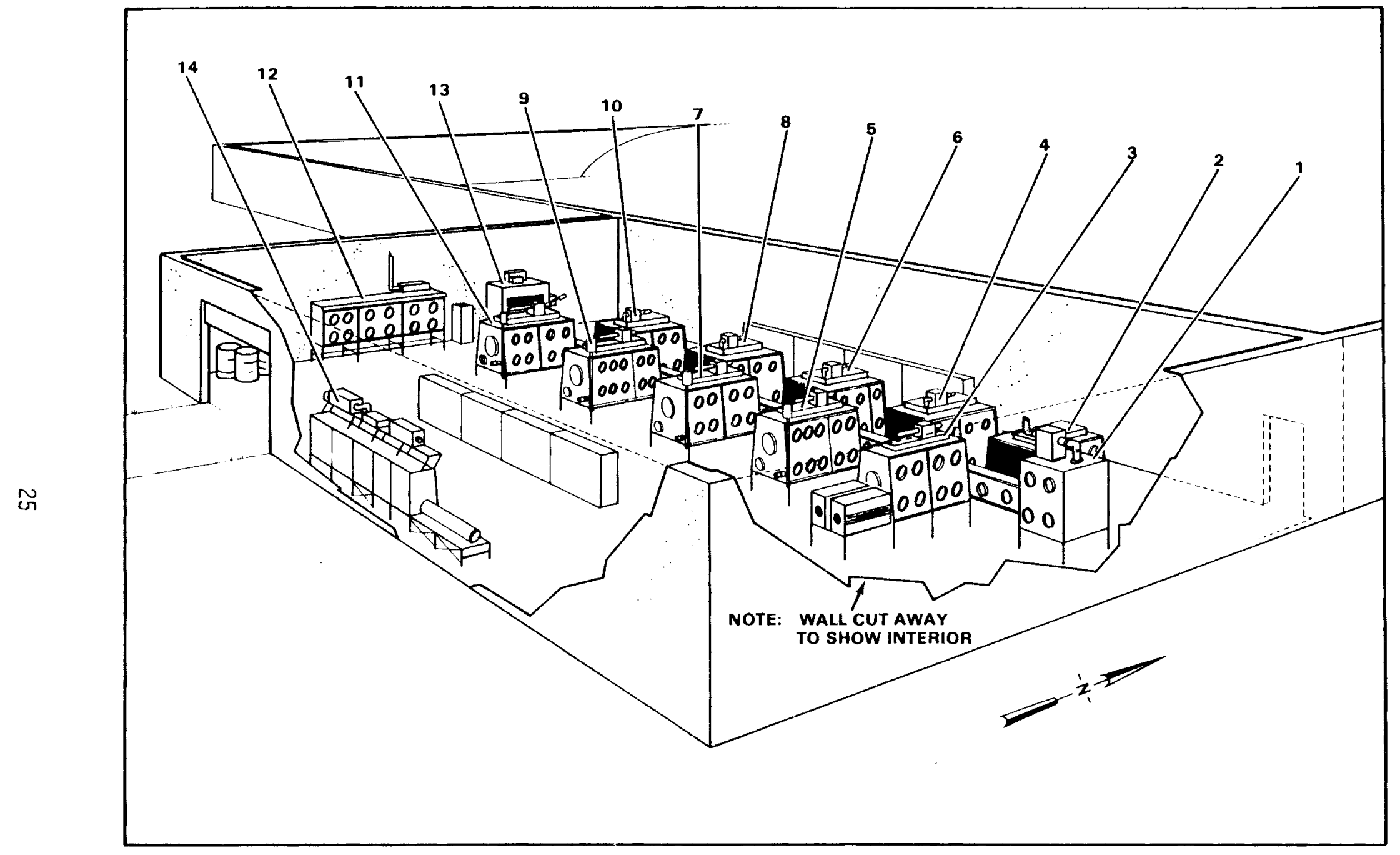

FIGURE 7. Advanced Fuels Laboratory 
TABLE 6. Inventories of Dispersible Materials at Risk and Duty Cycles for Enclosures in the Advanced Fuels Laboratory, Fabrication Mode

\begin{tabular}{|c|c|c|c|c|c|}
\hline $\begin{array}{l}\text { Glove Box } \\
\text { Number } \\
\end{array}$ & Function & $\begin{array}{l}\text { Dispersible } \\
\text { Mat'l at Risk }\end{array}$ & $\begin{aligned} \text { Max. Match }(\mathrm{a}) \\
\mathrm{kg} \mathrm{Pu} \\
\end{aligned}$ & $\begin{array}{l}\text { Batch }(b) \\
\mathrm{kgPu}\end{array}$ & $\begin{array}{l}\text { Duty Cycle(c) } \\
\mathrm{kg} \mathrm{Pu} \mathrm{wk/wk}\end{array}$ \\
\hline ARD-1 & Transfer tunne 1 & MO, MC forms & 0.39 & 0.39 & 0.03 \\
\hline ARD-2 & Weigh, blend & $\mathrm{PuO}_{2}$ powder & 2.3 & 2.3 & 0.25 \\
\hline ARD-3 & Calcining, oxidizing & $\mathrm{PuO}_{2}$ powder & 1.9 & 1.9 & 0.27 \\
\hline ARD-4 & Crushing, milling, sieving & MC powder & 0.3 & 0.3 & 0.085 \\
\hline ARD-5 & Pellet pressing & MC S.C. (d) & -- & -- & 0.029 \\
\hline ARD-6 & Pellet pressing & MC S.C. (d) & -- & -- & 0.029 \\
\hline ARD -7 & Pellet pressing & MC S.C. (d) & -- & -- & 0.029 \\
\hline ARD-8 & Analytical & MC S.C. (d) & -- & -- & 0.029 \\
\hline ARD-9 & Sintered Pellet grinding & MC S.C. (d) & -- & -- & 0.029 \\
\hline ARD-10 & Sintering, reduction & MC S.C. (d) & -- & -- & 0.029 \\
\hline ARD- 11 & Inspection, rod loading & MC S.C. (d) & -- & -- & 0.029 \\
\hline ARD-12 & Rod decontamination & MC S.C. (d) & -- & -- & 0.029 \\
\hline ARD-13 & Rod welding(e) & MC S.C. (d) & -- & -- & 0.029 \\
\hline ARD-14 & Rod welding & MC S.C. (d) & -- & -- & $\frac{0.029}{0.90}$ \\
\hline \multicolumn{6}{|c|}{$\begin{array}{l}\text { (a) Maximum quantity of material allowed in enclosure. } \\
\text { (b) Quantity of material routinely used in process. } \\
\text { (c) Fraction of work week in which } 1 \mathrm{~kg} \text { of uncontained plutonium in } \\
\text { dispersible form is present in enclosure. } \\
\text { (d) MC S.C.: mixed carbide surface contamination, } 15 \% \mathrm{Pu}, 7.5 \mathrm{~g} \mathrm{MC} / \mathrm{m}^{2} \\
\text { (e) No longer in service }\end{array}$} \\
\hline
\end{tabular}




\section{Building Exhaust Filtration System (Fenthouse)}

All potentially contaminated gases exhausted from the building are filtered by high-efficiency particulate air (HEPA) filters prior to discharge. The final exhaust filters for the three systems in the PFDL--room, glove box and hoods (and AFL)--are located in the penthouse. Each system passes the gases through two successive stages of filtration. The number of HEPA filters that make up each stage varies with the gas flow processed through the system. A group of filters comprising a stage of filtration is called a bank.

The room exhaust system handles air from the operations and is normally recycled after filtration. There are 32 metal-cased HEPA filters in this system located at the north end of the penthouse.

The glove box and hood exhaust system is the primary contributor to the airborne release of radioactive particulate material in the gaseous effluents. The glove box and hood exhausts are handled by three separate units with a total of 36 metal-cased HEPA filters.

All plywood-cased HEPA filters (10) are used in the exhaust filtration system for the AFL and are located at the extreme south end of the penthouse. Most of the glove boxes in this system are on a complete recycle of inert gas, and only exhaust into the system to maintain negative pressure in the glove box in the face of fluctuations in barometric pressure. 


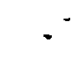

$\checkmark$

$\because$

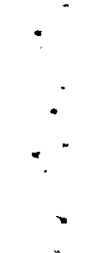


DAMAGE SCENARIOS

The points germane to the estimation of source terms from the damage scenarios postulated by Mehta, Smith and MCDonald (1978) and EDAC (1977b) for wind and seismic hazard in order of increasing severity are recapitulated below.

WIND DAMAGE SCENARIOS (Mehta, Smith and MCDonald 1978)

- Nomina 1 wind speed $130 \mathrm{mph}, 2 \times 10^{-5}$ per year probability of occurrence. Holes, $16 \mathrm{ft}^{2}$, in the northeast and northwest corners of the penthouse roof result from the stripping of the roof. Plywood-cased HEPA filters can be disconnected and displaced. A few filters may break open on impact during displacement. Filter media contained in case.

- Nominal wind speed $160 \mathrm{mph}, 7 \times 10^{-6}$ per year probability of occurrence. Situation in penthouse as above. No significant damage leading to the airborne release of contained material in CPL or CER. Standard-size door in east wall of PDL fails; one enclosure perforated. Six-foot wide strips of wall cladding lost from southwest and southeast corner of AFL. One glove box, probably in outer location, perforated.

- Nomina 1 wind speed $200 \mathrm{mph}, 2 \times 10^{-6}$ per year probability of occurrence. Most of the decking of penthouse roof and four-foot wide strip on corners of wall lost. Most plywood-cased HEPA filters broken open. Few metalcased filters perforated. Exterior wall cladding stripped and interior walls destroyed in CPL, CER, AFL, and PDL. Wind blows freely through areas. Most glove boxes perforated with holes ranging from 3 in. in dia. to $4 \times 12 \mathrm{in}$.

- Nominal wind speed $260 \mathrm{mph}, 2 \times 10^{-7}$ per year probability of occurrence. Most wall cladding stripped from penthouse and air circulates freely through area. Damage to air-handling equipment extensive. Plywood-cased filters crushed. Some metal-cased filters perforated. Wall cladding stripped and interior walls destroyed in CPL, CER, PDL, and AFL allowing wind to blow freely through areas. Some boxes in each area crushed and remainder perforated. 


\section{SEISMIC DAMAGE SCENARIOS (EDAC 1977b)}

- Less than $0.09 \mathrm{~g}$ ground acceleration. No significant damage postulated.

- $0.09 \mathrm{~g}$ to 0.18 ground acceleration, $1 \times 10^{-4}$ per year probability of occurrence at $0.18 \mathrm{~g}$. Wall cladding loosened but not lost (integrity of structure not breached). Oxygen cylinder in AFL topples.

- $0.18 \mathrm{~g}$ to $0.25 \mathrm{~g}$ ground acceleration, $4 \times 10^{-5}$ per year probability of occurrence at $0.25 \mathrm{~g}$. Wall cladding loosened but not lost. The 24-in.-dia. process vessels in glove box 241 overturns. Local release in CPL.

- Greater than $0.39 \mathrm{~g}$ ground acceleration, less than $2 \times 10^{-5}$ per year probability of occurrence. Steel exterior siding fails at $0.39 \mathrm{~g}$ exposing interior to ambient atmosphere. Overhead Pu transfer lines fail at 0.39 to $0.49 \mathrm{~g}$. Building collapses in place at $0.49 \mathrm{~g}$. Estimated $3 / 4$ enclosures crushed (range $1 / 2$ to $7 / 8$ ) with remainder perforated. 


\section{APPROACH AND FACTORS USED IN ESTIMATING SOURCE TERMS}

Source terms are estimated to provide data for the calculation of potential radiation dose to the general population from the Cheswick facility. A principal concern is that fraction of the airborne particulate material that can be transported downwind, inhaled by human beings, and deposited in the deep lung (alveolar region). In addition, the remaining fraction of airborne particulate material (in the order of 100 to $200 \mu \mathrm{m}$ AED) that is redistributed beyond the area of the facility is also considered in this study since it poses a potential surface-contamination and long-term resuspension problem.

Various kinds of information are required to arrive at a source term estimate. How much material can be affected by the event? What fraction of the material affected is made airborne by the event? What is the size distribution of the material airborne? What is the behavior of the airborne material in the time span required for release? What are the release rates and characteristics of the airborne material released to the ambient atmosphere? The factors and considerations used in order to answer these questions are detailed below.

\section{INVENTORIES OF DISPERSIBLE MATERIALS AT RISK}

\section{Enclosures}

The quantity of material potentially available for dispersion is the quantity of material in dispersible form that can be exposed to the conditions described in the accident scenarios. Even enclosures that do not routinely process materials in dispersible form are assumed in this study to be contaminated over a period of time, and the surface contamination (deposited particles and dried solutions) is considered a dispersible form. The quantity of material present depends upon the level of surface contamination and the total surface area contaminated. The level of surface contamination depends upon housekeeping and accountability practices but does not exceed the levels at which the contamination is readily visible to the unaided eye. The total area contaminated depends upon the size of the enclosure and the equipment contained within the enclosure. 
All appreciable quantities of $\mathrm{Pu}$ are separated from the atmosphere within the building by at least one barrier. Most are in enclosures in the four areas designated as areas of concern. The inventories of Pu in dispersible form found in these four areas are listed in Tables 3, 4, 5, and 6. Because of the energy required to subdivide pellets into the respirable size range, only powders and liquids are considered dispersible forms. All other enclosures are assumed to be contaminated with a powder form of the material handled. (In the case of enclosures holding plutonium nitrate or oxalate, it is further assumed that air oxidation over a long time span has converted all the material to $\mathrm{PuO}_{2}$; such an assumption increases the quantity of $\mathrm{Pu}$ potentially airborne and is therefore conservative.)

To derive an average surface contamination inventory, a glove box representative of all the enclosures in each area was chosen by comparison of photographs of all glove boxes (supplied by Westinghouse) with the examples in EDAC, Section 4 (1977a). Three of the four glove boxes found in the PDL are represented by Figure 4-9 in that document and have dimensions of 4-ft high $x$ $8-f t$ long $\times 3-f t$ deep. The volume of the enclosure is $2.7 \mathrm{~m}^{3}$, and the surface area of the walls is approximately $12.5 \mathrm{~m}^{2}$. The total interior surface area is assumed to be twice the wall area to compensate for equipment, piping, etc.

Ten of the 14 glove boxes in the AFL are represented by Figure $4-3$ in EDAC (1977a) and have dimensions of 4-ft high $\times$ 8-ft long $\times 2.5-f t$ deep. The volume of the glove box is $2.3 \mathrm{~m}^{3}$ with a total interior surface area of $23 \mathrm{~m}^{2}$.

The dimensions of the glove boxes in the CPL and CER are more varied. Most of the enclosures in the CPL can be represented by the glove boxes depicted in Figures 4-4 through 4-6 (EDAC 1977a). The glove box shown in Figure 4-5 was selected as representative and has a volume of $5.5 \mathrm{~m}^{3}$ and a total interior surface area of $41 \mathrm{~m}^{2}$. The enclosures in the CER showed so much variation that the dimensions of all 20 glove boxes were estimated from the photographs and an average value used: volume $3.3 \mathrm{~m}^{3}$ and a total interior surface of $28 \mathrm{~m}^{2}$. 
Westinghouse estimated an average surface contamination value of $1.1 \mathrm{~g}$ $\mathrm{Pu} / \mathrm{m}^{2}$ based on exterior dose rates for glove boxes over a 5-yr period (Westinghouse 1974, pp. 5.1-12 to 5.1-13). Mishima, Schwendiman and Ayer (1978, p. 35) estimated a surface contamination level of $7.5 \mathrm{~g}$ powder per square meter $\left(6.6 \mathrm{~g} \mathrm{Pu}\right.$ as $\left.\mathrm{PuO}_{2}\right)$ from other sources. A value of $7.5 \mathrm{~g}$ powder per square meter appears conservative.

Table 7 indicates the quantity of Pu present as surface contamination for the typical enclosure in each area for the various types of material found in that area.

Overhead Plutonium Transfer Lines

Polyethylene-lined 3/4-in.-dia. stainless-steel (304) pipes are used to transfer aqueous $\mathrm{Pu}$ between enclosures in the $\mathrm{CPL}$. The $\mathrm{Pu}$ content of the solutions ranges from $25 \mathrm{mg} \mathrm{Pu} / \mathrm{l}$ (waste from oxalate precipitation and ion exchange separation) to $70 \mathrm{~g} \mathrm{Pu} / \mathrm{e}$ (à maximum value for product solutions from ion exchange separation). The volume of waste solutions is much greater than the other solutions transferred. With the exception of the ion exchange system that uses a 3 to 5 psig pressure, transfers of liquids are by vacuum and the lines "sucked dry" after transfer. Thus, bulk quantities of liquid are not available in the line while the lines are not in service. If the lines are broken, liquid transfer will cease unless a siphoning action is induced or the liquid is under pressure. In either case, any liquid spilled from the lines issues from a large opening (1/2-in.-dia. size of pipe) under little pressure (less than 5 psig).

It is estimated that the lines are in use for 9 days during the 6 weeks required to process material from a single contract. Three contracts a year are required for the design basis throughput. Thus, on a yearly basis, the lines are in use $12.5 \mathrm{hr}$ per wk. The operational value for the ion exchange product is $40 \mathrm{~g} \mathrm{Pu} / \mathrm{l}$. An average value of $20 \mathrm{~g} \mathrm{Pu} / \mathrm{l}$ is used for the $\mathrm{Pu}$ concentration in the lines to compensate for the large volumes of liquid of lesser Pu content transferred (waste, IX feed, etc.).

\section{HEPA Filters in Final Exhaust Filter Banks in Penthouse}

The filters in the penthouse are the final exhaust filters for three systems--room, glove box, and AFL. Each system is equipped with two stages of 
TABLE 7. Plutonium Content of Surface Contamination in Typical Enclosures as a Function of Plutonium Compounds

\begin{tabular}{|c|c|c|c|c|c|c|}
\hline \multirow[b]{2}{*}{ Area } & \multirow{2}{*}{$\begin{array}{c}\text { Volume } \\
\mathrm{m}^{3} \\
\end{array}$} & \multirow{2}{*}{$\begin{array}{l}\operatorname{TISA}_{\mathrm{ISA}}(\mathrm{a}) \\
\mathrm{m}^{2} \\
\end{array}$} & \multicolumn{4}{|c|}{ Grams Plutonium } \\
\hline & & & $\mathrm{PuO2}$ & $\mathrm{Pu}\left(\mathrm{NO}_{3}\right)_{4}$ & $\operatorname{MOX}(b)$ & $M C(c)$ \\
\hline Advanced Fuels Laboratory & 2.3 & 23 & 152 & -- & 6.9 & 29 \\
\hline Process Development Lab. & 2.7 & 25 & 165 & -- & 7.5 & -- \\
\hline Ceramics Processing Lab. & 3.3 & 28 & 185 & -- & 8.4 & -- \\
\hline Chemical Processing Lab. & 5.5 & 41 & 271 & 151 & 12.0 & -. \\
\hline
\end{tabular}

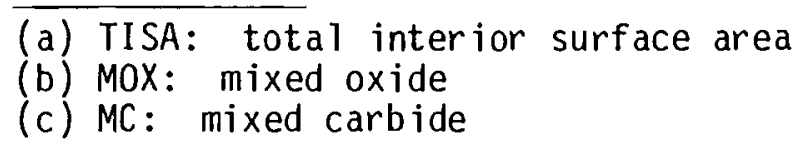


filtration. The room system handles air from the operating areas and is normally recycled after filtration. Normally, little if any airborne radioactivity is found in operating areas, and little accumulates on the filters in this system.

The glove box system is the primary contributor to the airborne release of radioactivity in the gaseous effluents. An average loading of $1 \mathrm{~g} \mathrm{Pu}$ at replacement per filter is used by Westinghouse (Westinghouse 1974, p. 5.1-13),

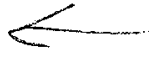
with a high measured value of $4 \mathrm{~g} \mathrm{Pu}$ at change-out, for the initial filter in the glove box exhaust system. The material accumulates over some period of time and only reaches these values at the end of the period. Since the filters at this location are not tested after installation, their efficiency is not assumed to be as-rated, but poor efficiency would be detected by increase in the presence of radioactivity downstream in the system. It is assumed that these filters are $99 \%$ efficient and $10 \mathrm{mg} \mathrm{Pu}$ per filter is transmitted. The final stages of HEPA filters in the penthouse are challenged by the combined exhausts from many filters, and they may not be changed as frequently as glove box filters. An average value of $100 \mathrm{mg} \mathrm{Pu}$ per filter is assumed. All filters in the HEPA filter banks in the penthouse are validated in-place and must exceed $99.95 \%$ efficiency. Thus, an average loading for the filters in the second bank is $0.05 \mathrm{mg}$ Pu.

Both the filters in the room and glove box system are held in metal enclosures (metal-encased). There are 32 filters in the room system and 36 filters in the three other air filtering systems. All filters are normally in service. The combined inventory is estimated to be $1800 \mathrm{mg} \mathrm{Pu}$, and thus the average loading of each metal-encased filter is assumed to be $26.5 \mathrm{mg} \mathrm{Pu}$. The range of $\mathrm{Pu}$ content is 0 to $400 \mathrm{mg}$.

All plywood-cased filters are used in.the exhaust filtration system for the AFL. Most of the glove boxes using the system are on a complete recycle of inert gas and only exhaust into the system to maintain negative pressure in the glove box in the face of fluctuations in barometric pressure. A few glove boxes (1, 2, 3 and 12) are single-pass-air as in the other areas. Thus, the filters in the AFL are not expected to attain the loading of the other glove 
box system. It is assumed that each first-stage filter contains $10 \mathrm{mg} \mathrm{Pu}$ and each second-stage filter contains $0.005 \mathrm{mg} \mathrm{Pu}$. The system is assumed to contain a total of 10 filters holding a total of $40 \mathrm{mg} P u$ for an average of 5.0 $\mathrm{mg} \mathrm{Pu}$. The range is 0 to $40 \mathrm{mg}$ Pu.

\section{DAMAGE LEVELS AND RATIOS}

\section{Damage Levels}

\section{Enclosures}

Enclosures are postulated to sustain two levels of containment loss in the damage scenarios mentioned earlier. They are, in order of increasing severity, perforation and crush. Loss of a single filter outside the enclosure is not considered as a significant consequence leading to a serious airborne release in this study for two reasons: only the metal-cased inlet filter located under the glove box is external in almost all cases, and having a single opening into a static enclosure (no outflow of gas and release of particles governed by diffusion) does not present a potential for a large airborne release.

The following are damage levels described by Mehta, Smith and McDonald (1978, pp. 32-33):

- Crushing of Glove Box: If a heavy object falls on the glove box, structural members of the box may collapse resulting in the glove box being crushed. This event could occur if a load-bearing wall or building frame should collapse, thus allowing the roof structure to fall downward. In this case the integrity of the glove box would be violated, and the material inside the glove box would be exposed to the atmosphere.

- Perforation of the Glove Box: Pieces of timber, concrete blocks, loose pieces of pipe or equipment could strike a glove box causing an opening in the glove box window. Plutonium stored in canisters is not likely to be released in this case, but loose material in powder form could possibly escape the confines of the glove box. Failure of an exterior wall could allow the wind to circulate through the building, causing 
loose objects to be thrown against the glove boxes. Windborne debris could cause missile impact to the glove box and may cause perforation. Overhead Plutonium Transfer Lines

The damage to the overhead piping is described as "breaking" in the wind damage scenario (Mehta, Smith and McDonald, 1978, p. 48) and "rupture" in the seismic damage scenario (EDAC 1977b, p. 5-7). It is postulated that the pipe is catastrophically broken as a result of cyclic stressing of the pipe.

\section{HEPA Filters}

Two levels of damage have been designated for each of the two types of filters (plywood-and metal-cased) in the damage scenarios. The two levels for the plywood-cased filters are:

- broken: the integrity of the case is violated, but the filter retains its original shape and dimension. The filter media is retained.

- crushed: the case is destroyed and the filter media displaced.

The two levels of damage designated for metal-cased filters are:

- perforated: a projectile passes through the filter. Because of the orientation of the filters, the most probable direction is from side to side. The surface area of a side is $2 \mathrm{ft}^{2}$. A quantity of filter media is displaced from the case equivalent to the fraction of the area covered by the impact area of the projectile.

- crushed: as above.

Damage Ratios

Most of the damage described is incurred from events that cannot be precisely defined (i.e., the direction from which missiles penetrate the structure, the section of the structure that yields first to stress, the manner in which the roof collapses, etc.). The events are considered random, and it is assumed that an equal probability of damage applies to all items of concern in the building. The fraction of total items (enclosures or HEPA filters) incurring the level of damage specified is termed the damage ratios. Damage ratios have been estimated for wind and seismic damage scenarios: 


\section{Wind Damage}

- $130 \mathrm{mph}$ : one tenth of the plywood-cased filters are broken (range one twelfth to one eighth)

- $160 \mathrm{mph}:$ one third the plywood-cased filters are broken (range one fourth to seven sixteenths); one enclosure each perforated in the POL and AFL.

- $200 \mathrm{mph}$ : three fourths of the plywood-cased filters are broken (range nine sixteenths to one); one third of the metal-cased filters are perforated (range one fourth to seven sixteenths); one half the enclosures in all areas perforated (range three eighths to two thirds); some overhead piping broken (by analogy of the above, one half with range of three eighths to seven sixteenths).

- $260 \mathrm{mph}$ : all plywood-cased filters crushed; one half of the metal-cased filters perforated (range three eighths to two thirds); three fourths of the enclosures in all areas crushed (range nine sixteenths to one).

\section{Seismic Damage}

- less than $0.09 \mathrm{~g}$ : no significant damage

- 0.09 to $0.18 \mathrm{~g}: 0_{2}$ cylinder topples

- 0.18 to $0.25 \mathrm{~g}$ : vessels in glove box 241 overturn

- greater than $0.39 \mathrm{~g}$ : all filters assumed crushed; all overhead Pu transfer lines broken; and three fourths of all enclosures crushed (range one half to seven eighths) with remainder perforated.

\section{FRACTIONAL AIRBORNE RELEASE OF DISPERSIBLE MATERIALS AT RISK}

The quality of material injected and retained in the air volume near the source of release is influenced by many factors including the characteristics of the source material, the type and level of stress applied to the source material, and the wind field near the point of injection. Even if all the parameters were completely known, precise evaluations are not possible with the current state-of-the-art. Factors used are a composite of available experimental data, theoretic considerations, and engineering judgment, and the 
factors applied are based on the phenomena-induced behavior of the materials and equipment involved. (a) The fractional airborne release factors applied in this study are:

Enclosures

\section{Powders in Perforated Enclosures}

Enclosures are postulated to be perforated by impact of wind-generated missiles on plastic windows, metal walls, and rubber gloves. In addition, there is impact on windows of windand earthquake-generated debris after toppling, etc. The severity of displacement of the enclosure content ranges from mild to moderate. Mild shaking is postulated to generate a quasi-stable airborne mass loading of $100 \mathrm{mg} / \mathrm{m}^{3}$ (Mishima, 1973, p. F.11) in a volume of $1 \mathrm{ft}^{3}$ around the source. Moderate shaking (toppling is assumed to cause the powder to slide/fall down the floor of the enclosure and be made airborne on impact from the $90^{\circ}$ rotation of the enclosure) is postulated to generate an airborne mass loading of $300 \mathrm{mg} / \mathrm{m}^{3}$ (Mishima, Schwendiman and Ayer 1978 , p. 30) in one tenth the volume of the enclosure. The size distribution of the airborne powder in both cases is further assumed to be similar to that postulated by Schwendiman for fine $\mathrm{PuO}_{2}$ powders used in fuel fabrication (Schwendiman 1977, Figure 1) and used by Westinghouse for as-received and in-process powders (Westinghouse 1974, Table 5.1-2). Figure 8 is a plot of AED vs. cumulative mass fraction for the two distributions.

\footnotetext{
(a) It should be noted that fires are not considered in the damage scenarios for several reasons. At the air velocity range of the wind damage scenarios (130 to $260 \mathrm{mph}$ ), the potential for large fires is low. For the maximum seismic damage scenarios, the building collapses in-place and would smother a major fire. In all other seismic scenarios, the structure remains intact and the consequences of a major fire in an operational facility are to be assessed in a Safety Evaluation Report.
} 


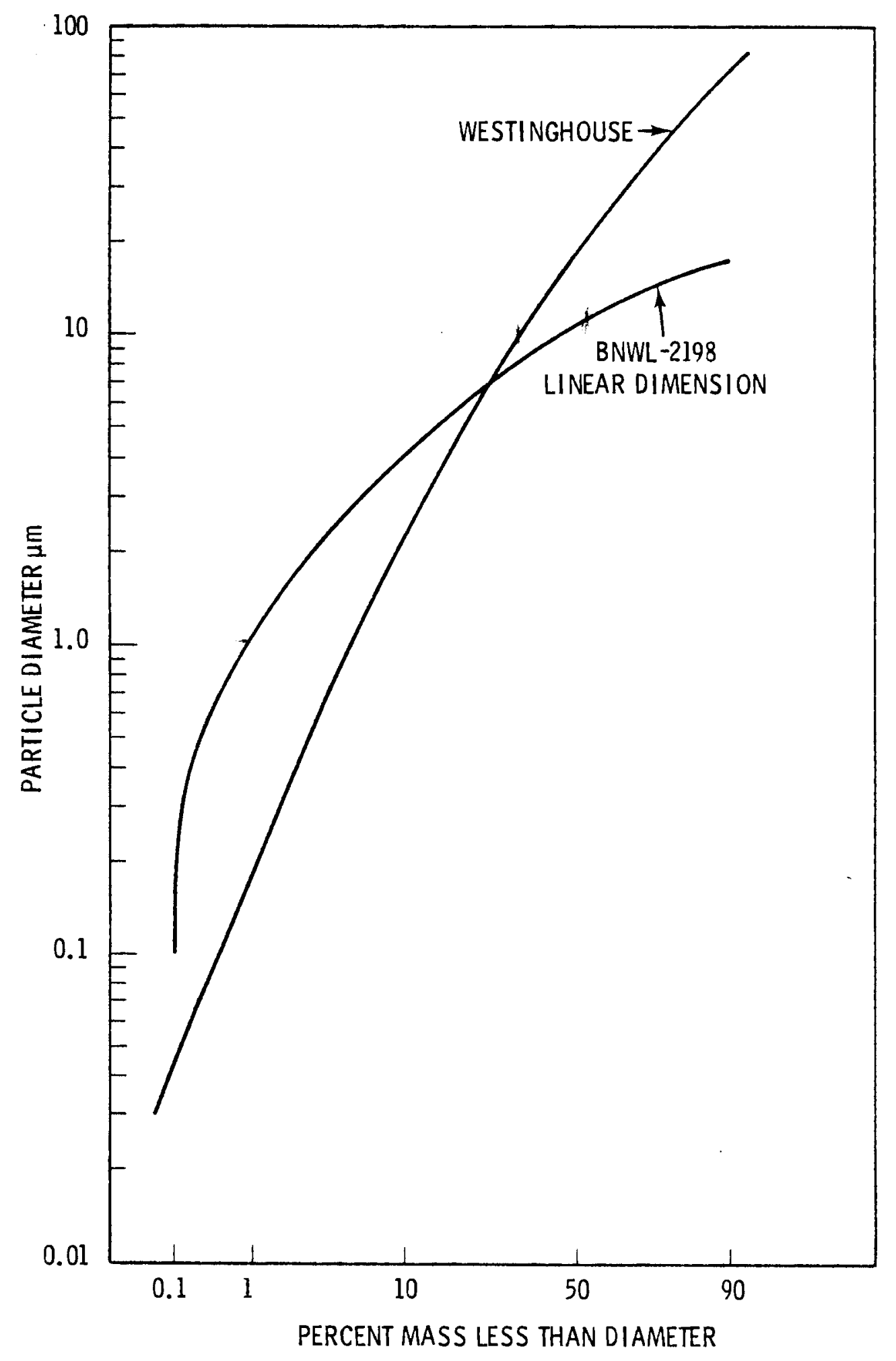

FIGURE 8. Particle Size Distribution of $\mathrm{PuO}_{2}$ Powders 
The total mass airborne in the typical enclosures in each area are:

- AFL--range $2.8 \mathrm{mg}$ to $230 \mathrm{mg}$, average $120 \mathrm{mg}, 4$ enclosures

- PDL--range $2.8 \mathrm{mg}$ to $270 \mathrm{mg}$, average $140 \mathrm{mg}$, 4 enclosures

- CER--range $2.8 \mathrm{mg}$ to $330 \mathrm{mg}$, average $170 \mathrm{mg}$, 4 enclosures

- CPL--range $2.8 \mathrm{mg}$ to $550 \mathrm{mg}$, average $280 \mathrm{mg}, 6$ enclosures

\section{Powders in Crushed Enclosures}

A value of $300 \mathrm{mg} / \mathrm{m}^{3}$ was selected as a transient mass loading in a previous study (Mishima, Schwendiman and Ayer 1978, p. 30) and is applied here. The total mass instantaneous release from the typical enclosures in each area containing powders are:

- AFL--2.8 g powder

- PDL--3.2 g powder

- CER--4.0 g powder

- CPL--9.9 g powder

The size distribution of the airborne material assumed is represented by Figure 8 .

\section{Liquids in Perforated Enclosures}

Aqueous plutonium solutions are only found in the CPL. Three enclosures (glove boxes 233A, 241 and 242) contain metal process vessels. Liquids are found in glass vessels in three enclosures (glove boxes 221, 231 and 233). Glass vessels may be broken by shaking or impact incurred during perforation. Metal vessels are assumed not to rupture during perforation of the enclosures but may suffer leaks allowing the liquid to flow from the container. Neither event appears to have the potential to generate large numbers of fine drops from the solutions in the containers.

The mass concentration of the airborne liquid droplets generated under these conditions would be small. Fog is a naturally-occurring, visible aerosol of fine water droplets in air and has a mass concentration of 10 $\mathrm{mg} / \mathrm{m}^{3}$ (Dak Ridge 1970, pp. 8-47). It is anticipated that the mass airborne 
concentrations of liquid droplets in the respirable size range generated under these conditions would not exceed that found for fogs, and thus the mass airborne concentration in this size fraction would be in the range of 0 to 10 $\mathrm{mg} / \mathrm{m}^{3}$. An average value of $5 \mathrm{mg} / \mathrm{m}^{3}$ (one-half fog?) is used. Higher pressures yield finer sprays (see Figure 9) and, because of the low energy available in these situations, the size distribution of the liquid droplets generated would be no finer than the coarsest spray shown in Figure 9 . Thus, $2.5 \mathrm{~g}$ of solution per cubic meter is postulated to be airborne as drops $100 \mu \mathrm{m}$ AED or less.

The volume of the typical enclosure in the CPL is $5.5 \mathrm{~m}^{3}$ and thus $28 \mathrm{mg}$ of solution as drops $10 \mu \mathrm{m}$ AED or less and $14 \mathrm{~g}$ of solution as drops $100 \mu \mathrm{m}$ AED or less are airborne. The most concentrated solution handled in the three enclosures are:

- glove box 233: dissolver product, $8 \mathrm{~g} \mathrm{Pu/l}$

- glove box 231: IX columns $40 \mathrm{~g} \mathrm{Pu/ \ell}$

- glove box 221: oxalate precipitation, $40 \mathrm{~g} \mathrm{Pu/ \ell}$

The density of the liquid is conservatively assumed to be $1.0 \mathrm{~g} / \mathrm{cm}^{3}$. The volumes of the solutions in each size fraction are $0.028 \mathrm{~cm}^{3}$ and 14 $\mathrm{cm}^{3}$ respectively and represent $0.22 \mathrm{mg}$ and $110 \mathrm{mg} P u$ at a concentration of $8 \mathrm{~g} \mathrm{Pu} / \mathrm{l}$ and $11 \mathrm{mg}$ and $560 \mathrm{mg} \mathrm{Pu}$ at a concentration of $40 \mathrm{~g} \mathrm{Pu} / \mathrm{l}$.

The liquids leaked from containers to the enclosure are resuspended at a rate of $10^{-9}$ to $10^{-10}$ per sec (Mishima, Schwendiman and Ayer 1978, p. 39) if warranted by the air velocities in the enclosures.

\section{Liquids in Crushed Enclosures}

It is postulated that all glass vessels are ruptured and all metal vessels compromised. The mass airborne concentrations are $10 \mathrm{mg}$ solution per cubic meter for the respirable size fraction with $5000 \mathrm{mg}$ solution per cubic meter for drops $100 \mu \mathrm{m}$ AED or less. The total Pu mass loading for enclosures for the two Pu concentrations above are:

- $8 \mathrm{~g}$ Pu/l: $0.44 \mathrm{mg}$ Pu in respirable fraction, $220 \mathrm{mg}$ Pu total airborne

- $40 \mathrm{~g} P u / l: 2.2 \mathrm{mg} \mathrm{Pu}$ in respirable fraction, $1200 \mathrm{mg}$ Pu total airborne 


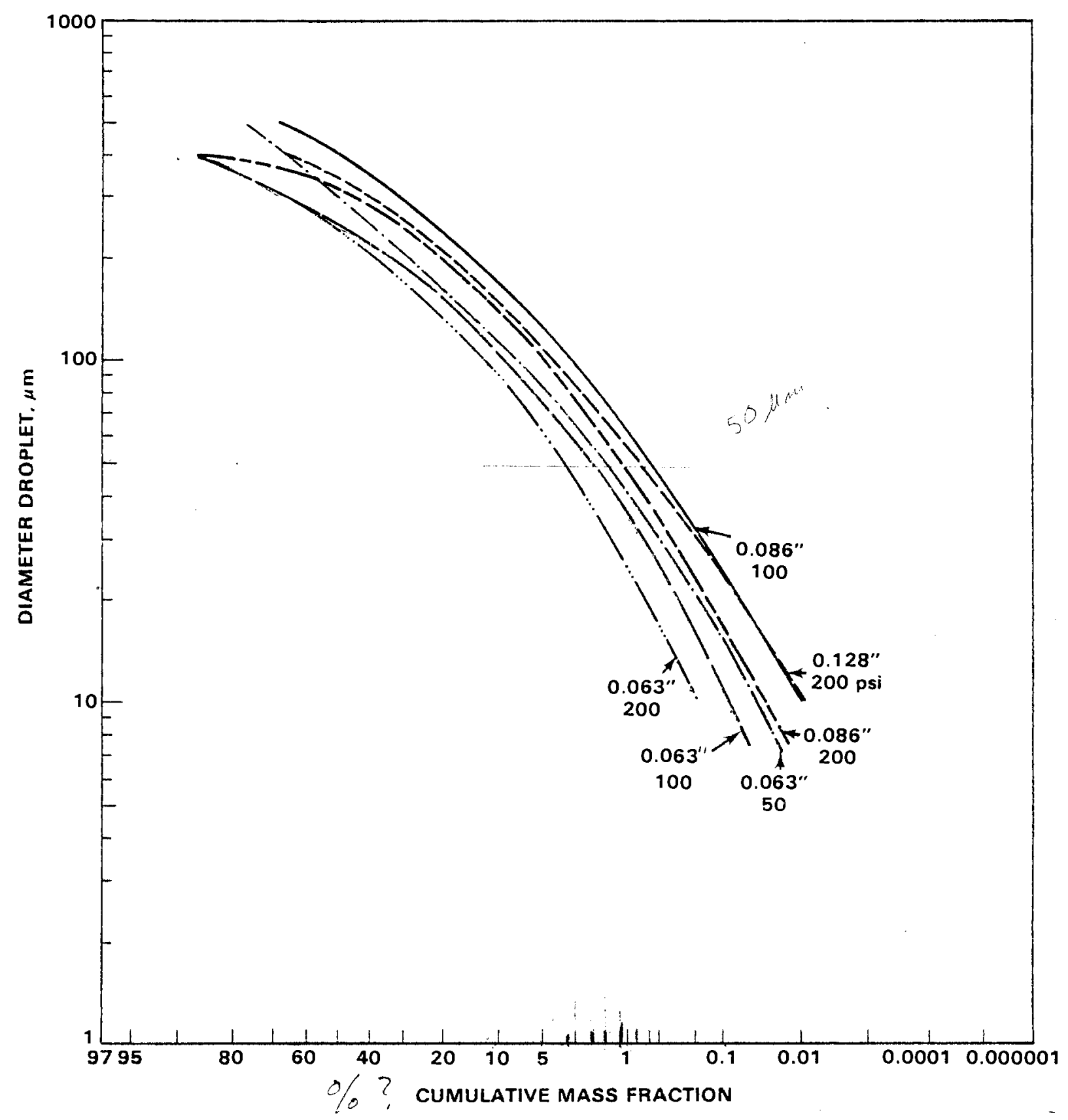

FIGURE 9. Mass Fraction versus Droplet Diameters for Sprays as a Function of Orifice Diameter and Upstream Pressure 


\section{Surface Contamination in Perforated Enclosures}

As stated in the section on powders in perforated enclosures, the shaking of the enclosure can range from mild to moderate. Resuspension factors (Steward 1967, p. 63) ${ }^{(a)}$ covering a range of 11 orders of magnitude have been reported (Mishima 1964, Table III). The highest values, $10^{-2}$ to $10^{-4} \mathrm{~m}^{-1}$, were found for resuspension by or combination of mechanical and aerodynamic forces (Glauberman, Bootman and Breslin 1967, pp. 172-174). Moderate shaking does not appear to be as effective a resuspension mechanism as when a combination of mechanical and aerodynamic stress and a resuspension factor of $10^{-4} \mathrm{~m}^{-1}$ is applied. Furthermore, it is also postulated that the material is only injected into one-fourth the volume of the enclosure. The surface contamination level has been assigned a value of $7.5 \mathrm{~g}$ powder $/ \mathrm{m}^{2}$ and, for the typical enclosures in the four areas, the total masses of the powders airborne are:

- $\operatorname{AFL}\left(2.3 \mathrm{~m}^{3}\right): 0.43 \mathrm{mg}$

- PDL $\left(2.7 \mathrm{~m}^{3}\right): 0.51 \mathrm{mg}$

- $\operatorname{CER}\left(3.3 \mathrm{~m}^{3}\right): 0.62 \mathrm{mg}$

- $\operatorname{CPL}\left(5.5 \mathrm{~m}^{3}\right): 1.0 \mathrm{mg}$

All the airborne material is assumed to be in the respirable size range. Surface Contamination in Crushed Enclosures

From one half to three fourths of the surface contamination found in enclosures appear to be fixed on the surface and requires harsh, corrosive treatment for removal (Mishima, Schwendiman and Ayer 1978, pp. 35-36). Thus, one half or less is in fact dispersible. It is assumed for the purposes of this analysis that a resuspension factor of $10^{-2} \mathrm{~m}^{-1}$ can be applied resulting in airborne mass concentrations of $75 \mathrm{mg}$ powder $/ \mathrm{m}^{3}$ within the enclosures, and total masses airborne in the enclosures in the four areas are:

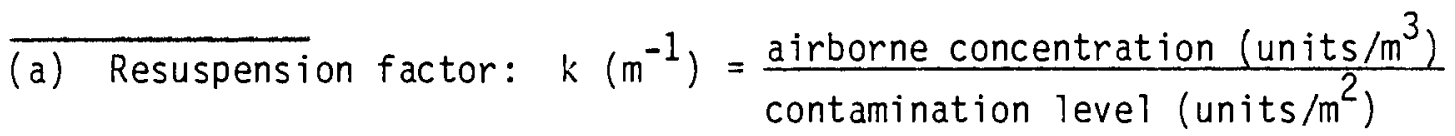


- AFL $\left(2.3 \mathrm{~m}^{3}\right): 170 \mathrm{mg}$ powder

- PDL $\left(2.7 \mathrm{~m}^{3}\right): 200 \mathrm{mg}$ powder

- $\operatorname{CER}\left(3.3 \mathrm{~m}^{3}\right): 250 \mathrm{mg}$ powder

- $\operatorname{CPL}\left(5.5 \mathrm{~m}^{3}\right): 410 \mathrm{mg}$ powder

A11 the remaining material is susceptible to resuspension at a rate of $10^{-8} / \mathrm{sec}$ to $10^{-10} / \mathrm{sec}$ as air velocities warrant.

Overhead Plutonium Transfer Lines

Considerable stress is applied to the structure and equipment prior to failure of the overhead piping for both wind and seismic hazard. Thus, it is postulated that the flow of liquid ceases when the pipe fails; flow stops naturally for vacuum transfers, and it is assumed the pump failure occurs for liquid transfers under positive pressure (IX system only). It is possible for transfer of product and waste to occur at the same time. The total length of the product line is approximately $80 \mathrm{ft}$, and the lines have an estimated volume of $6.9 \mathrm{l}$. The length of the waste line is approximately $75 \mathrm{ft}$ and has an estimated volume of $6.5 \mathrm{l}$. It is postulated that the lines whip to and fro on failure and one-tenth the total contained volume is converted into a spray as a consequence of the failure. Thus, 0.69 \& of Pu product solution are converted into the coarsest spray shown in Figure 9 , and $0.069 \mathrm{~cm}^{3}$ of drops in the respirable size range and $35 \mathrm{~cm}^{3}$ of drops $100 \mu \mathrm{m}$ AED or less are formed. For waste solutions $0.065 \mathrm{~cm}^{3}$ of respirable drops and $33 \mathrm{~cm}^{3}$ of drops $100 \mu \mathrm{m}$ AED or less are generated.

HEPA Filters

\section{Broken Plywood-cased Filters}

Plywood-cased filters are postulated to break upon impact with the ground after being displaced by the wind blowing through the penthouse. The integrity of the case is assumed to be lost, but the filter media remains intact. It is assumed that cracks equal to inlet and outlet openings $1 \times 12$ in. are generated in the case. Under these conditions, volumetric airflow through the filter does not greatly exceed its rated flow of $1000 \mathrm{cfm}$ even at a wind speed of $200 \mathrm{mph}$. 
Not much of the collected material would be lost at such airflow even if the flow were reversed through the filter. It is postulated that $1 \%$ of the mass accumulated upon the filter media is lost upon impact and the remaining inventory resuspended at a rate of $10^{-10} / \mathrm{sec}$ to $10^{-8} / \mathrm{sec}$ as a function of increasing wind speed.

\section{Perforated Metal-cased Filters}

It is postulated that metal-cased filters can be perforated by winddriven missiles. The range of perforations in enclosures was estimated to be from 0.045 to $0.33 \mathrm{ft}^{2}$ (Mehta, Smith and McDonald 1978, p. 49). The area of the side panel of a standard HEPA filter is $2 \mathrm{ft}^{2}$. On this basis, from $2.5 \%$ to $16.5 \%$ of the filter could be affected. A blunt missile passing through the fragile filter media could tear or shred the glass fiber mat. Assuming all the affected material is shredded is conservative and the assumption is made for the purposes of this study. It is postulated that $50 \%$ of the material accumulated on the shredded filter media is dislodged as particles in the respirable size range, and the remainder is relocated attached to fragments of the glass fiber mat. The remainder of the accumulated material is subject to resuspension at rates from $10^{-10}$ to $10^{-8} / \mathrm{sec}$ if air velocities passing over the surface warrant.

\section{Crushed HEPA Filters (Plywood- or Metal-cased)}

It is postulated that the filter is impacted with sufficient force to destroy the case and displace all the filter media. Under these conditions, it is postulated that $10 \%$ of the accumulated material is instantaneously dislodged from the filter media as respirable particles and the remainder exposed to the winds in the area. Resuspension rates of $10^{-10}$ to $10^{-8} / \mathrm{sec}$ are applied if air velocities over the exposed surfaces warrant.

\section{Resuspension of Deposited Materials}

Materials lying on surfaces can be entrained in flowing gases passing over the surface by interactions between the surface and atmosphere. 


\section{Powders}

Powders released from containment and exposed to the ambient wind field can be made airborne. Resuspension rates of $10^{-10}$ to $10^{-8}$ resuspended fraction per sec for a fine powder fom prairie terrain have been reported (Sehmel and Lloyd 1976, pp. 846-855), and wind speeds were measured from approximately 1 to $20 \mathrm{~m} / \mathrm{sec}$. Resuspension rates were near $10^{-10} / \mathrm{sec}$ at $1 \mathrm{~m} / \mathrm{sec}$ increasing rapidly to $10^{-8} / \mathrm{sec}$ at $5 \mathrm{~m} / \mathrm{sec}$ where they appeared to plateau (Sehmel and Lloyd 1976, Figure 3).

For the seismic hazard scenarios, the annual average wind speed at the greater Pittsburgh airport of approximately $10 \mathrm{mph}(4.5 \mathrm{~m} / \mathrm{sec})$ is used. The maximum total velocity (summation of rotational and translational velocities) is used for the wind hazard scenarios, and tornados are assumed for the wind speed greater than $130 \mathrm{mph}$ (Fujita 1977, Figure 6). Tornados are embedded in a parent storm, and based on Fugita's model (1978, Table 7.10), the tornado funnel representing the maximum velocities postulated passes over the facility in 8 to $11 \mathrm{sec}$. Since the winds following a tornado are much lower, resuspension factors of $10^{-10} / \mathrm{sec}$ are applied for wind speeds of 1 to $5 \mathrm{mph}(0.45$ to $2.2 \mathrm{~m} / \mathrm{sec}$ ) and $10^{-8} / \mathrm{sec}$ for wind speeds greater than $5 \mathrm{mph}$. Resuspension rates are assumed to be insignificant at less than $1 \mathrm{mph}$.

\section{Liquids}

Liquids appear to be resuspended by the formation of thin films (e.g., tips of waves, etc.), film breakup, and the entrainment of fine droplets. Liquids have greater physical mobility and considerable viscous energy is required for communition (Monk 1959). Therefore, the resuspension rates for liquids should be less than for powders.

Resuspension rates of $10^{-13} / \mathrm{sec}$ ( $\mathrm{Pu}$ nitrate solution from a stainless stee 1 plate at $1 \mathrm{~m} / \mathrm{sec}$ ) to $10^{-6} / \mathrm{sec}$ (uranium nitrate solution from prairie soi? up to $20 \mathrm{mph}$ ) have been reported (Mishima et al., 1979, Tables A.IV and A.V). A resuspension rate of $10^{-9} / \mathrm{sec}$ to $10^{-10} / \mathrm{sec}$ is an average value based on the data above and is less than the $10^{-8} / \mathrm{sec}$ used for powders. 


\section{ATMOSPHERE EXCHANGE RATES}

Contained volumes that have limited access to the ambient wind field will exchange the contents of their atmospheres with the surroundings at a rate determined by the flow through the openings, the particle size distribution of the airborne particulate material, and exponential dilution. Airflow through an opening is dependent on the size of the opening, the velocity of air striking the opening, and resistance to flow.

\section{Atmosphere Exchange Rate--Wind Hazard}

The contained volumes of concern in this study are the penthouse and production areas, glove boxes, and filters. Various size openings have been postulated for each. For the wind damage scenarios, the atmosphere exchange rates are:

\section{$130 \mathrm{mph}$}

Postulated in the northeast and northwest corners of the penthouse roof are $16-\mathrm{ft}^{2}$ openings. Neglecting resistance to flow, the volumetric flow rate in and out of the area is estimated to be $1.8 \times 10^{5} \mathrm{cfm}$. The smallest cross-sectional area for the penthouse is approximately $400 \mathrm{ft}^{2}$ giving a nominal wind speed of $5.1 \mathrm{mph}(2.3 \mathrm{~m} / \mathrm{sec})$. The postulated opening in the plywood-cased filters is postulated to be $1 \times 12$ in. giving a nominal volumetric flow of $38 \mathrm{cfm}$ (less than $4 \%$ of rated flow for the filter). Particles released from the filters are assumed to be $10 \mu \mathrm{m}$ AED or less. The terminal velocity for a $10-\mu \mathrm{m}$ unit density sphere is $0.3 \mathrm{~cm} / \mathrm{sec}$ (see Figure 10) and is much less than the nominal velocity through the area. The estimated volume of the penthouse is $4.0 \times 10^{4} \mathrm{ft}^{3}$, and approximately $99 \%$ of the airborne mass is removed per min.

\section{$160 \mathrm{mph}$}

Penthouse. Openings occur as above, resulting in nominal wind speeds of $6.3 \mathrm{mph}(2.8 \mathrm{~m} / \mathrm{sec})$. Volumetric flow through a plywood-cased filter is estimated to be $46 \mathrm{cfm}$ (approximately $5 \%$ of rated flow for the filter). The $2.2-x-10^{5}$-cfm volumetric flow in and out of the area removes $99.6 \%$ of the airborne mass per min. 


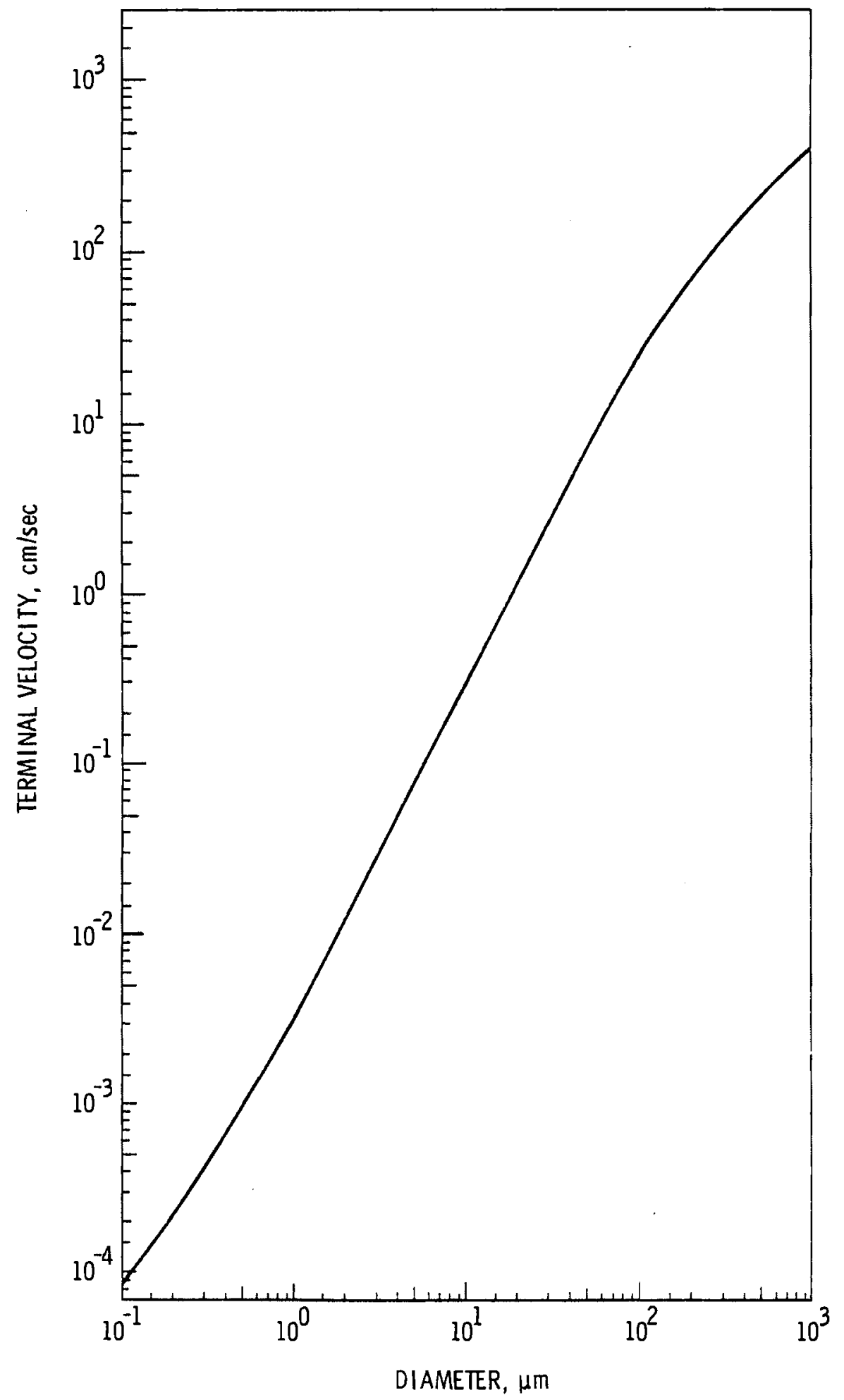

FIGURE 10. Terminal Velocities of Unit Density Spheres (1 Atm, 200 C) [Based on Dennis 1976, p. 122] 
AFL. Openings $90 \mathrm{ft}^{2}$ are generated in the southwest and southeast corners of the AFL. The nominal wind speed through the area is $75 \mathrm{mph}$ (approximately $34 \mathrm{~m} / \mathrm{sec}$ ) and the volumetric airflow is estimated to be $1.2 \times 10^{6} \mathrm{cfm}$. Essentially all the airborne particulate material released in the area is instantaneously carried out to the ambient atmosphere around the facility.

For the openings postulated for enclosures ( 0.049 to $\left.0.33 \mathrm{ft}^{2}\right)$, the volumetric flow in and out of enclosures is 150 to $1000 \mathrm{cfm}$, and the nominal air velocities through the enclosures (using the minimal cross-sectional area) are from 7.6 to $52 \mathrm{~cm} / \mathrm{sec}$. Greater than $99 \%$ of the material made airborne within an enclosure is released in $1 \mathrm{~min}$. The airflow $(52 \mathrm{~cm} / \mathrm{sec})$ is the terminal velocity of a unit density sphere of $200 \mu \mathrm{m}$ (see Figure 10).

PDL. An opening of $21 \mathrm{ft}^{2}$ (standard-size door) occurs in the east wall of the PDL. The volumetric flow in the area is estimated to be $4.0 \times 10^{5} \mathrm{cfm}$ resulting in a nominal wind speed in the area of $23 \mathrm{mph}(10 \mathrm{~m} / \mathrm{sec})$. Materials airborne in the area are instantaneously released to the ambient atmosphere.

The volumetric airflows into the enclosures from the postulated openings range from 100 to $660 \mathrm{cfm}$ resulting in nominal air velocities in the enclosures of 4.3 to $28 \mathrm{~cm} / \mathrm{sec}$ (terminal velocity of $100-\mu \mathrm{m}$ unit density sphere). Greater than $99 \%$ of the material airborne in the enclosure is released in $1 \mathrm{~min}$.

$200 \mathrm{mph}$

Penthouse. An opening $6400 \mathrm{ft}^{2}$ (approximately $80 \%$ of the roof) is postulated on the north edge of the roof, along with $40-\mathrm{ft}^{2}$ openings at the corners of the wall. The wind blows freely through the area, and the nominal wind speed through the area is $200 \mathrm{mph}(89 \mathrm{~m} / \mathrm{sec})$. Materials airborne in the area are assumed to be instantaneously released from the facility. The volumetric airflow through broken plywood-cased filters is $580 \mathrm{cfm}$.

The size of the perforations in the metal-cased filters is postulated to range from 0.049 to $0.33 \mathrm{ft}^{2}$, and the volumetric airflows are estimated at 340 to $2300 \mathrm{cfm}$. 
Production Areas (AFL, PDL, CER, and CPL). The exterior cladding and interior walls fail, and the areas are exposed to the ambient wind field. Volumetric airflow through the enclosures in the four areas ranges from 870 to $5700 \mathrm{cfm}$ giving from 4.5 to 70 air changes per minute for the enclosures. A11 airborne material would instantaneously be released from the enclosures at these air change rates. The nominal air velocities in the enclosures range from 23 to $290 \mathrm{~cm} / \mathrm{sec}$.

\section{$260 \mathrm{mph}$}

As in the case of the damage scenarios at lesser wind speeds, the volumetric exchange rates for all contained volumes are such that all materials made airborne in them are essentially instantaneously carried out of the contained volumes. The nominal air velocities exceed the terminal velocity for the largest particle size for powders (see Figures 8 and 10), approximately 11 $\mathrm{cm} / \mathrm{sec}$.

\section{Atmosphere Exchange Rate--Seismic Hazard}

The atmosphere exchange rates for the seismic damage scenarios are based on a mean wind speed of $10 \mathrm{mph}(4.5 \mathrm{~m} / \mathrm{sec})$ and are given below:

- less than $0.09 \mathrm{~g}$ ground acceleration: no significant damage leading to the airborne release of contained materials.

- 0.09 to $0.18 \mathrm{~g}$ ground acceleration: wall cladding not lost; therefore, facility containment still functional. Since the exhaust systems are still functional, breaches whose cross-sectional areas are less than the size of two glove ports (approximately $0.7 \mathrm{ft}^{2}$ ) do not result in loss of directional flow--air indrawn into the enclosure. Any exchange of atmospheres would be insignificant within the context of this study.

- 0.18 to $0.25 \mathrm{~g}$ ground acceleration: as above.

- greater than $0.39 \mathrm{~g}$ ground acceleration:

1. $0.39 \mathrm{~g}$ ground acceleration: The exterior wall cladding and all areas are exposed to the ambient wind field.

2. 0.39 to $0.49 \mathrm{~g}$ ground acceleration: overhead Pu transfer lines fail.

3. $0.49 \mathrm{~g}$ ground acceleration: the facility collapses in-place. 
Perforated enclosures and other equipment are buried under debris and are not exposed to the ambient wind field.

Air velocities in the area are estimated to be $48 \mathrm{mph}$ (approximately 21 $\mathrm{m} / \mathrm{sec}$ ) during damage to the equipment and is sufficiently high to assure all material released from containment is instantaneously injected into the ambient atmosphere. Atmosphere exchange rates from perforated enclosures are postulated to be $5 \%$ per $\mathrm{hr}$ and resuspension rates diminished.

\section{SOURCE TERM RANGES}

Three values are estimated for each potential source term--a "best estimate" with an upper and lower bound. The "best estimate" value is derived by combining the "best estimate" damage ratios for equipment given in the damage scenarios with the "on-the-average" inventories of dispersible materials found in the various items of concern. The "on-the-average" inventories are the average quantities of $\mathrm{Pu}$ found per hour in enclosures and overhead Pu transfer lines or the average mass loading for filters. The upper limit source term value is calculated by assuming the presence of normal operational quantities of $\mathrm{Pu}$ in $\mathrm{a} 11$ enclosures and the upper limit damage ratios. The lower limit source term values are calculated by combining the lower limit damage ratios with the airborne release if only surface contamination or minimal quantities of $\mathrm{Pu}$ is in jeopardy (essentially the facility is inoperative). 


\section{SOURCE TERM ESTIMATES}

In the previous sections of this document, the various components (i.e., inventories of dispersible materials in various areas, damage levels and inventories, fractional airborne releases, etc.) required to estimate the source terms for the postulated damage scenarios have been described. The components will be combined in this section with the specific conditions postulated for each damage to arrive at three source term estimates for each scenario--upper limit, "best estimate," and lower limit.

The estimates are divided into the mass of airborne plutonium particulate material in the respirable size fraction released during five time intervals covering a four-day period. The quantity designated as instantaneous is the mass released from the facility within a few minutes following the hazardous event. The mass estimated in the remaining four time periods are from two sources--the delayed release of material airborne in enclosures and the resuspension of dispersible materials exposed to the ambient wind field. Delayed releases from enclosures were postulated for only the two scenarios where the integrity of the facility was not violated: 0.09 to $0.18 \mathrm{~g}$ and 0.18 to $0.25 \mathrm{~g}$ ground acceleration. The estimated releases were less than $10^{-7} \mathrm{~g} \mathrm{Pu}$ in both cases. The estimated airflow through the enclosures in all wind hazard scenarios in this study and for greater than $0.39 \mathrm{~g}$ ground acceleration were estimated to be sufficient to sweep all airborne material from the enclosures within minutes.

The source term contributions of each area (penthouse, AFL, PDL, CER, and $\mathrm{CPL}$ ) are listed for each scenario. All estimates are only given with a single significant figure.

Drawings are used to illustrate the type and range of damage that could result to key areas from the scenarios described. The illustrations are not an attempt to show what actually happens--the data available and the state-ofthe-art are not sufficient to predict where failure might be initiated nor the precise levels of damage that would be inflicted upon each item. Certain details of the facility have been omitted for clarity in the drawings. Furthermore, the response of the production areas to levels of stress are the same and, in 
these cases, the conditions in one or two areas are depicted as representative of the conditions in all four areas.

The discussion is divided into wind and seismic hazard in order of increasing severity.

\section{SOURCE TERM ESTIMATES FROM WIND HAZARD}

$130 \mathrm{mph}, 2 \times 10^{-5} / \mathrm{yr}$ Probability of Occurrence

The only area suffering significant damage at this level of wind hazard is the penthouse. Air enters the area via $16-\mathrm{ft}^{2}$ openings and, assuming zero back-pressure and a nominal cross-sectional area of $400 \mathrm{ft}^{2}$ in the east-west direction, the air results in a velocity of $5.1 \mathrm{mph}(2.3 \mathrm{~m} / \mathrm{sec})$.

One tenth of the plywood-cased HEPA filters serving the AFL are postulated to be displaced and break open upon impact with the ground. The situation is illustrated in Figure 11. Upper and lower-bound values are estimated to be one eighth and one twelfth, respectively.

One percent of the accumulated inventory is postulated to be dislodged and released from the filter by impact. The "on-the-average" inventory of dispersible material is estimated to be $5 \mathrm{mg} \mathrm{Pu}$ with an upper and lower bound of 200 and $0 \mathrm{mg} \mathrm{Pu}$, respectively. Flow through the filter, assuming a 1 - x 12-in. opening, is $38 \mathrm{cfm}$ (much less than the rated flow of $1000 \mathrm{cfm}$ ). Resuspension of particulate material accumulated upon the filter mat is not anticipated at these flows. The estimated source terms are tabulated in Table 8.

$160 \mathrm{mph}, 7 \times 10^{-6} / \mathrm{yr}$ Probability of Occurrence

\section{Penthouse}

Air enters and exits in the area via $16-\mathrm{ft}^{2}$ holes. Under the same assumptions used in the previous scenario, the air velocity through the area is estimated to be $6.3 \mathrm{mph}(2.8 \mathrm{~m} / \mathrm{sec})$. One third of the plywood-cased filters serving the AFL are postulated to be displaced and broken upon impact with the floor. The upper and lower bounds are seven sixteenths and one quarter, respectively. The situation is shown graphically in Figure 12 . 


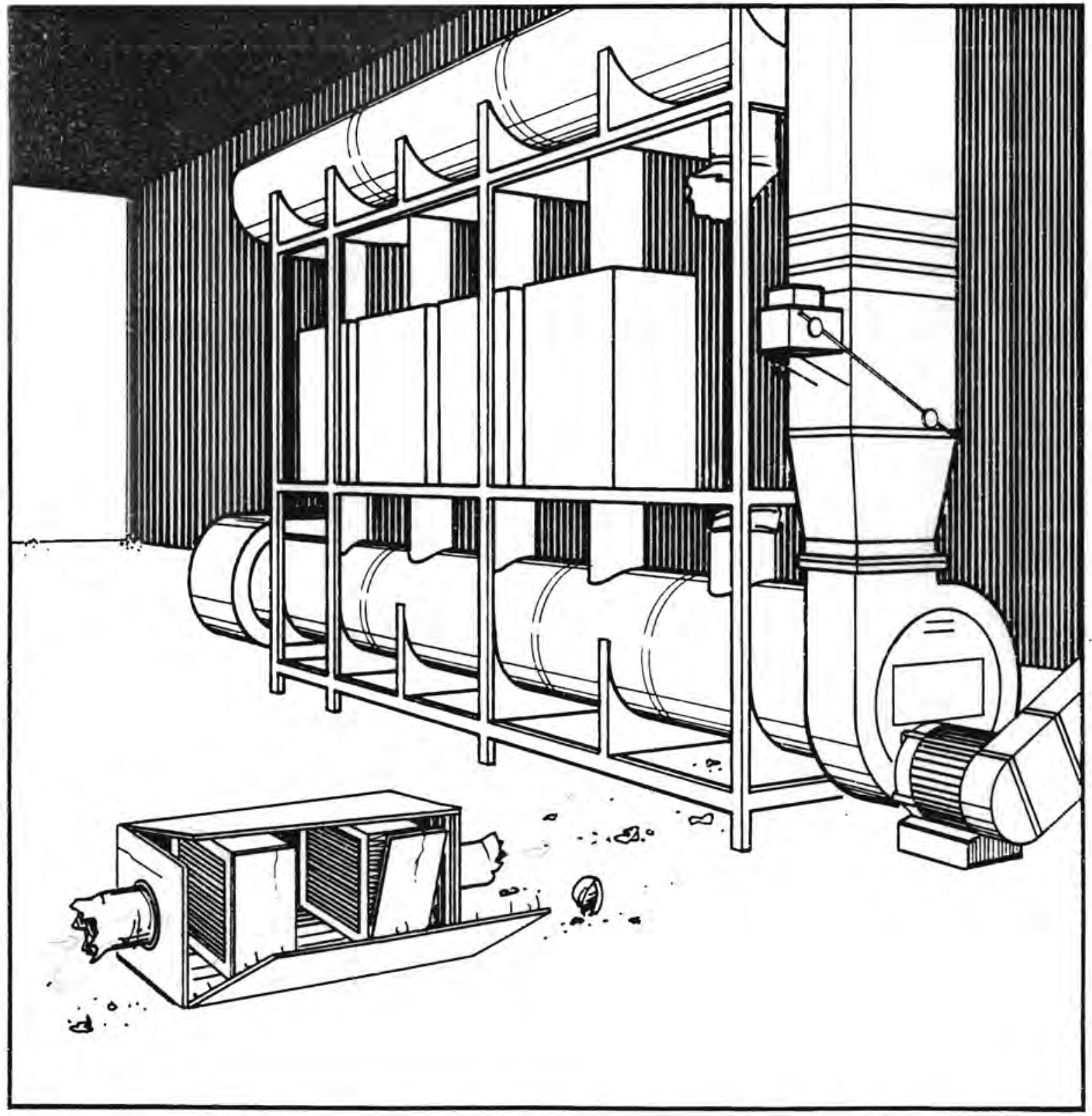

FIGURE 11. Range and Type of Damage Anticipated in the Penthouse at a Wind Hazard Level of $130 \mathrm{mph}$ 
TABLE 8. Contributions of Various Areas in the Westinghouse PFDL to Wind and Seismic Hazard Source Term Estimates, Wind Hazard, $130 \mathrm{mph}$, $2 \times 10^{-5}$ Per Year Probability of Occurrence. Mass Plutonjum Airborne as Particles $10 \mu \mathrm{m}$ AED or Less, grams $\underline{\text { CER }}$ Penthouse
Pen

UPPER LIMIT ESTIMATE

$$
\begin{aligned}
& \text { Instantaneous } \\
& \text { additional mass released } \\
& \text { in next } 2 \text { hours } \\
& \text { in next } 6 \text { hours } \\
& \text { in next } 16 \text { hours } \\
& \text { in next } 3 \text { days }
\end{aligned}
$$

Inst ant aneous

additional mass released

in next 2 hours

in next 6 hours

in next 16 hours

in next 3 days

Inst ant aneous

additional mass released

in next 2 hours

in next 6 hours

in next 16 hours

in next 3 days
$3 \times 10^{-4}$

$-$

--

$-$

$--$

\section{BEST ESTIMATE}

$5 \times 10^{-5}$

$--$

$-$

-

$--$

\section{LOWER LIMIT ESTIMATES}

$-$

$--$ 


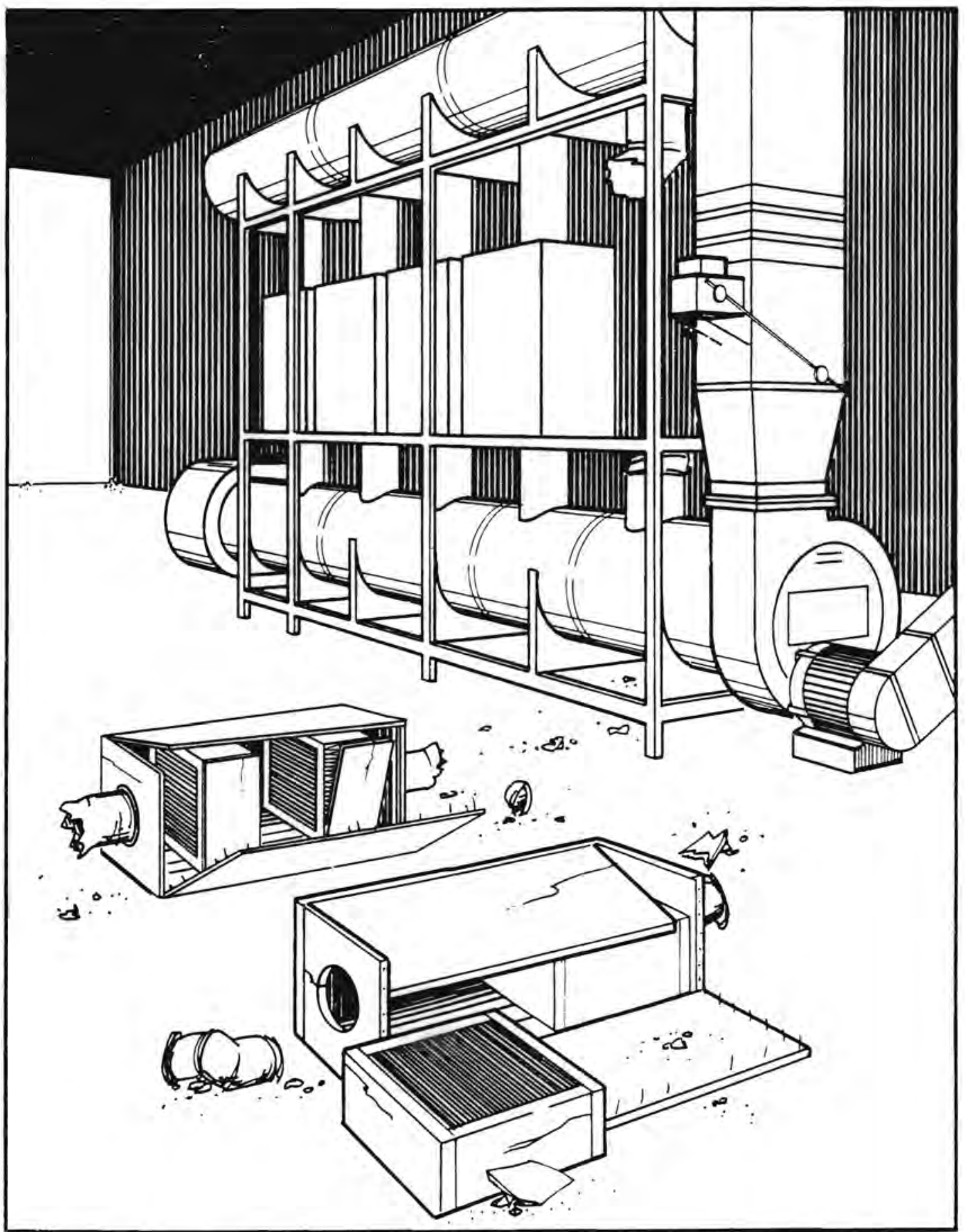

FIGURE 12. Range and Type of Damage Anticipated in the Penthouse at a Wind Hazard Level of $160 \mathrm{mph}$ 
The inventories of dispersible materials and estimated release factors are covered in the previous scenario. The contributions of the penthouse to the overall source term estimated for this scenario are listed in Table 9.

AFL

Air enters and exits the area via $90-\mathrm{ft}^{2}$ holes in the southeast and southwest corners. The cross-sectional area in the east-west direction is estimated to be $600 \mathrm{ft}^{2}$ resulting in a nominal air velocity of $75 \mathrm{mph}$ ( 34 $\mathrm{m} / \mathrm{sec})$. It is postulated that one enclosure is perforated with openings ranging in size from 0.05 to $0.33 \mathrm{ft}^{2}$. The situation is illustrated in Figure 13. The air velocity through the enclosure is estimated to be 7.6 to $52 \mathrm{~cm} / \mathrm{sec}$. The velocities through the enclosure correspond to the terminal velocities of particles 5 to $150 \mu \mathrm{m}$ AED. There are 14 enclosures in the AFL, and the perforation of a single enclosure is estimated to release onefourteenth the mass airborne if all enclosures were perforated. The air velocities are less than those believed to result in significant resuspension of dispersible material exposed in the enclosures. The contributions from the AFL to the mass airborne release of respirable particles from the facility are listed in Table 9.

$\underline{P D L}$

Air is postulated to enter the area through a standard-sized door $\left(21 \mathrm{ft}^{2}\right.$ ) in the east wa11. The nominal cross-sectional area of the POL in the east-west direction is estimated to be $200 \mathrm{ft}^{2}$ giving a nominal air velocity of $23 \mathrm{mph}(10.3 \mathrm{~m} / \mathrm{sec})$. Perforation of a single enclosure with the same range of openings as in the AFL is postulated, resulting in air velocities of 4.3 to $28 \mathrm{~cm} / \mathrm{sec}$ through the enclosure. The situation is illustrated in Figure 14. The airflows are sufficient to reduce the mass loading within the enclosure to $0.1 \%$ of their initial value within 1 min but are not sufficient to result in significant resuspension of exposed dispersible materials using the criterion for this study. The contribution of the PDL to the overall mass airborne release of particles in the respirable size range is listed in Table 9. 
TABLE 9. Contributions of Various Areas in the Westinghouse PFDL to Wind Seismic Hazard Source Term Estimates, Wind Hazard, $160 \mathrm{mph}, 7 \times 10^{-6}$ Per Year Probability of Occurrence.

Instantaneous

additional mass released

in next 2 hours

in next 6 hours

in next 3 days in next 16 hours

Mass Plutonium Airborne as Particles $10 \mu \mathrm{m}$ AED or Less, Grams

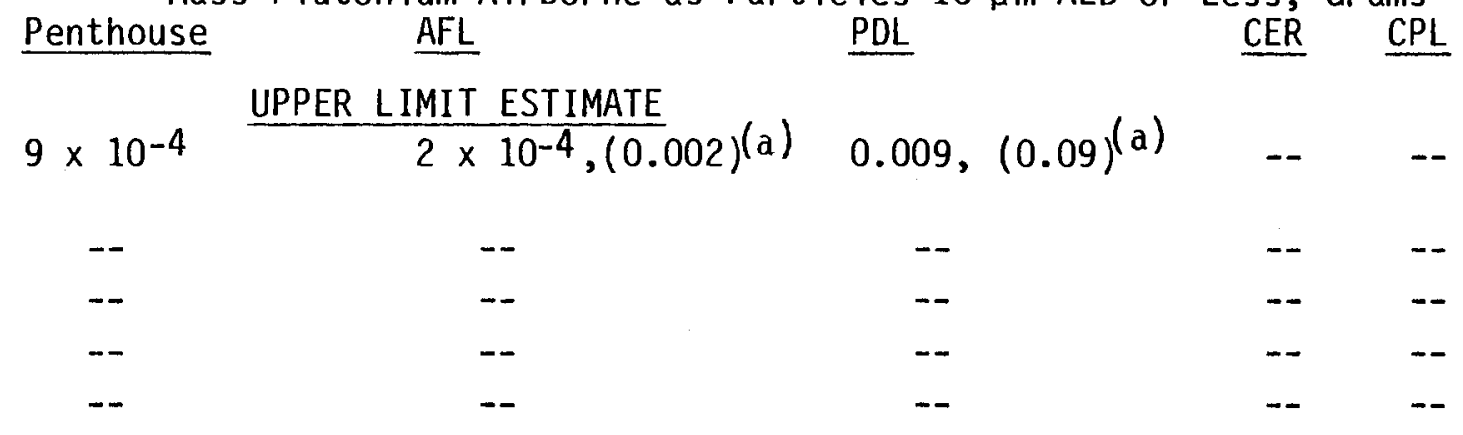

\section{BEST ESTIMATE}

$$
2 \times 10^{-4} \quad 2 \times 10^{-4},(0.002)^{(a)} 0.003,(0.03)^{(a)}
$$

additional mass released

Inst antaneous

additional mass released

$\begin{array}{ll}-- & -- \\ -- & - \\ -- & - \\ -- & --\end{array}$

\section{LOWER LIMIT' ESTIMATES}

0

$$
1 \times 10^{-4}
$$

$3 \times 10^{-4}$

$-$

$-$

$-$

$--$

--
--
--

in next 2 hours

in next 6 hours

in next 16 hours

in next 3 days

in next 2 hours

in next 6 hours

in next 16 hours

in next 3 days

$--\quad--$

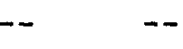

$--$

(a) Total mass released of plutonium 


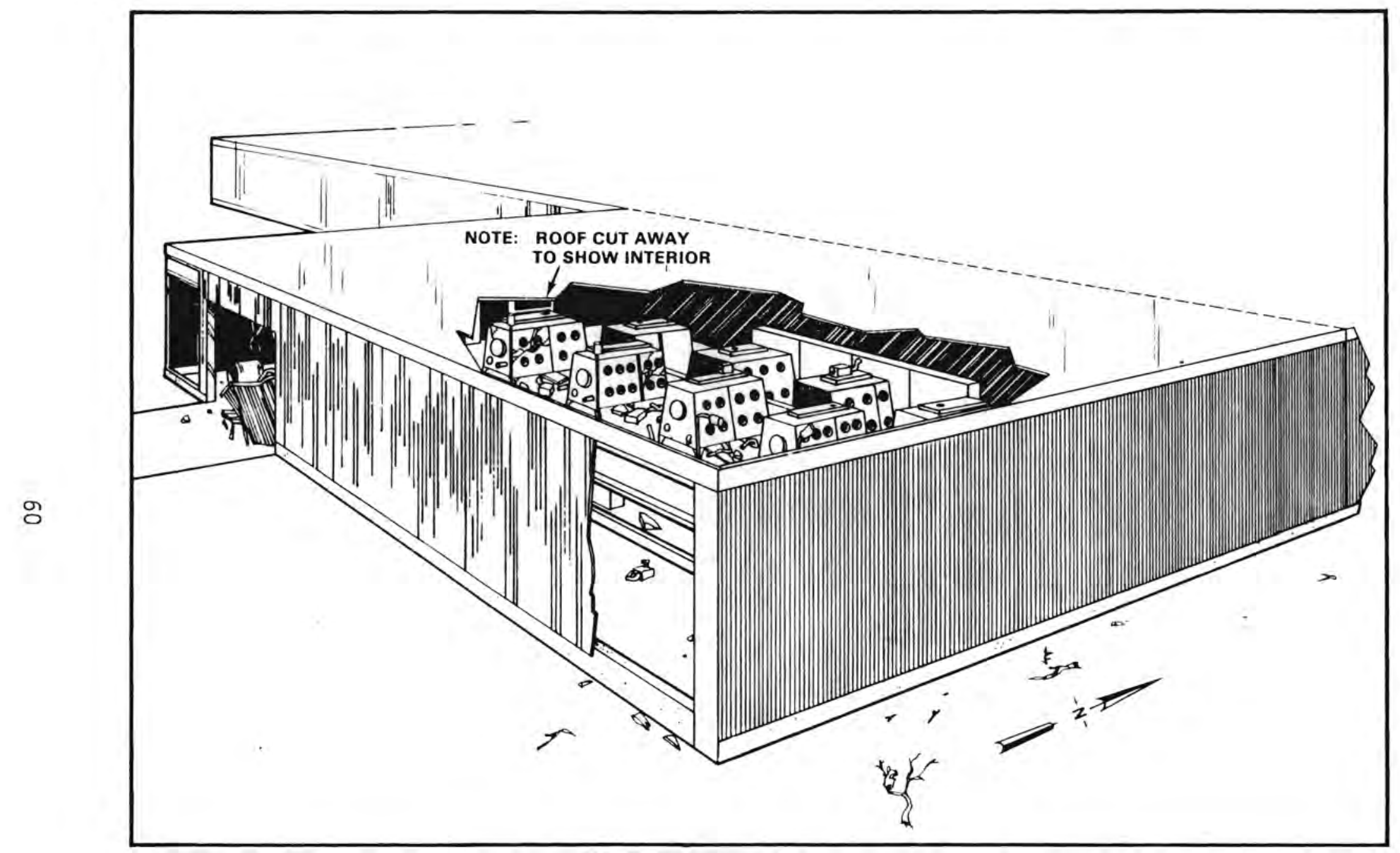

FIGURE 13. Range and Type of Damage Anticipated in the AFL at a Wind Hazard Level of $160 \mathrm{mph}$ 


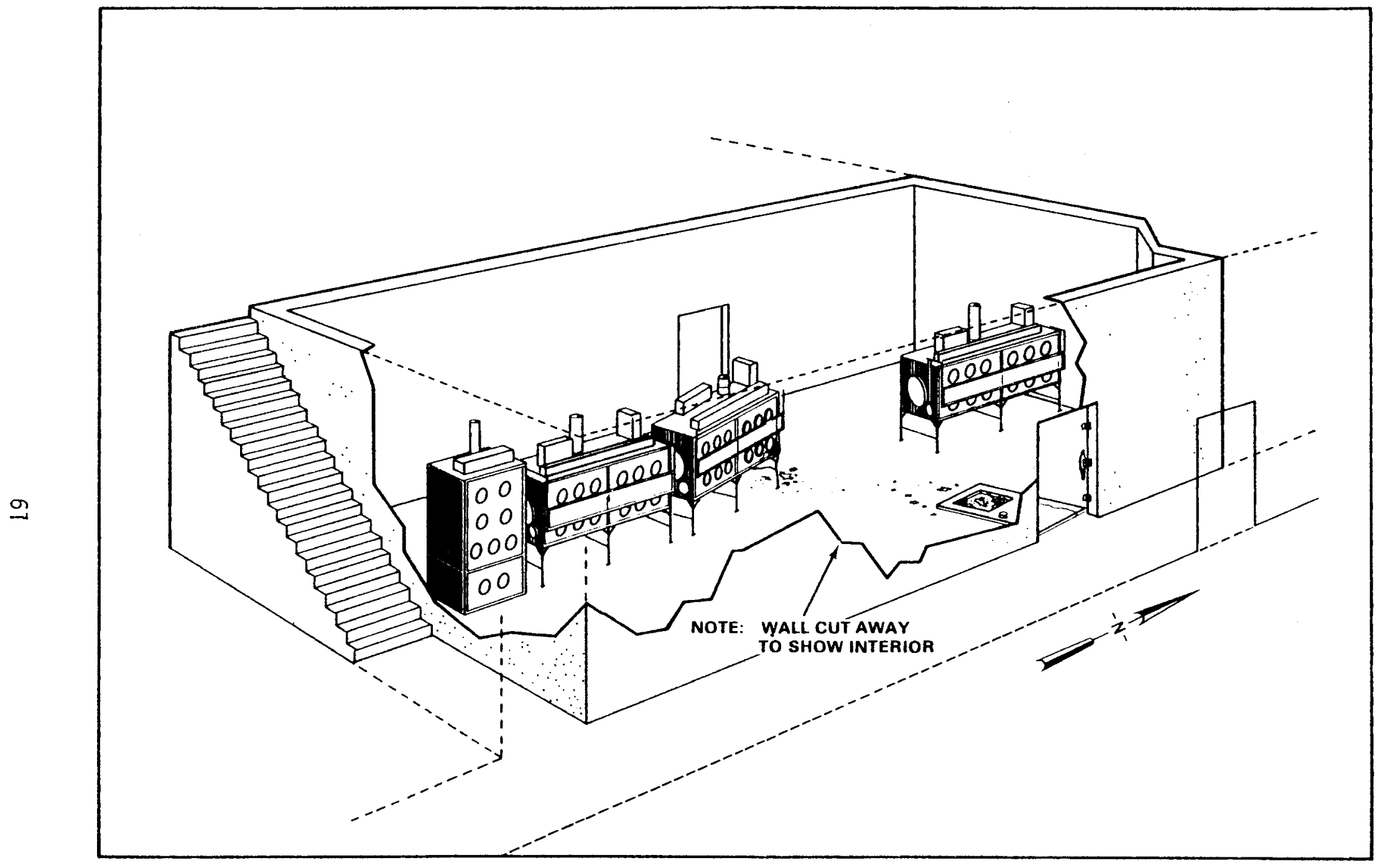

FIGURE 14. Range and Type of Damage Anticipated in the PDL at a Wind Hazard Level of $200 \mathrm{mph}$ 
$200 \mathrm{mph}, 2 \times 10^{-6} / \mathrm{yr}$ Probability of Occurrence

\section{Penthouse}

Air enters the area through the open roof resulting in an estimated air velocity of $200 \mathrm{mph}(89 \mathrm{~m} / \mathrm{sec})$. It is postulated that three quarters of the plywood-cased filters are broken (as described in the first scenario) and one third of the metal-cased filters are perforated with openings ranging from 0.05 to $0.33 \mathrm{ft}^{2}$. The situation for the metal-cased filter is shown in Figure 15.

The anticipated inventories of dispersible materials in the plywood-cased filters and the fractional airborne release upon breaking is covered in the first wind hazard scenario. The upper and lower-bound values are estimated to range from all-the-filters-broken to nine sixteenths, respectively. The estimated instantaneous release values are:

- "best estimate": $0.4 \mathrm{mg} \mathrm{Pu}$

- upper bound: $2 \mathrm{mg}$ Pu

- lower bound: 0 (assumes new filters)

The volumetric airflow through the postulated opening is $1500 \mathrm{cfm}$ and is not considered to result in significant resuspension. Using Fujita's model (1978, Table 7.10), the tornado would pass over a position the size of the PFDL at this velocity in approximately $9 \mathrm{sec}$, and the facility would only be subjected to these maximum velocities for a very short duration.

A total of $1800 \mathrm{mg}$ Pu as dispersible material is assumed to be found on al1 68 metal-cased filters with a range of 7200 to $0 \mathrm{mg}$. The area of any side of a filter is $2 \mathrm{ft}^{2}$, and impact areas of 0.05 to $0.33 \mathrm{ft}^{2}$ could involve from $2.5 \%$ to $16.5 \%$ of the filter mat. It is postulated that one-half the material involved is released as particles in the respirable size range and one half as coarser material (particles attached to remnants of the fiber mat) that is exposed to resuspension. Airflow through the damaged filters could exceed the rated flow for the filters, and a resuspension rate of $3.6 \times 10^{-7} / \mathrm{hr}$ is applied. The mass airborne releases of particulate material in the respirable size range are estimated to be: 


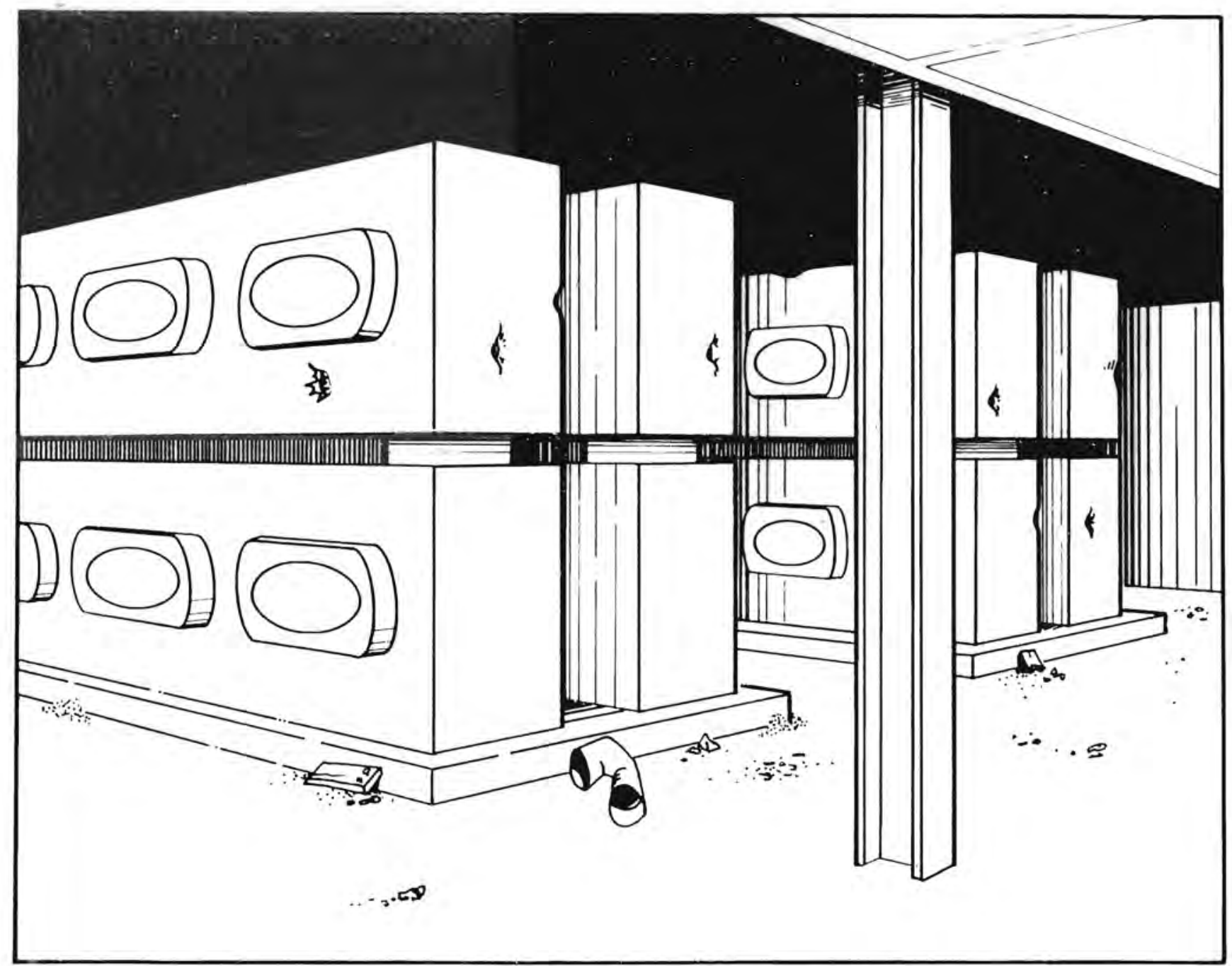

FIGURE 15. Range and Type of Damage Anticipated in the Penthouse at a Wind Hazard Level of $200 \mathrm{mph}$, Damage to Metal-Cased Filters Serving the Remaining Production Areas 
- "best estimate": instantaneous, $0.03 \mathrm{~g}$ Pu; time dependent, $2 \times 10^{-2} \mathrm{mg}$ $\mathrm{Pu} / \mathrm{hr}$

- upper bound: instantaneous, $0.4 \mathrm{~g} \mathrm{Pu}$; time dependent, $1 \times 10^{-2} \mathrm{mg} \mathrm{Pu}$

- lower bound: 0

The contributions of the penthouse to the overall source term from this scenario are listed in Table 10.

$\underline{A F L}$

The integrity of the structure is completely compromised in all four production areas; the exterior wall cladding is stripped from the frame and the interior concrete plaster walls are destroyed. Air, at ambient velocity, can freely circulate through the area, but the maximum velocity passes over the facility in seconds. One half of the enclosures in all areas are perforated with openings ranging from 0.05 to $0.33 \mathrm{ft}^{2}$. The estimated upper and lower bounds of damage are two thirds and three eighths, respectively. The situation in the AFL, representative of the situation in all four production areas, is shown graphically in Figure 16 .

The nominal air velocity through a "typical" AFL enclosure is estimated to range from 43 to $290 \mathrm{~cm} / \mathrm{sec}$ and is sufficient to release instantaneously all material airborne in the enclosure. At these air velocities a resuspension rate of $3.6 \times 10^{-7} / \mathrm{hr}$ is applied to the dispersible materials exposed in the enclosures. The inventories of dispersible materials present in the 14 enclosures in the AFL are shown in Table 6 . The contributions from the AFL to the overall mass airborne release of $\mathrm{Pu}$ in the respirable size fraction are listed in Table 10.

$\underline{P D L}$

The nominal velocity through a "typical" PDL enclosure is estimated to range from 37 to $240 \mathrm{~cm} / \mathrm{sec}$ and appears sufficient to instantaneously release all material airborne in the enclosure. At these velocities, a resuspension rate of $3.6 \times 10^{-7} / \mathrm{hr}$ was applied. The inventory of dispersible materials in the four PDL enclosures is listed in Table 3 , and the contributions to the overall source term from the facility for this scenario are listed in Table 10. 
TABLE 10. Contributions of Various Areas in the Westinghouse PFDL to Wind and Seismic Hazard Source Term Estimates, Wind Hazard, $200 \mathrm{mph}, 2 \times 10^{-6}$ Per Year Probability of Occurrence.

\section{Mass Plutonium Airborne as Particles $10 \mu \mathrm{m}$ AED or Less, grams

Penthouse AFL PDL $\underline{\text { CER }}$ CPL

UPPER LIMIT ESTIMATE

Instant aneous

additional mass released

in next 2 hours

in next 6 hours

in next 16 hours

in next 3 days

or Instantaneous

in next 2 hours

in next 6 hours

in next 16 hours

in next 3 days

0.4

$2 \times 10^{-4}$

$6 \times 10^{-4}$

$2 \times 10^{-3}$

$7 \times 10^{-3}$

0.03

$4 \times 10^{-5}$

$1 \times 10^{-4}$

$3 \times 10^{-4}$

$1 \times 10^{-3}$

$$
0.02(0.2)^{(a)}
$$

$0.02(0.2)^{(a)}$

$0.02(0.2)^{(a)}$

$0.02(0.2)^{(a)}$

$2 \times 10^{-3}$
$7 \times 10^{-3}$
0.02
0.09

$3 \times 10^{-3}$
$7 \times 10^{-3}$
0.02
0.1

$6 \times 10$

0.02

0.05

0.2

\section{BEST ESTIMATE}

$0.01 \mathrm{~g}(0.1 \mathrm{~g})^{(\mathrm{a})} \quad 0.006(0.06)^{(\mathrm{a})}$

$0.02(0.2 g)^{(a)}$

$0.01(0.1)^{(a)}$

$\begin{array}{ll}3 \times 10^{-4} & 4 \times 10^{-4} \\ 1 \times 10^{-3} & 1 \times 10^{-3} \\ 3 \times 10^{-3} & 3 \times 10^{-3} \\ 0.01 & 0.01\end{array}$

$1 \times 10^{-3}$

$3 \times 10^{-3}$

$9 \times 10^{-3}$

0.04

\section{LOWER LIMIT ESTIMATES}

\section{Inst ant aneous}

additional mass released

in next 2 hours

in next 6 hours

in next 16 hours

in next 3 days
0

$\begin{array}{lll}-- & 2 \times 10^{-4} & 1 \times 10^{-4} \\ -- & 5 \times 10^{-4} & 4 \times 10^{-4} \\ -- & 1 \times 10^{-3} & 1 \times 10^{-3} \\ -- & 6 \times 10^{-3} & 3 \times 10^{-3}\end{array}$

$6 \times 10^{-4}$

$1 \times 10^{-4}$

$4 \times 10^{-4}$

$1 \times 10^{-3}$

$5 \times 10^{-3}$

(a) Total mass airborne release of plutonium 


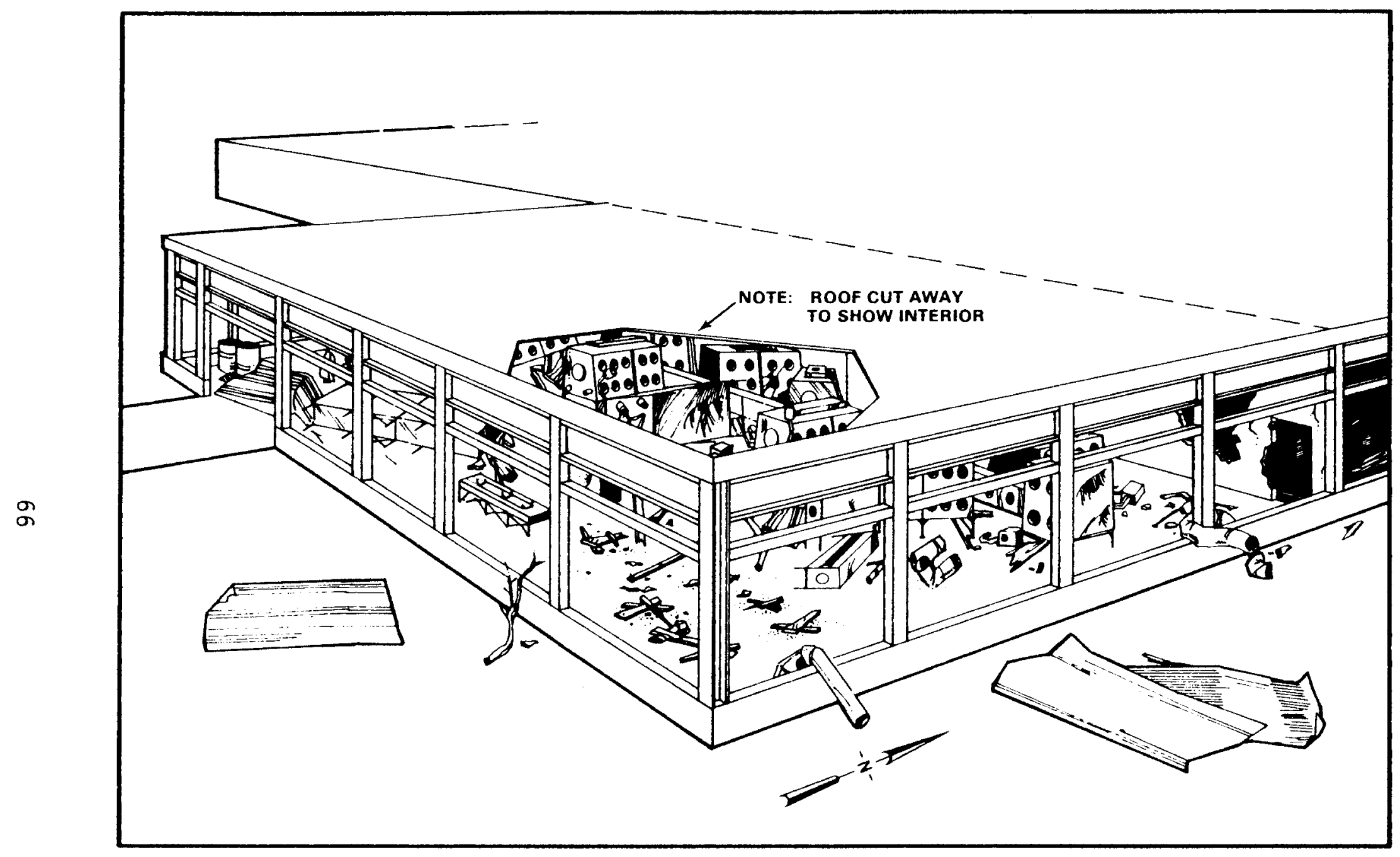

FIGURE 16. Range and Type of Damage Anticipated in the Production Areas, Using the AFL as the Representative, at a Wind Hazard Level of $200 \mathrm{mph}$ 
CER

The nominal air velocity through a "typical" CER enclosure is estimated to range from 31 to $210 \mathrm{~cm} / \mathrm{sec}$ and appears to be sufficient to instantaneously release all materials airborne in the enclosure. At these velocities, a resuspension rate of $3.6 \times 10^{-7} / \mathrm{hr}$ was applied. The inventory of dispersible materials in the 20 CER enclosures is listed in Table 4, and the contributions from the CER to the overall source term are listed in Table 10.

CPL

The nominal air velocity through a "typical" CPL enclosure is estimated to range from 23 to $150 \mathrm{~cm} / \mathrm{sec}$ and appears sufficient to instantaneously release all material airborne in the enclosure. At these velocities, a resuspension rate of $3.6 \times 10^{-7} / \mathrm{hr}$ was applied. The inventory of dispersible materials in the 13 enclosures in the CPL are listed in Table 5, and the contributions from the CPL to the overall source terms from the facility for this scenario are shown in Table 10.

$260 \mathrm{mph}, 2 \times 10^{-7} / \mathrm{yr}$ Probability of Occurrence

\section{Penthouse}

Most of the exterior wall cladding is stripped from the metal frame and air at ambient velocity can circulate freely through the penthouse. Maximum velocities are only present for seconds. It is postulated that all the plywood-cased filters are crushed and one-half the metal-cased filters perforated. The upper and lower bounds for the perforations are estimated to be two thirds and three eighths, respectively. The situations are illustrated in Figures $17 \mathrm{a}$ and $17 \mathrm{~b}$.

It is postulated that $10 \%$ of all material accumulated on crushed filters is instantaneously released, and the remaining material is exposed to the ambient wind field. A resuspension rate of $3.6 \times 10^{-5} / \mathrm{hr}$ is applied.

From 0.03 to 0.017 of the material accumulated on perforated filters is displaced. Half of the displaced material is assumed to be instantaneously released with the remainder resuspended at a rate of $3.6 \times 10^{-5} / \mathrm{hr}$. The 


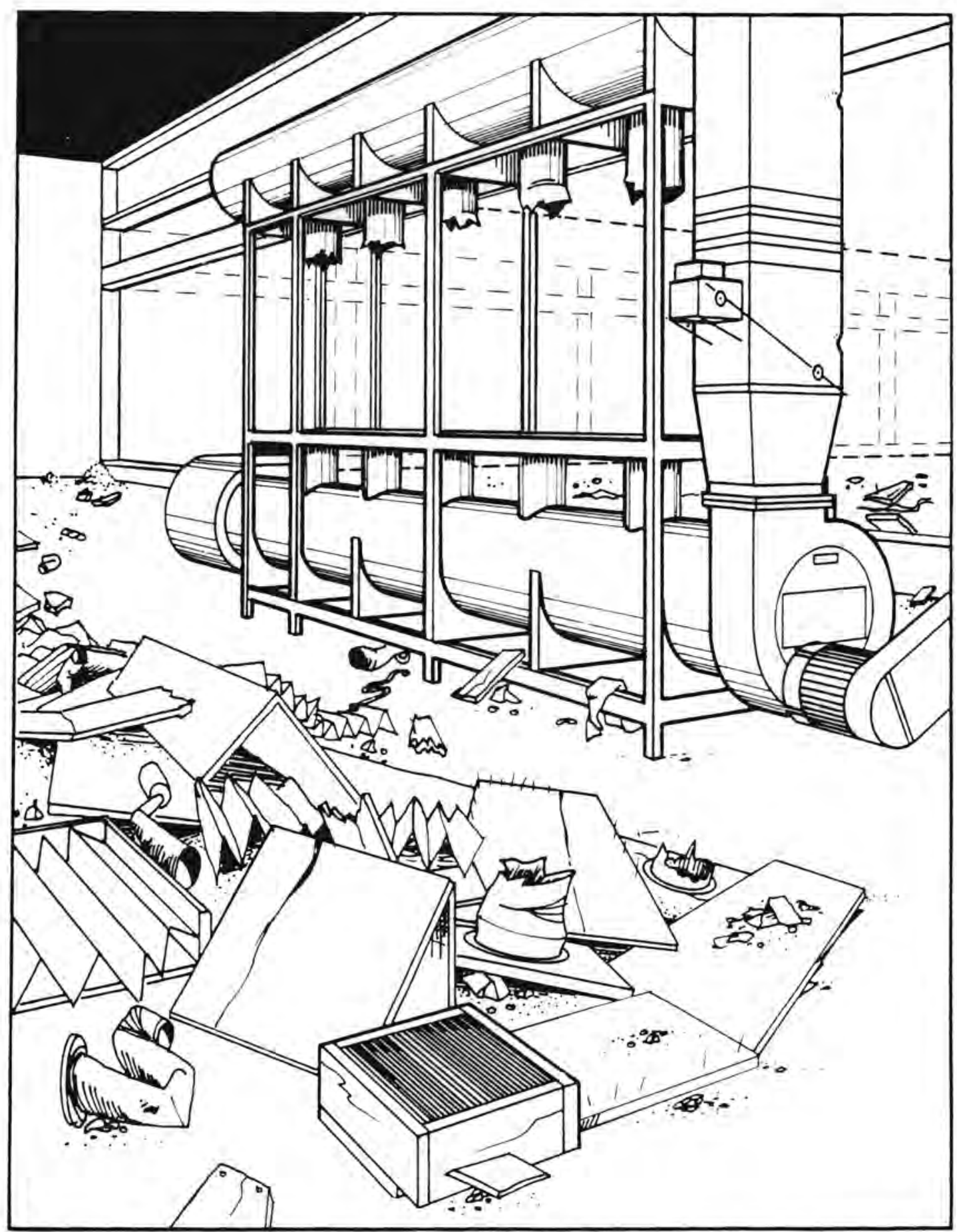

FIGURE 17a. Range and Type of Damage Anticipated in the Plywood-Cased Filters (Penthouse) at a Wind Hazard Level of $260 \mathrm{mph}$ 


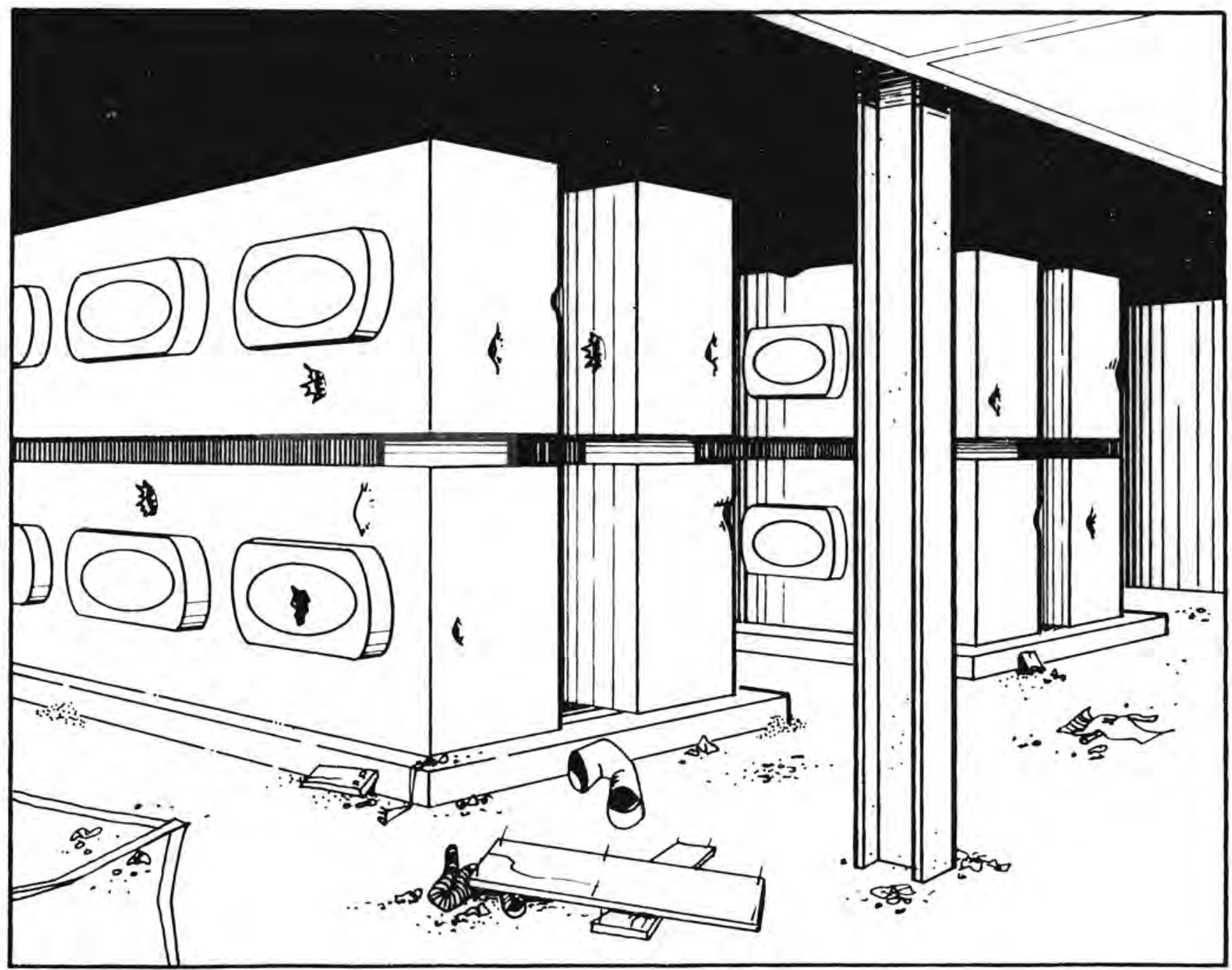

FIGURE 17b. Range and Type of Damage Anticipated in the Metal-Cased Filters (Penthouse) at a Wind Hazard Level of $260 \mathrm{mph}$ 
material not displaced from the filters is subjected, at maximum, to one to four times the volumetric flow for which the filter is rated. A resuspension rate of $3.6 \times 10^{-7} / \mathrm{hr}$ is applied to this material.

The contributions from the penthouse to the overall source term from the facility for this scenario are listed in Table 11.

Production Areas (AFL, PDL, CER, and CPL)

All the exterior wall cladding is stripped from its metal frame, and all interior concrete plaster walls are destroyed. The ambient wind field can freely circulate through the areas, but maximum wind speeds pass over the facility in seconds. It is estimated that three-quarters of a 11 the enclosures are crushed with a range of nine sixteenths to one. All remaining enclosures are assumed to be perforated. The situation is illustrated in Figure 18 .

The nominal air velocity through all production enclosures through openings 0.05 to $0.33 \mathrm{ft}^{2}$ are estimated to be sufficiently high to release essentially all airborne material with $1 \mathrm{~min}$. The exchange rate is essentially instantaneous, and a resuspension rate of $3.6 \times 10^{-5} / \mathrm{hr}$ is applied to all dispersible material held in these enclosures. The contributions from each area to the overall source term from this facility for this scenario are shown in Table 11.

\section{SOURCE TERM ESTIMATES FROM SEISMIC HAZARD}

Less than $0.09 \mathrm{~g}$ Peak Ground Acceleration

No significant damage leading to the airborne release of $\mathrm{Pu}$ is postulated. 0.09 to $0.18 \mathrm{~g}$ Peak Ground Acceleration, $1 \times 10^{-4} / \mathrm{yr}$ Probability of Occurrence

At this level of seismic activity, it is postulated that the exterior steel siding panels yield (but do not fail) and the pressurized cylinder of oxygen in the AFL fails. Thus, it is assumed that although the in-leakage rate into the building may increase, directional flow is maintained and the integrity of the containment is not compromised. 
TABLE 11. Contributions of Various Areas in the Westinghouse PFDL to Wind and Seismic Hazard Source Term Estimates, Wind Hazard, $260 \mathrm{mph}, 2 \times 10^{-7}$ Per Year Probability of Occurrence.

Mass Plutonium Airborne as Particles $10 \mu \mathrm{m}$ AED or Less, grams

$$
\text { Penthouse AFL } \quad \underline{\text { PDL }} \text { CER } \quad \text { CPL }
$$

UPPER LIMIT ESTIMATE

$\begin{array}{clcccc}\text { Instantaneous } & 0.4 & 0.6(6)(a) & 0.9(9)(a) & 0.8(7)(a) & 4(32)(a) \\ \begin{array}{c}\text { additional mass released } \\ \text { in next } 2 \text { hours }\end{array} & 4 \times 10^{-5} & 0.4 & 0.4 & 1 & 0.4 \\ \text { in next } 6 \text { hours } & 1 \times 10^{-4} & 1 & 1 & 3 & 1 \\ \text { in next } 16 \text { hours } & 4 \times 10^{-4} & 3 & 3 & 8 & 3 \\ \text { in next 3 days } & 2 \times 10^{-3} & 13 & 16 & 35 & 14\end{array}$

BEST ESTIMATE

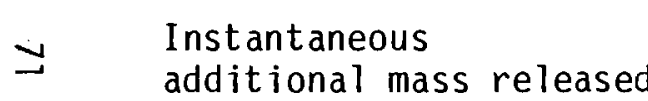

$\begin{array}{llll}\text { in next } 2 \text { hours } & 7 \times 10^{-6} & 0.05 & 0.06 \\ \text { in next } 6 \text { hours } & 2 \times 10^{-5} & 0.2 & 0.1 \\ \text { in next } 16 \text { hours } & 5 \times 10^{-5} & 0.4 & 0.5 \\ \text { in next } 3 \text { days } & 2 \times 10^{-4} & 2 & 2\end{array}$
$0.4(3)(a)$
$0.6(6)(a) \quad 3(3)(a)$

LOWER LIMIT ESTIMATES

Instantaneous
additional mass released

$\begin{array}{lll}\text { in next } 2 \text { hours } & -- & 0.03 \\ \text { in next } 6 \text { hours } & -- & 0.08 \\ \text { in next } 16 \text { hours } & -- & 0.2 \\ \text { in next } 3 \text { days } & -- & 1\end{array}$

0.3

0.3

0.3

2

$0.03 \quad 0.02$

0.02
0.05

0.04

0.1

0.1

0.3

in next 3 days

1

0.2

0.7

0.3

0.9

(a) Total mass airborne release of plutonium 


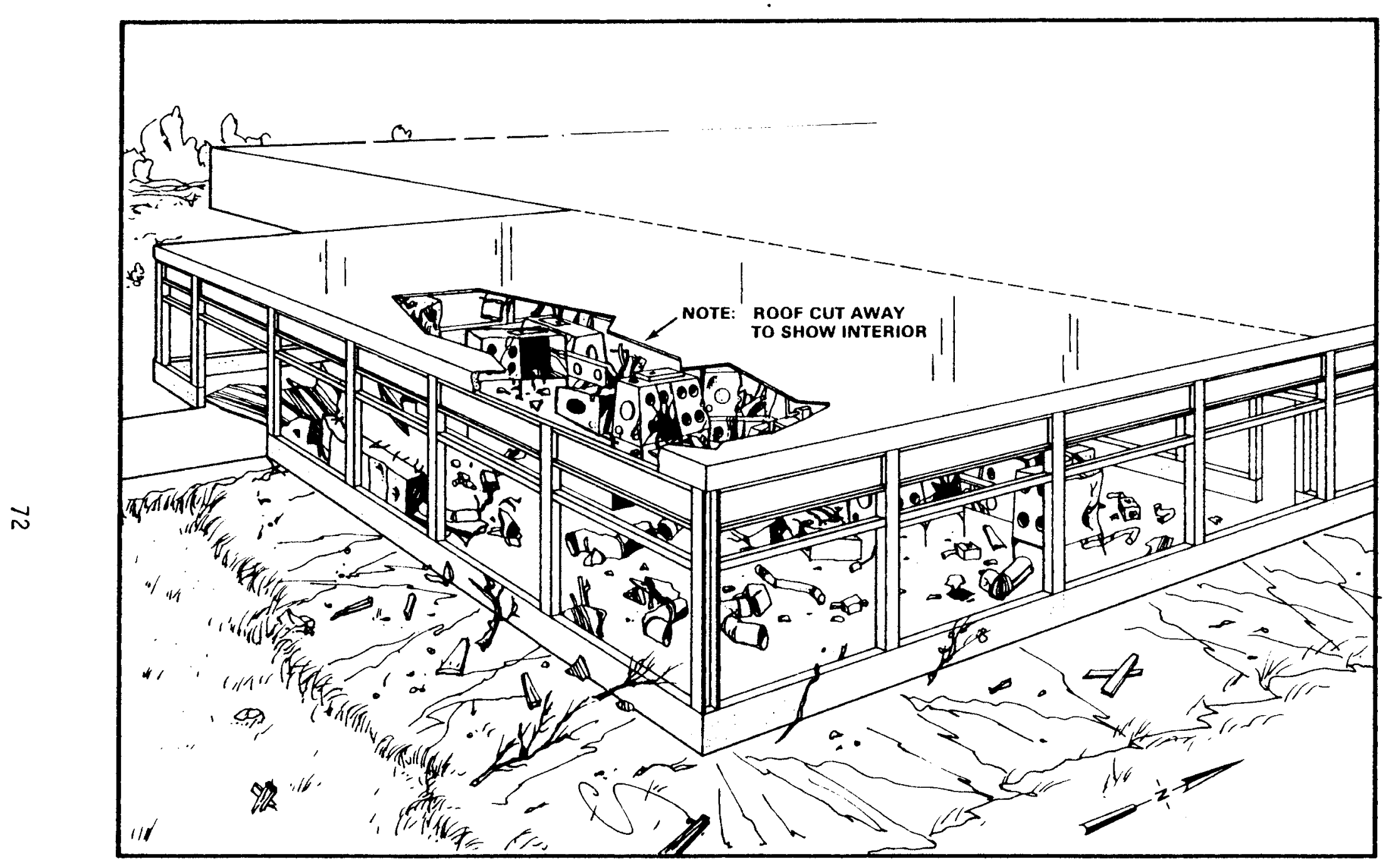

FIGURE 18. Range and Type of Damage Anticipated in the Production Areas at a Wind Hazard Level of $260 \mathrm{mph}$, AFL Representative of All Areas 
If the valve on the end of a pressurized cylinder of gas is lost catastrophically, the cylinder can become a missile and cause damage in the facility. It is postulated that one of the 14 enclosures in the AFL is perforated (by toppling and striking an object or by debris generated by the missile interacting with other items, etc.). The situation is illustrated in Figure 19. Air velocities in the area under ventilation flow are in the order of cms/min. Any material airborne within the areas are filtered through two levels of HEPA filters prior to release to the ambient atmosphere around the facility. A transmission factor of $2.5 \times 10^{-7}$ would be applied. A value of less than $10^{-7}$ is reported (see Table 12).

$0.18 \mathrm{~g}$ to $0.25 \mathrm{~g}$ Peak Ground Acceleration, $4 \times 10^{-5}$ Per Year Probability of Occurrence

The facility still retains its integrity although the damage to the walls increases. In addition to the damage sustained in the previous scenario, the four 24-in.-dia. process vessels in glove box 241 in the CPL topple (see Figure 20).

Two of the four vessels ( $R-7$ and -8$)$ hold IX feed solutions whose concentrations range from 4 to $8 \mathrm{~g} P u$ per/l, and the remaining two ( $R-14$ and -15 ) hold waste solutions that have a concentration of $25 \mathrm{mg} \mathrm{Pu}$ per/l during an undesignated portion of the recovery operation. (The time period of the waste operation represents 0.346 of a year/year at design throughput.) The volumes of the four vessels range from 294 to $374 \ell$. The "best estimate" source term is based on two vessels filled with the "average" volume and concentration available in the area $50 \%$ of the time. The lower bound was taken as one full waste vessel available and the upper bound as all four vessels filled.

As in the case of the overhead Pu transfer line it is assumed that $10 \%$ of the liquid involved can form a "coarse spray"; $5 \%$ of the liquid forms droplets $100 \mu \mathrm{m}$ AED or less with $0.01 \%$ as droplets $10 \mu \mathrm{m}$ AED or less. The material airborne in the CPL atmosphere passes through two banks of HEPA filters prior to release to the ambient atmosphere around the facility. A resuspension rate of $3.6 \times 10^{-7} / \mathrm{hr}$ was applied to the liquid spilled on the floor. The calculated masses of airborne Pu released ranged from $5 \times 10^{-13}$ to $8 \times 10^{-9} \mathrm{~g}$ and are all reported as less than $10^{-7} \mathrm{~g} \mathrm{Pu}$ (see Table 13). 


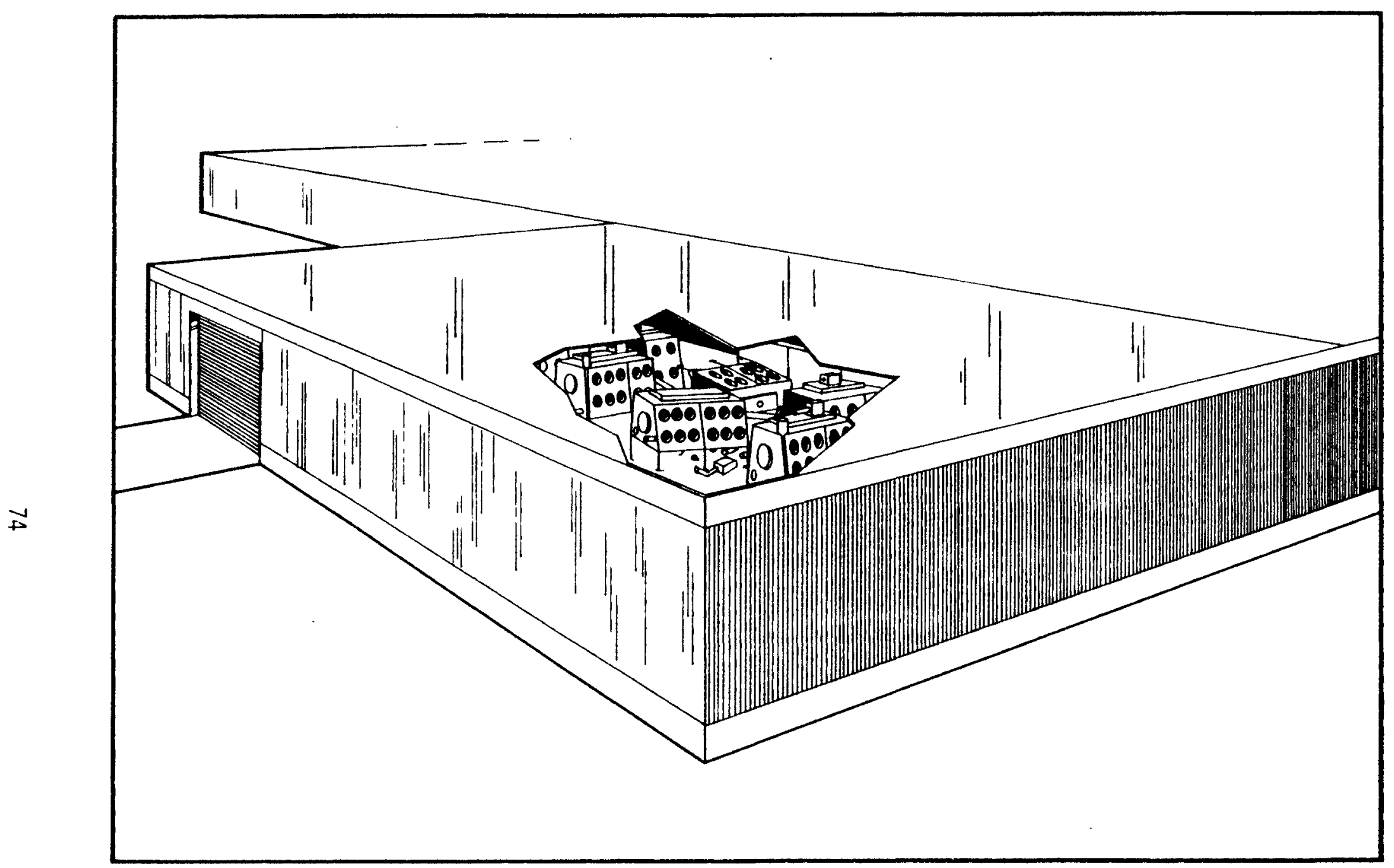

FIGURE 19. Range and Type of Damage Anticipated in the AFL at a Seismic Hazard Level of 0.09 to $0.18 \mathrm{~g}$ Ground Acceleration 
TABLE 12. Contributions of Various Areas in the Westinghouse PFDL to Wind and Seismic Hazard Source Term Estimates, Seismic Hazard, 0.09 to $0.18 \mathrm{~g}$ Ground

Acceleration, $1 \times 10^{-4}$ Per Year Probability of 0ccurrence.

Mass Plutonium Airborne as Particles $10 \mu \mathrm{m}$ AED or Less, grams

\section{Penthouse $\quad \underline{A F L} \quad \underline{P D L}$
UPPER LIMIT ESTIMATE}

Instantaneous
additional mass released

ditional mass released

in next 2 hours
(a)
(a)
a)

in next 16 hours

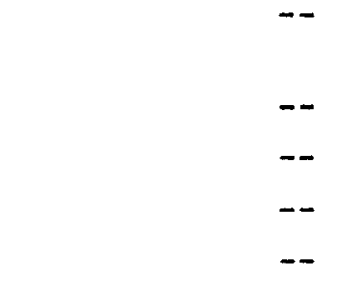

\section{BEST ESTIMATE}

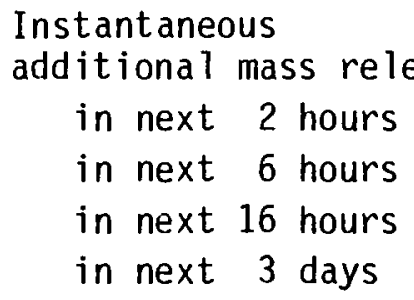

$-$

- (a)

- (a)

(a)

$--$

\section{LOWER LIMIT ESTIMATES}

Instantaneous

additional mass released

$\begin{array}{llr}\text { in next } 2 \text { hours } & -- & \text { (a) } \\ \text { in next } 6 \text { hours } & -- & \text { (a) } \\ \text { in next } 16 \text { hours } & -- & \text { (a) } \\ \text { in next } 3 \text { days } & -- & --\end{array}$

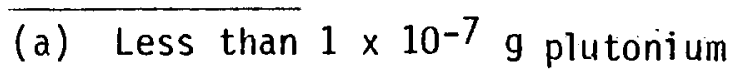




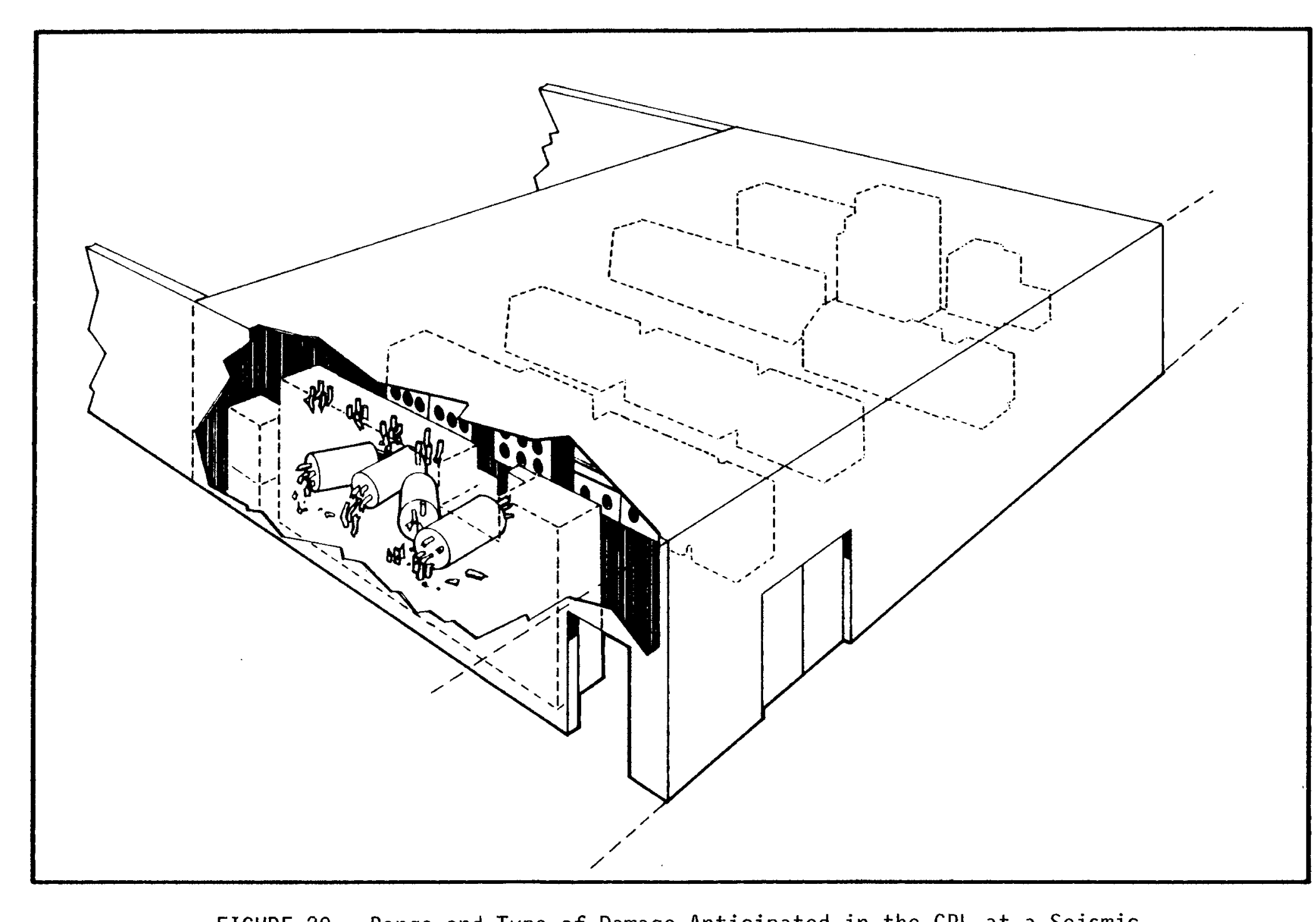


TABLE 13. Contributions of Various Areas in the Westinghouse PFDL to Wind and Seismic Hazard Source Term Estimates, Seismic Hazard, 0.18 to $0.25 \mathrm{~g}$ $4 \times 10^{-5}$ Per Year Probability of Occurrence.

Mass Plutonium Airborne as Particles $10 \mu \mathrm{m}$ AED or Less, grams

\section{Penthouse AFL $\quad$ PDL \\ UPPER LIMIT ESTIMATE}

Instantaneous

additional mass released

in next 2 hours

in next 6 hours

in next 16 hours

in next 3 days

Instantaneous

additional mass released

in next 2 hours

in next 6 hours

in next 16 hours

in next 3 days

additional mass released

in next 2 hours

in next 6 hours

in next 16 hours

in next 3 days

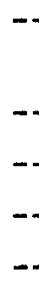

--

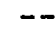

$-$

(a)

(a)

(a)

--

\section{BEST ESTIMATE}

--
--
-
--

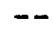

(a)

(a)

(a)

--

LOWER LIMIT ESTIMATES
CER

CPL

(a)

(a)

(a)

(a)

(a)

(a)

(a)

(a)

(a)

(a)

(a) Calculated value less than $10^{-7} \mathrm{~g}$ plutonium 
Greater than $0.39 \mathrm{~g}$ Peak Ground Acceleration, Less than $3 \times 10^{-5}$ Per Year Probability of Occurrence

At this level of seismic activity, the steel exterior siding fails. As the level increases towards $0.49 \mathrm{~g}$, the overhead Pu transfer 1 ines and exhaust ducts rupture. At approximately $0.49 \mathrm{~g}$, the building collapses. Situations in the AFL and CPL are illustrated in Figures $21 \mathrm{a}$ and $21 \mathrm{~b}$ and are representations of the situation in all production areas.

If the siding fails, the material made airborne in the two previous scenarios can be released directly to the ambient atmosphere. The failure of the overhead $\mathrm{Pu}$ transfer lines would release:

- "best estimate": instantaneous--1 $-10^{-4} \mathrm{~g} \mathrm{Pu}$ (total mass release $0.05 \mathrm{~g} \mathrm{Pu})$ resuspension--5 $\times 10^{-4} \mathrm{~g} \mathrm{Pu} / \mathrm{hr}$

- upper bound: instantaneous--4 $410^{-4} \mathrm{~g}$ Pu (total mass release $0.2 \mathrm{~g} \mathrm{Pu}$ ) resuspension--2 $2 \times 10^{-3} \mathrm{~g} \mathrm{Pu} / \mathrm{hr}$

- lower bound: $\frac{\text { instantaneous }}{3 \times 10^{-5} \mathrm{~g} \mathrm{Pu} \text { ) }} \times 10^{-8} \mathrm{~g} \mathrm{Pu}$ (total mass release resuspension--3 $\times 10^{-7} \mathrm{~g} \mathrm{Pu} / \mathrm{hr}$

At building collapse, the source term estimates for the various areas are:

\section{Penthouse}

All the filters (plywood and metal cased) are assumed to be crushed. Ten percent of all materials accumulated on the filters is assumed to be released instantaneously and a resuspension rate of $3.6 \times 10^{-7} / \mathrm{hr}$ applied to the remainder. The estimated airborne releases are shown in Table 14.

\section{Production Areas}

It is postulated that three fourths of all enclosures are crushed with the remainder penetrated. The upper and lower bounds are estimated at 


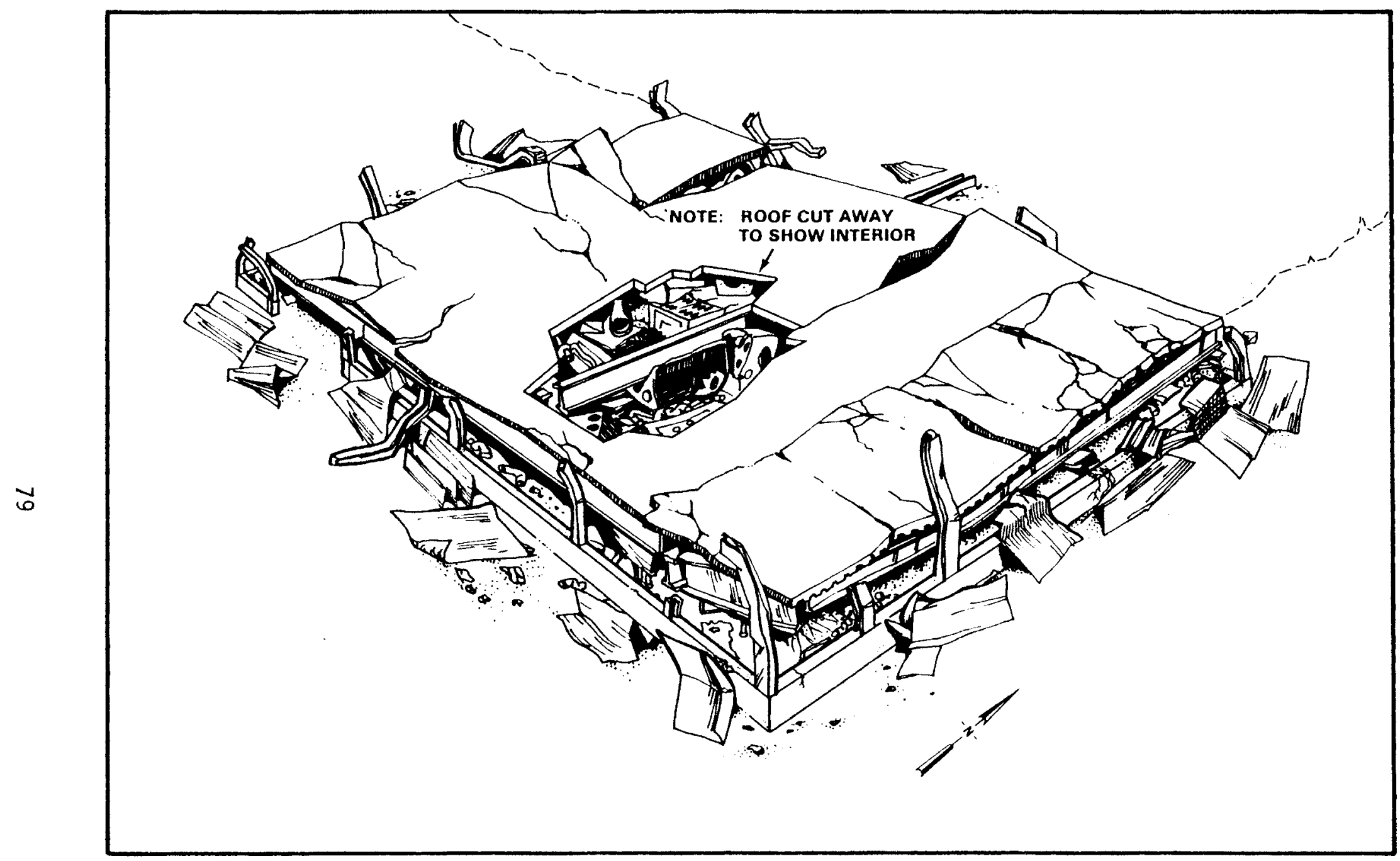

FIGURE 21a. Range and Type of Damage Anticipated in Production Areas at a Seismic Level in Excess of $0.39 \mathrm{~g}$ Ground Acceleration, Damage in AFL 


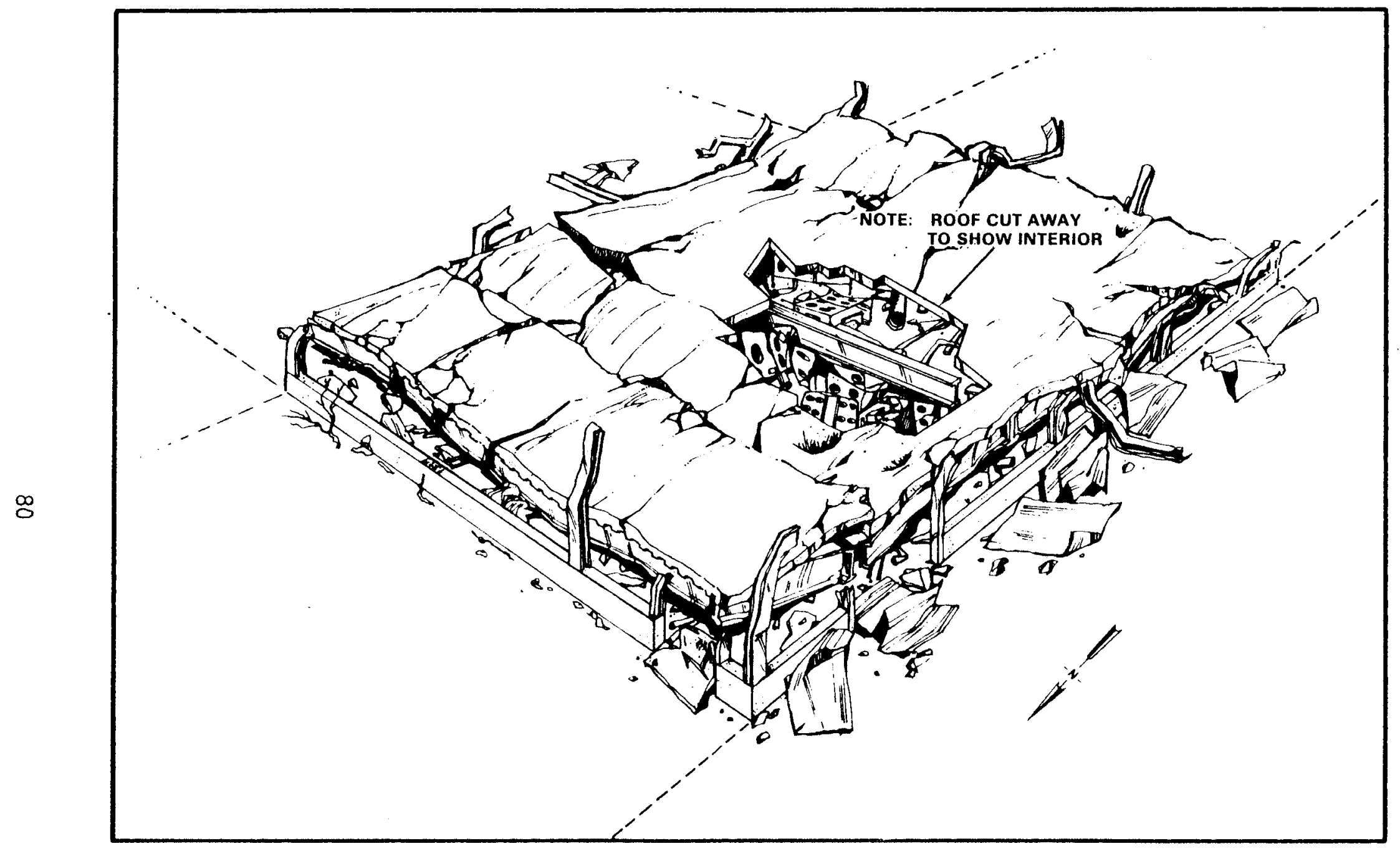

FIGURE 21b. Range and Type of Damage Anticipated in Production Areas at a Seismic Level in Excess of $0.39 \mathrm{~g}$ Ground Acceleration, Damage in CPL 
TABLE 14. Contributions of Various Areas in the Westinghouse PFDL to Wind and Seismic Hazard Source Term Estimates, Seismic Hazard, Greater than $0.39 \mathrm{~g}$ Ground Acceleration, less than $3 \times 10^{-5}$ Per Year Probability of 0ccurrence.

Mass Plutonium Airborne as Particles $10 \mu \mathrm{m}$ AED or less, grams Penthouse $\underline{A F L} \quad \underline{P D L} \quad \underline{C E R} \quad \underline{C P L}$

UPPER LIMIT ESTIMATE

\begin{tabular}{|c|c|c|c|c|c|}
\hline $\begin{array}{l}\text { Instantaneous } \\
\text { additional mass released }\end{array}$ & 0.2 & $0.6(6)(a)$ & $0.9(9)(a)$ & $0.8(7)(a)$ & $4(32)(a)$ \\
\hline in next 2 hours & $1 \times 10^{-6}$ & 0.4 & 0.4 & 1 & 0.4 \\
\hline in next 6 hours & $4 \times 10^{-6}$ & 1 & 1 & 3 & 1 \\
\hline in next 16 hours & $1 \times 10^{-5}$ & 3 & 3 & 8 & 3 \\
\hline in next 3 days & $4 \times 10^{-5}$ & 13 & 16 & 35 & 14 \\
\hline \multicolumn{6}{|c|}{ BEST ESTIMATE } \\
\hline $\begin{array}{l}\text { Instantaneous } \\
\text { additional mass released }\end{array}$ & $7 \times 10^{-4}$ & $0.5(5)(a)$ & $0.4(3)(a)$ & $0.6(6)(a)$ & $3(3)(a)$ \\
\hline in next 2 hours & $5 \times 10^{-6}$ & 0.5 & 0.06 & 0.2 & 0.3 \\
\hline in next 6 hours & $2 \times 10^{-5}$ & 0.2 & 0.1 & 0.5 & 0.8 \\
\hline in next 16 hours & $5 \times 10^{-5}$ & 0.4 & 0.5 & 1 & 2 \\
\hline in next 3 days & $2 \times 10^{-4}$ & 2 & 2 & 6 & 9 \\
\hline \multicolumn{6}{|c|}{ LOWER LIMIT ESTIMATES } \\
\hline $\begin{array}{l}\text { Instantaneous } \\
\text { additional mass released }\end{array}$ & - & 0.3 & 0.3 & 0.3 & 2 \\
\hline in next 2 hours & -- & 0.03 & 0.02 & 0.04 & 0.1 \\
\hline in next 6 hours & -- & 0.08 & 0.06 & 0.1 & 0.3 \\
\hline in next 16 hours & -- & 0.2 & 0.2 & 0.3 & 0.9 \\
\hline in next 3 days & -- & 1 & 0.7 & 1 & 4 \\
\hline
\end{tabular}

(a) Total mass airborne release of plutonium 
seven eighths and one half, respectively. The ambient wind field is low, but since the roof remains intact, air within the facility is forced out around the outer edges of the structure by the collapse of the roof. During the period when damage is inflicted on the enclosures, the nominal air velocity through the facility is estimated to be approximately $50 \mathrm{mph}$. At this velocity, all material airborne in perforated enclosures is released instantaneously. Thus, the instantaneous source term estimates for the production areas is the same as in the 260-mph wind scenario. Since much of the material in the enclosures is covered by the roof after the event, a lesser resuspension rate would appear to apply. Because of the uncertainties of the situation, the resuspension rate used in the wind hazard scenario is applied (a very conservative assumption). The estimated source terms are listed in Table 14. 


\section{REFERENCES}

Dennis, R., ed. 1976. Handbook of Aerosols. TID-26608, Technical Information Center. Energy Research and Development Administration.

Engineering Decision Analys is Corporation (EDAC). 1977a. Structural Condition Documentation and Structural Capacity Evaluation of the Westinghouse Laboratory Facility at Cheswick, Pennsylvania for Earthquake and Flood, Task I Structural Condition. Engineering Decision Analysis Company, Inc., for the Lawrence Livermore Laboratory, Livermore, CA.

Engineering Decision Analysis Corporation (EDAC). 1977b. Structural Condition Documentation and Structural Capacity Evaluation of the Westinghouse Laboratory Facility at Cheswick, Pennsylvania for Earthquake and Flood, Task II--Structural Capacity Evaluation, Seismic Evaluation. Engineering Decision Analysis Company, Inc., for the Lawrence Livermore Laboratory, Livermore, CA.

Fujita, T. T. 1977. Review of Severe Weather Meteorology at Westinghouse Electric Corporation, Cheswick, Pennsylvania. A report submitted to Argonne Nationa1 Laboratory under Contract No. 31-109-38-3731, The University of Chicago, Chicago, IL.

Fujita, T. T. 1978. Workbook for Tornadoes and High Wind for Engineering Applications. SMRP Research Paper 165, Sate?lite and Mesometeorological Research Project, University of Chicago, Chicago, IL.

Glauberman, H., W. R. Bootman, and A. J. Breslin. 1967. "Studies of the Significance of Surface Contamination." In Surface Contamination, ed. B. R. Fish, Pergamon Press, New York, NY.

McPherson, R. B. and E. C. Watson. 1979. Environmental Consequences of Postulated Plutonium Releases from the Babcock and Wilcox Plant, Leechburg, Pennsylvania, as a Result of Severe Natural Phenomena. PNL-2833, Pacific Northwest Laboratory, Richland, WA 99352.

Mehta, K. C., D. A. Smith, and J. R. McDonald. 1978. Response of Structures to Extreme Wind Hazard at the Westinghouse Plutonium Fuel Development Laboratory, Cheswick, Pennsyivania. VoT. 1, Institute for Disaster Research, Texas Tech University, Lubbock, TX.

Mercer, T. T. 1977. "Matching Sampler Penetration Curves to Definitions of Respirable Fraction." Health Physics. 33 (3): 259-264.

Mishima, J. 1964. A Review of Research on Plutonium Releases During Overheating and Fires. HW-83668, General Electric, Hanford Atomic Products Operations, RichTand, WA. 
Mishima, J. 1973. "Data Useful in the Evaluation of Airborne Plutonium from Postulated Accident Scenarios." Appendix F in Considerations in the Assessment of the Consequence of Effluents from Mixed Oxide Fuel Fabrication Plants. BNWL-1697, Pacific Northwest Laboratory, Richland, WA.

Mishima, J., L. C. Schwendiman, and J. E. Ayer. 1977a. Identification of Features With in Plutonium Fabrication Facilities Whose Failure May Have a Significant Effect on the Source-Term Features Observed in Westinghouse Plutonium Fuel Development Laboratory at Cheswick, PA. Pacific Northwest Laboratory, Richland, WA.

Mishima, J., L. C. Schwendiman, and J. E. Ayer. 1977b. Identification of Features Within Plutonium Fabrication Facilities Whose Failure May Have a Significant Effect on Source Term. Pacific Northwest Laboratory, Richland, WA.

Mishima, J., L. C. Schwendiman, and J. E. Ayer. 1978. An Estimate of Airborne Release of Plutonium from Babcock and Wilcox Plant as a Result of Severe Wind Hazard and Earthquake. PNL-2812, Pacific Northwest Laboratory, Richland, WA.

Mishima, J., R. B. McPherson, L. C. Schwendiman, E. C. Watson and J. E. Ayer. 1979. Source Term and Radiation Dose Estimates for Postulated Damage to the 102 Building at the General Electric Vallecitos Nuclear Center. PNL-2844, Pacific Northwest Laboratory, Richland, WA.

Monk, G. W. 1959. "Viscous Energy Dissipated During the Atomization of a Liquid." Journal of Applied Physics. 23 (2): 288.

Oak Ridge National Laboratory. 1970. Siting of Fuel Reprocessing and Waste Management Facilities. ORNL-4451, Oak Ridge National Laboratory, Oak Ridge, TN.

Schwendiman, L. C. 1977. Supporting Information for the Estimation of Plutonium 0xide Leak Rates Through Very Sma11 Apertures. BNWL-2198, Pacific Northwest Laboratory, Richland, WA

Sehme1, G. A. and F. D. Lloyd. 1976. "Particle Resuspension Rates." In Atmosphere-Surface Exchange of Particulate and Gaseous Pollutants, eds. R. J. Englemann and G. A. Sehmel. Technical Information Office, Office of Public Affairs, Energy Research and Development Administration.

Stewart, K. 1967. "The Resuspension of Particulate Material from Surfaces." In Surface Contamination, ed. B. R. Fish. Pergamon Press, New York, NY.

Tenekron Energy Analysts (TERA). 1977. Seismic Risk Analysis for Westinghouse Electric Facility, Cheswick, Pennsylvania. TERA Corporation, 2150 Shattuck Ave., Berkeley, CA 94704.

Westinghouse Corporation. 1974. Westinghouse Cheswick Site, Fuels Development Laboratories, Environmental Report. Westinghouse Nuclear Fuels Division, Box 355, Pittsburgh, PA 15230. 


\section{ACKNOWLEDGEMENTS}

Thanks are extended to Kishor C. Mehta of the Institute for Disaster Research, Texas Tech University, Lubbock, Texas, and Donald A. Wesley of the Engineering Decision Analysis Company, Inc., Irvine, California for their estimates used in this document for damage ratios and upper- and lower-bound values. 


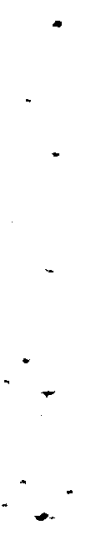


PNL-2965

UC-20e

\section{DISTRIBUTION}

No. of

Copies

OFFSITE

A. A. Churm

DOE Patent Division

9800 S. Cass Avenue

Argonne, IL 60439

27 DOE Technical Information Center

\section{U.S. Nuclear Regulatory Commission \\ Division of Technical Information and Document Control}

7920 Norfolk Avenue

Bethesda, MD 20014

James E. Carson

Division of Environmental

Impact Studies

Argonne National Laboratory

9700 S. Cass Avenue

Argonne, IL 60439

L. C. Rouse

U.S. Nuclear Regulatory Commission Washington, DC 20555

15 J. E. Ayer

U.S. Nuc lear Regulatory Commission Washington, DC 20555

W. Burkhardt

U.S. Nuclear Regulatory Commission Washington, DC 20555

J. W. Johnson

U.S. Nuclear Regulatory Commission Washington, D.C. 20555

W. E. Vesely

U.S. Nuclear Regulatory Commission Washington, D.C. 20555
No. of

Copies

OFFSITE

J. R. McDonald

Texas Tech University

Institute for Disaster Research

P.0. Box 4089

Lubbock, TX 79409

K. C. Mehta

Texas Tech University

Institute for Disaster Research

P.0. Box 4089

Lubbock, TX

R. P. Kennedy

Engineering Decision Analys is Company

2400 Michelson Drive

Irvine, CA 92715

D. W. Pepper

Savannah River Laboratory

Environmental Transport Division

E. I. duPont deNemour Company

Aiken, SC 29801

D. A. Wes ley

Engineering Decision Analysis Company

2400 Michelson Drive

Irvine, $C A 92715$

W. J. Hall

Newmark \& Associates

Civil Engineering Building

University of Illinois

Urbana, IL 61801

N. M. Newmark

Newmark \& Associates

Civil Engineering Building

University of Illinois

Urbana, IL 61801 
No. of

Copies

ONSITE

DOE Richland Operations Office

H. E. Ransom

39 Pacific Northwest Laboratory

C. E. Elderkin

G. B. Long (2)

R. B. McPherson

J. Mishima (25)

L. C. Schwendiman

E. C. Watson

R. K. Woodruff

Technical Information (5)

Publishing Coordination (2) 